\title{
ZnT8 Loss-of-Function Accelerates Functional Maturation of hESC-Derived $\beta$ Cells and Resists Metabolic Stress Induced Cell Death in Diabetes
}

Weida Li ( $\square$ liweida@tongji.edu.cn )

Translational Medical Center for Stem Cell Therapy and Institute for Regenerative Medicine, Shanghai East Hospital, Frontier Science Center for Stem Cell Research, School of Life Sciences and Techno https://orcid.org/0000-0001-8970-0633

\section{Qing Ma}

Translational Medical Center for Stem Cell Therapy and Institute for Regenerative Medicine, Shanghai East Hospital, Frontier Science Center for Stem Cell Research, School of Life Sciences and Techno

\section{Yi-Ni Xiao}

State Key Laboratory of Cell Biology, CAS Center for Excellence in Molecular Cell Science, Shanghai Institute of Biochemistry and Cell Biology, Chinese Academy of Sciences, University of Chinese Aca

\section{Sheng Li}

Translational Medical Center for Stem Cell Therapy and Institute for Regenerative Medicine, Shanghai East Hospital, Frontier Science Center for Stem Cell Research, School of Life Sciences and Techno

\section{Menghan Wang}

Cancer Institute and Hospital, Chinese Academy of Medical Sciences

\section{Zhihao Yang}

Frontier Science Center for Stem Cell Research, School of Life Sciences and Technology, Tongji University, Shanghai, China.

\section{Tinghui Xiao}

Translational Medical Center for Stem Cell Therapy and Institute for Regenerative Medicine, Shanghai East Hospital, Frontier Science Center for Stem Cell Research, School of Life Sciences and Techno

\section{Minglu Xu}

Frontier Science Center for Stem Cell Research, School of Life Sciences and Technology, Tongji University, Shanghai, China.

\section{Tengjiao Zhang}

Institute for Regenerative Medicine, Shanghai East Hospital, School of Life Sciences and Technology, Tongji University, Shanghai 200123, P.R. China

\section{Rui Hu}

Frontier Science Center for Stem Cell Research, School of Life Sciences and Technology, Tongji University, Shanghai, China. 
Tongji University

\section{Qing He}

Frontier Science Center for Stem Cell Research, School of Life Sciences and Technology, Tongji University, Shanghai, China.

\section{Qiang Su}

Translational Medical Center for Stem Cell Therapy and Institute for Regenerative Medicine, Shanghai East Hospital, Frontier Science Center for Stem Cell Research, School of Life Sciences and Techno

\section{Fei Yuan}

Frontier Science Center for Stem Cell Research, School of Life Sciences and Technology, Tongji University, Shanghai, China.

\section{jiaxu Zhao}

State Key Laboratory of Cell Biology, CAS Center for Excellence in Molecular Cell Science, Shanghai Institute of Biochemistry and Cell Biology, Chinese Academy of Sciences, University of Chinese Aca

\section{Zheng-Jun Chen}

Institute of Biochemistry and Cell Biology, Chinese Academy of Sciences

\section{Weiyang Shi}

Ocean University of China

\section{Qiaolin Deng}

Karolinska Institute https://orcid.org/0000-0001-5934-7816

\section{Xin Cheng}

Shanghai Institutes for Biological Sciences

\section{Article}

Keywords: ZnT8, metabolic stress, cell death, hESC-derived, $\beta$ cells, diabetes

Posted Date: September 18th, 2020

DOI: https://doi.org/10.21203/rs.3.rs-64651/v1

License: (c) (i) This work is licensed under a Creative Commons Attribution 4.0 International License. Read Full License

Version of Record: A version of this preprint was published at Nature Communications on July 16 th, 2022. See the published version at https://doi.org/10.1038/s41467-022-31829-9. 


\title{
ZnT8 loss-of-function accelerates functional maturation of hESC-derived $\beta$ cells and resists metabolic stress induced cell death in diabetes
}

Qing Ma ${ }^{1,2 \#}$, Yi-Ni Xiao ${ }^{3 \#}$, Sheng $\mathrm{Li}^{1,2}$, Menghan Wang ${ }^{4}$, Zhihao Yang ${ }^{12}$, Tinghui Xiao ${ }^{1,2}$, Minglu $\mathrm{Xu}^{12}$, Tengjiao Zhang ${ }^{1}$, Rui $\mathrm{Hu}^{1,2}$, Zhen-Ning Zhang ${ }^{1,2}$, Qing $\mathrm{He}^{1,2}$, Qiang $\mathrm{Su}^{1,2}$, Fei Yuan ${ }^{1,2}$, Jiaxu Zhao $^{3}$, Zheng-jun Chen ${ }^{3,5}$, Weiyang Shi ${ }^{6}$, Qiaolin Deng ${ }^{4 *}$, Xin Cheng ${ }^{3 *}$, Weida Li $^{1,2^{*}}$

${ }^{1}$ Frontier Science Center for Stem Cell Research, School of Life Sciences and Technology, Tongji University, Shanghai, China.

${ }^{2}$ Tsingtao Advanced Research Institute, Tongji University.

${ }^{3}$ State Key Laboratory of Cell Biology, CAS Center for Excellence in Molecular Cell Science, Shanghai Institute of Biochemistry and Cell Biology, Chinese Academy of Sciences, University of Chinese Academy of Sciences, 320 Yueyang Road, 200031, Shanghai, China.

${ }^{4}$ Department of Physiology and Pharmacology, Karolinska Institute, 17177 Solna, Sweden.

5 School of Life Science and Technology, ShanghaiTech University, 230 Haike Road, 201210, Shanghai, China.

${ }^{6}$ Ministry of Education Key Laboratory of Marine Genetics and Breeding, College of Marine Life Sciences, Ocean University of China, Tsingtao, 266003, China

Correspondence: qiaolin.deng@ki.se(Q. D.), xcheng@sibcb.ac.cn (X. C.), liweida@tongji.edu.cn (W. L.)

\begin{abstract}
:
Human embryonic stem cells (hESCs) derived $\beta$ cells (SC- $\beta$ cells) hold great promise for diabetes treatment, yet how to achieve functional maturation of these SC- $\beta$ cells and protect them against metabolic stresses such as glucotoxicity and lipotoxicity remain elusive. By single cell RNA-seq pseudotime analysis, we revealed that ZnT8 is involved in SC- $\beta$ cells functional maturation process
\end{abstract}


and its loss of function (LOF) accelerates functional maturation of SC- $\beta$ cells. As a result, ZnT8 LOF improves glucose-stimulated insulin secretion (GSIS) and enhances proinsulin to insulin conversion efficiency in SC- $\beta$ cells, both in vitro and in vivo, by releasing the negative feedback of zinc inhibition on insulin secretion. Furthermore, SC- $\beta$ cells with ZnT8 LOF are resistant to metabolic stresses induced cell death, as lipotoxicity or glucotoxicity, displaying higher survival. Most importantly, transplantation of $S L C 30 A 8^{-/-}$SC- $\beta$ cells into diabetic mice significantly improves glycemia restoration and SC- $\beta$ cell survival with long-term stability. Therefore, our study offers an advanced cell replacement therapy for diabetes with both improved SC- $\beta$ cell survival and function against metabolic stress.

\section{Introduction}

Pancreatic $\beta$ cell loss and dysfunction underlie diabetes mellitus ${ }^{1,2}$. Although whole pancreas or islet transplantation offers an alternative to insulin treatment in diabetic patients, they are severely limited by the scarcity of donor organs. Stem cell-based cell therapy from human pluripotent stem cells (hPSCs) to functional pancreatic $\beta$ cells (SC- $\beta$ cells) turns to be a promising approach for diabetes treatment and drug development ${ }^{3-7}$. However, limited functional maturation of these SC- $\beta$ cells hampers this strategy as a cell replacement therapy for diabetes, especially the lack of sensitivity to glucose stimulation $^{8,9} 10$.

Moreover, the fragility of the SC- $\beta$ cells remains as another major challenge. Even though the encapsulation of SC- $\beta$ cells could prevent risks of immune destruction and oncogenic transformation, this physical barrier is still susceptible to glucotoxicity and lipotoxiciy and oxidative stress that directly annihilate $\beta$ cells' function and viability. Therefore, it is also essential to protect transplanted SC- $\beta$ cells' function and survival against the harmful environment recurrent in the diabetic patients to achieve long-term functionality and stability.

Human genome-wide association studied (GWAS) have identified various genetic predispositions related to both $\beta$ cell malfunction and diabetes susceptibility, suggesting human $\beta$ cells could be born 
with "fragility" and later be devastated under metabolic stresses ${ }^{11,12}$. Interestingly, recent studies have reported that loss-of-function (LOF) of SLC $30 A 8$ encoding ZnT8 (zinc transporter, enriched in islet $\beta$ cell ) protects against human diabetes by enhancing insulin secretion capacity ${ }^{1,2}$, implying that some human pancreatic $\beta$ cells could alternatively be born with "robustness" ${ }^{13}$. Based on these previous studies, we hypothesized that ZnT8 LOF could potentially promote functionality of the SC- $\beta$ cells.

Furthermore, either lipotoxicity or glucotoxicity as metabolic stress is detrimental to human pancreatic $\beta$ cell survival ${ }^{14-16}$, which is also recurrent in diabetic patient as a key challenge to cell replacement therapy jeopardizing the viability of transplanted SC- $\beta$ cells. Therefore, it would be highly valuable to examine if human embryonic stem cells (hESCs)-derived $\beta$ cells harboring ZnT8 LOF could potentially offer an advanced stem cell-based cell replacement therapy for diabetes with improved functional maturation and survival against metabolic stresses.

To test this, we applied CRISPR/Cas9 technology and introduced ZnT8 LOF mutation into genome of the hESCs which were step-wisely differentiated into functional pancreatic $\beta$ cells. The generated pancreatic $\beta$ cells with ZnT8 LOF obtain accelerated functional maturation, showing significantly improved insulin secretion capacity and proinsulin to insulin conversion efficiency both in vitro and in vivo. Moreover, ZnT8 LOF alleviated the glucose toxicity and palmitate-induced lipotoxicity with improved cell viability. Most importantly, the generated human pancreatic cells with ZnT8 LOF dramatically improved restoration of normoglycemia in diabetic mice with long-term stability, offering an advanced stem cell-based cell replacement therapy.

\section{Results}

Single cell RNA-seq pseudotime analysis reveals accelerated functional maturation of SC- $\beta$ cells by ZnT8 LOF

To track the differentiation process of SC- $\beta$ cells, we first generated a Mel1 NKX6.1:linker2a:mCherry

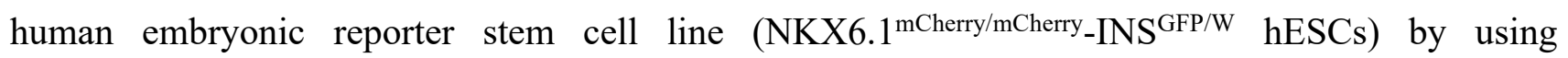


CRISPR/Cas9 ${ }^{17}$ knock-in strategy in Mel1 $\mathrm{INS}^{\mathrm{GFP} / \mathrm{W}}$ hESCs ${ }^{18}$. Through a stepwise method ${ }^{8,9}$ of pancreatic $\beta$ cell differentiation, the expression of mCherry fluorescence driven by the endogenous NKX6.1 promoter was observed throughout the pancreatic progenitor cell stage (S4) to mature SC- $\beta$ cell stage (S7); GFP expression under INS promoter was initially weak in endocrine progenitor cell stage (S5) and then highly expressed in mature SC- $\beta$ cells (S7) which formed cell cluster structures (Fig. 1a). Differentiation efficiency was measured by specifically expressed genes of each stage (Fig. 1a).

In order to explore the effects of ZnT8 LOF on the differentiation and function of SC- $\beta$ cells, SLC30A8 knockout $\left(S L C 30 A 8^{-/}\right)$hESC line was established by introducing a SLC30A8 nonsense mutation (c.479_524del, p.Y169fx) on exon4 in the aforementioned NKX6.1 mCherry/mCherry $_{-}$INS $^{\mathrm{GFP} / \mathrm{W}}$ hESC line (Supplementary Table 1). This CRISPR/Cas9-based genome editing was designed to create a premature stop codon in the reporter line (Extended Data Fig. 1a). LOF of this nonsense SLC30A8 variant was validated by qRT-PCR, which showed that SLC30A8 mRNA expression in mature SC- $\beta$ cells harboring this nonsense mutation (hereinafter referred to as $S L C 30 A 8^{-/-}$SC- $\beta$ cells) was almost abolished compared with its WT counterpart (hereinafter referred to as WT SC- $\beta$ cells) (Extended Data Fig. $1 \mathrm{~b}, p<0.0001)$. Concomitantly, ZnT8 protein was not detected in SLC30A8 ${ }^{-/}$SC- $\beta$ cells (Extended Data Fig. 1c, d). Compared to the WT counterpart, ZnT8 LOF did not affect hESCs' morphology or self-renew capacity. The gene expression of pluripotent stem cell markers and capacity of teratoma formation were comparable to those of WT hESCs (Extended Data Fig. 1e, f). Taken together, these data confirmed that the nonsense mutation of c.479_524 del, p. Y169fx is indeed a LOF variant and the $S L C 30 A 8^{-/}$hESCs were suitable for interrogating the effects of ZnT8 LOF on SC- $\beta$ cell differentiation.

We examined how ZnT8 LOF affected cellular differentiation from definitive endoderm at each stage to mature SC- $\beta$ cell. ZnT8 LOF also had no obvious effect on SC- $\beta$ cell differentiation efficiency at the definitive endoderm stage (Extended Data Fig. 2a, b), pancreatic progenitor stage (Extended 
Data Fig. 2c, d) and immature SC- $\beta$ cell stage (Extended Data Fig. 2e, f). This data, combined with the observation that $S L C 30 A 8$ is specifically expressed during maturation process (from S6 to S7) (Fig. 1b), confirmed that ZnT8 LOF does not affect the early cell fate specification of SC- $\beta$ cells.

To systematically investigate the effect of ZnT8 LOF in SC- $\beta$ cell maturation, we performed single cell RNA-seq at both S6 (immature) and S7 (mature) for WT SC- $\beta$ cells (S6WT, S7WT) and SLC30A8${ }^{\text {- }}$ SC- $\beta$ cells (S6KO, S7KO) by sorting double-positive GFP and mCherry representing SC- $\beta$ cells with both INS and NKX6.1 expression (Fig. 1c). In total, 272, 274, 463 and 534 cells were collected from S6WT, S6KO, S7WT and S7KO SC- $\beta$ cells, respectively. All cells were clustered into 7 clusters using $t$-distributed stochastic neighbor embedding ( $t$-SNE) (Extended Data Fig. 3a). We first excluded 3 small clusters (Cls4, 5 and 6) from downstream analysis based on their low correlation with the rest of cells indicating low quality (Extended Data Fig. 3b). The remaining 4 major clusters, i.e. 0 to 3 mainly comprising S7WT, S6KO, S7KO and S6WT with 283, 331, 424 and 324 cells, respectively showed specific gene expression profiles (Fig. 1d). In order to understand the molecular feature of each cluster, we identified the differentially expressed genes (DEGs) for pair-wise comparisons, i.e. S6WT vs S6KO and S7WT vs S7KO, S6WT vs S7WT, S6KO vs S7KO, resulting in four corresponding groups of genes (i.e. group 1-4) with gene expression characteristics under biological conditions. Group 1 (S6WT vs S6KO) and Group 2 (S7WT vs S7KO) represented the genes altered between WT and SLC $30 A 8^{-/-} \mathrm{SC}-\beta$ cells at S6 or S7. At S6, the pancreatic progenitor marker SOX4 expression was higher in WT, while the genes like PCSK1 and PCSK2 that related to $\beta$ cell function were enriched in S6KO SC- $\beta$ cells (Fig. 1e, Extended Data Fig. 4a). At S7, the genes important to $\beta$ cell function and maturation, such as INS, $P A X 4, P D X 1$, and $N K X 6.1$ were significantly upregulated in S7KO (Fig. 1f, Extended Data Fig. 4b). Group 3 (S6WT vs S7WT) and Group 4 (S6KO vs S7KO) represented the genes altered in WT or KO SC- $\beta$ cells during the maturation process, such as upregulation of $S L C 7 A 2$, ONECUT2, and IGF1R. Notably, MAFB, expressed in mature human islet $\beta$ cells, was specifically enriched in S7KO $\beta$ cells (Extended Data Fig. 4c-f). 
Next, we applied Monocle v2.0 to reconstruct the maturation process to further illustrate ZnT8 LOF in increased maturation process in more detail and ordered all cells from 4 major clusters along the pseudotime trajectory. After annotating the cell identity and summarizing the distribution of S6WT, S6KO, S7WT and S7KO cells along the pseudotime trajectory, we found that both S6KO and S7KO cells were overrepresented towards the maturation trajectory comparing to corresponding S6WT and S7WT cells, suggesting the maturation process was accelerated in $S L C 30 A 8^{-/-}$SC- $\beta$ cells (Fig. 1g, h). We then plotted several genes involved for SC- $\beta$ cell maturation in both WT and SLC30A8-/- cells. Interestingly, genes related to $\beta$ cell function such as $V A M P 2, P C S K 2$, and PCSK1 had significant increased levels and proportions in either $\mathrm{S} 6 \mathrm{KO}$ or $\mathrm{S} 7 \mathrm{KO}$, or both. Importantly, ITGA1 (CD49a), a recently identified surface marker for functional and mature $\beta$ cells derived from hPSC ${ }^{19}$, was also significantly enriched in SLC30A8-- SC- $\beta$ cells at both S6 and S7. By contrast, CPA1 and NEUROG3 enriched in pancreatic progenitors, had significantly decreased levels in SLC $30 A 8^{-/-}$SC- $\beta$ cells, further supporting accelerated maturation in $S L C 30 A 8^{---}$SC- $\beta$ cells (Fig. 1i).

\section{Accelerated functional maturation by ZnT8 LOF in SC- $\beta$ cells is manifested by improved sensitivity to glucose stimulation and proinsulin to insulin conversion}

Pancreatic $\beta$ cells gain the capacity of glucose-stimulated insulin secretion (GSIS) as they mature ${ }^{20}$, and GSIS is one of the basic features to evaluate $\beta$ cell function upon maturation. Single cell RNA-seq data showed that several insulin secretion pathway-related genes were upregulated in $S L C 30 A 8^{-/}$SC$\beta$ cells, such as $N K X 6.1, P D X 1, C C N D 2, V A M P 2, S Y T 13, R A B 3 B, C A D P S$, INS (Extended Data Fig. 5a). The gene set enrichment analysis (GSEA) also confirmed that the insulin secretion pathway was dramatically more enriched in SLC $30 A 8^{--}$SC- $\beta$ cells at both the S6 and S7 than that in WT SC- $\beta$ cells (Fig. 2a). Moreover, pancreas development, glucose homeostasis, carbohydrate homeostasis and peptide hormone secretion are among the top 10 enriched biological processes from gene ontology (GO) enrichment analysis at S7KO (relative to S7WT) (Fig. 2b). The qRT-PCR assays also revealed 
increased relative insulin expression level in $S L C 30 A 8^{---}$SC- $\beta$ cells (Fig. 2c). Our single cell RNA-seq revealed that ZnT8 LOF contributes to upregulation of insulin secretion-related genes and pathways.

In order to verify whether SC- $\beta$ cells with ZnT8 LOF gain more sensitivity of insulin secretion, we analyzed the GSIS of SC- $\beta$ cells at S7 by scoring the ratio of insulin release in high glucose $(20 \mathrm{mM})$ to that in low glucose $(2 \mathrm{mM})$ in 2 consecutive cycles. We observed that GSIS was significantly enhanced in $S L C 30 A 8^{-/-}$SC- $\beta$ cells upon high glucose stimulation in both cycle1 (WT, $1.30 \pm 0.10$; $\left.S L C 30 A 8^{-/-}, S L C 30 A 8^{-/-}, 1.65 \pm 0.11 ; p=0.0297\right)$ and cycle2 (WT, $1.34 \pm 0.07 ; S L C 30 A 8^{-/-}, 1.75 \pm$ 0.16; $p=0.0303$ ) (Fig. 2d). Moreover, the amount of insulin secretion upon potassium chloride (KCl) or tolbutamide ( $\mathrm{K}_{\mathrm{ATP}}$ channel blocker) stimulation were also moderately elevated in $S L C 30 A 8^{-/} \mathrm{SC}-\beta$ cells (Fig. 2e, f). Furthermore, the dynamic perifusion assay confirmed that $S L C 30 A 8^{-/-}$SC- $\beta$ cells enhanced insulin secretion upon high level glucose or exendin-4 stimulation. The area under the curve (AUC) analysis showed significant increase of insulin release in $S L C 30 A 8^{-/-} \mathrm{SC}-\beta$ cells under various conditions (Fig. 2g, Extended Data Fig. 5b). Moreover, the PCSK1 encoding prohormone convertase $\mathrm{PC} 1 / 3$ that activates the proinsulin to insulin conversion by proteolysis ${ }^{21-23}$ was increasingly expressed from our single cell transcriptomic profiling at the S6, indicating that the conversion efficiency might be also enhanced in $S L C 30 A 8^{-/}$mature SC- $\beta$ cell. To validate this, we checked the proinsulin conversion efficiency in the SLC $30 A 8^{-/-}$SC- $\beta$ cells by comparing intracellular total proinsulin to Cpeptide ratio, and found that the ratio was significantly decreased in the $S L C 30 A^{-/-}$SC- $\beta$ cells (Fig. $2 \mathrm{~h}$, $p=0.0016$ ), suggesting an increased conversion efficiency compared to WT $\beta$ cells. To further confirm this in vivo, we transplanted both WT and $S L C 30 A 8^{-/}$SC- $\beta$ cells into the kidneys of immune compromised mice (SCID-Beige), and the serum levels of human proinsulin and C-peptide were measured (Fig. 2i). Notably, human proinsulin/C-peptide ration was significantly decreased in mice with $S L C 30 A 8^{-/-}$SC- $\beta$ cell transplants $(8.82 \% \pm 1.59 \%)$ compared to that with WT SC- $\beta$ cells $(13.94 \%$ $\pm 1.14 \%$ ) further confirming that proinsulin conversion efficiency was also enhanced in $S L C 30 A 8^{-/}$ SC- $\beta$ cells (Fig. $2 \mathrm{j}, p=0.0397$ ) in vivo. Moreover, the GSIS (human insulin) was also significantly 
increased in mice transplanted with $S L C 30 A 8^{-/-}$SC- $\beta$ cells compared to that with WT SC- $\beta$ cells (Fig. $2 \mathrm{k}, p=0.0477)$. Taken together, both in vitro and in vivo results further corroborate that the SC- $\beta$ cells with ZnT8 LOF show advanced functional maturation.

\section{ZnT8 LOF promotes sensitivity to glucose stimulation of SC- $\beta$ cells by releasing zinc inhibition}

To decipher how ZnT8 LOF improves SC- $\beta$ cell function, we focused on the its zinc-transportation regulation. We used a sensitive zinc fluorescent indicator "Zinquin" to monitor the zinc level inside the insulin secretory granules ${ }^{24}$ and observed that the typical "dotted" pattern of granular zinc found in WT SC- $\beta$ cells was largely missing in the $S L C 30 A 8^{-/-}$SC- $\beta$ cells (Fig. 3a). Next, we examined whether the lack of granular zinc contributes to enhancement of insulin secretion.

It has been demonstrated that ZnT8 LOF affects zinc-dependent insulin hexamer formation, which yields the inactive insulin form in the insulin secretory granules ${ }^{25-30}$. Since the dense-core structure is the characteristic of the insulin secretory granules that contain insulin hexamers facilitated with granular zinc ${ }^{31-33}$, we scored the dense-core granules in both WT and SLC 30A8- SC- $\beta$ cells with electron microscopy (EM). We found the number of dense-core structures of insulin-zinc crystals were more in WT than those in $S L C 30 A 8^{-/-} \mathrm{SC}-\beta$ cells at S7 (Fig. 3b, c, $p=0.0139$ ). Similarly, the immature insulin granules in $S L C 30 A 8^{-/-} \mathrm{SC}-\beta$ cell looked paler than those in WT at S6 (Extended Data Fig. 5c, d). These results suggested that the insulin hexamers and dense-core structure formation could be disrupted in the $S L C 30 A 8^{-/-}$SC- $\beta$ cells due to decreased zinc level. Furthermore, we examined whether zinc-dependent insulin hexamer formation interruption could enhance insulin secretion. To address this, we constructed another hESC line "B10" that carried a human insulin variant with a mutation of "His-B10-Asp" (Extended Data Fig. 6a). This mutation abolished insulin hexamer formation due to lack of the conserved zinc-coordinating B10 histidine ${ }^{34-37}$. We found that although SC- $\beta$ cell differentiation efficiency and the ability of zinc transport were not affected by the B10 mutation (Extended Data Fig. 6b-d), insulin secretion was severely impaired rather than improved with the 
absence of hexamer formation (Extended Data Fig. 6e), ruling out the possibility that disruption of insulin hexamer formation contribute to improved insulin secretion in the $S L C 30 A 8^{-/-}$SC- $\beta$ cells.

It is known that extracellular zinc can be endocytosed by the Zip family members to the cytoplasm of pancreatic $\beta$ cells ${ }^{38-40}$. Cytosolic zinc is further transported by ZnT8 to the insulin secretory granules and eventually co-secreted with insulin into the extracellular spaces. A high level of extracellular zinc has an inhibitory effect on GSIS in rodent islets ${ }^{41-43}$, raising another possibility that co-secreted zinc might be involved in the negative feedback of insulin secretion in an autocrine manner. To test this, we added zinc to the zinc-free medium containing SLC $30 A 8^{-/-}$mature SC- $\beta$ cells to monitor insulin release upon glucose stimulation (Fig. 3d). Ectopically added zinc inhibited insulin secretion in SLC $30 A 8^{-/-}$SC- $\beta$ cells in a dose-dependent manner as measured by the high glucose/low glucose insulin release ratio with added zinc (control, $4.19 ; 125 \mu \mathrm{M}, 2.28 ; 250 \mu \mathrm{M}, 0.78 ; \mathrm{n} \geq 60 \mathrm{SC}-\beta$ cell clusters for each dose, Fig. 3e). In addition, the dynamic response of C-peptide release from SLC30A8- SC- $\beta$ cells to $20 \mathrm{mM}$ glucose was inhibited by added $250 \mu \mathrm{M}$ zinc in the perifusion assay (Fig. 3f).

To determine how the granular zinc level correlated with insulin release, we analyzed the insulin level and granular zinc intensity by visualizing INS ${ }^{\text {GFP/W }}$ (INS-GFP) and Zinquin staining in both SC$\beta$ cell clusters and dissociated $\beta$ cells. A significant negative-correlation showing higher granular zinc content in weakly INS-GFP-expressed SC- $\beta$ cells $(33.33 \% \pm 2.40 \%)$ compared to strongly INS-GFPexpressed SC- $\beta$ cells $(17.33 \% \pm 1.76 \%)$ (Fig. $3 g, h)$, suggesting that zinc concentration may regulate insulin level in SC- $\beta$ cells. To further confirm that increased granular zinc suppresses insulin expression, we restored the granular zinc level by ectopically expressing $S L C 30 A 8$ via adenovirus transduction in $S L C 30 A 8^{-/}$SC- $\beta$ cells. The results showed that increased granular zinc indeed significantly suppressed insulin expression level as evidenced by the attenuated INS-GFP level. By contrast, the $S L C 30 A 8^{-/-}$SC- $\beta$ cells transfected with adenovirus carrying reporter gene (mCherry) as a control showed no decreased GFP level (Fig. 3i, j and Extended Data Fig. 6f, g). All these results 
supported our conclusion that ZnT8 LOF reduces granular zinc storage and consequently releases the negative feedback inhibition on insulin secretion and upregulates insulin expression in SC- $\beta$ cells.

\section{Less zinc transportation activity contributes to more functional maturation of SC- $\beta$ cells}

We demonstrated that ZnT8 LOF improves functional maturation of SC- $\beta$ cells by abolishing zinc transportation, however, there was still one discrepancy of ZnT8 zinc transportation activity on diabetes occurrence. The WT SLC30A8 R325 variant ${ }^{44,45}$ has long been considered to possess a zinc transportation activity inferior to that of the W325 variant (in which arginine is replaced by the tryptophan at position 325 of the $\mathrm{ZnT} 8)^{27,46}$ and is associated with higher risk of diabetes than the W325 variant, which contradicts the protective role of $S L C 30 A 8$ LOF against diabetes ${ }^{1}$. Nevertheless, this conclusion was based on ectopic overexpression of the human R325 and W325 variants by plasmid transfection or adenovirus infection in either a mouse or rat tumor cell line ${ }^{27,46}$. In order to reconcile this unsolved discrepancy, we introduced the W325 mutation into the Mel1 NKX6.1 ${ }^{\text {mCherry/mCherry }}$ INS $^{\text {GFP/W }}$ hESCs by CRISPR/Cas9 based genome editing and differentiated the R325 (WT) and the W325 variant hESCs into $\beta$ cells (Extended Data Fig. 7a). Although R325 did not significantly differ from W325 in SC- $\beta$ cell differentiation efficiency as measured by NKX6.1-mCherry and INS-GFP (Extended Data Fig. 7b), we found that when Zinquin was used to assess the granular zinc level, the R325 SC- $\beta$ cells displayed significantly stronger zinc intensity than the W325 SC- $\beta$ cells at S7 stage (Extended Data Fig. 7c, d). According to the EM images, the insulin granules in W325 SC- $\beta$ cells were paler than that in R325 (Extended Data Fig. 7e)This result clearly demonstrated that the R325 variant actually possesses zinc transportation capacity superior to that of the W325 variant, which is in line with recent biochemistry study ${ }^{47}$. Finally, the perifusion assays confirmed that the W325 SC- $\beta$ cells are more sensitive to the glucose stimulation than the R325 SC- $\beta$ cells. The AUC analysis confirmed that insulin release upon high glucose stimulation is significantly enhanced in the W325 SC- $\beta$ cells (Extended Data Fig. 7f). These results reconciled the long-standing discrepancy of previous human 
genetic studies on the contradicting diabetes risks of these two variants of $S L C 30 A 8^{1,44}$, and further confirmed that granular zinc less zinc transportation activity contributes to more functional maturation of SC- $\beta$ cells.

\section{ZnT8 LOF SC- $\beta$ cells are resistant to lipotoxicity and glucotoxicity induced cell death}

In diabetic patients, lipotoxicity and glucotoxicity are two crucial risk factors associated with $\beta$ cell failure. It remains unknown whether ZnT8 LOF could protect $\beta$ cell against either lipotoxicity or glucotoxicity as diabetic stress, which has deleterious effect on $\beta$ cell function and survival. To test the lipotoxicity effect on SC- $\beta$ cells, palmitate (PA) with a final concentration of $1 \mathrm{mM}$ was added to WT or SLC $30 A 8^{-/-}$SC- $\beta$ cells for $48 \mathrm{~h}$. Cells treated with PA or vehicle (as control, $\mathrm{Ct}$ ) were harvested to extract RNA for RNA-seq. GO enrichment analysis from RNA-seq highlighted the downregulated biological processes of the cell death and apoptotic process in $S L C 30 A 8^{-/-}$SC- $\beta$ cells treated with PA (KO-PA) as compared to WT SC- $\beta$ cells treated with PA (WT-PA) (Fig. 4a). While compared to WTPA, the cell cycle related GO was upregulated in KO-PA (Fig. 4b), suggesting ZnT8 LOF protects SC$\beta$ cells from PA-triggered cell death. To validate the results of RNA-seq, cell death rate in each group (WT-Ct, WT-PA, KO-Ct, KO-PA) was measured by annexin V and capspase-3 staining. There was no significant difference between WT and $S L C 30 A 8^{-/-} \mathrm{SC}-\beta$ cells under the control $(\mathrm{Ct})$ conditions. However, the fluorescence intensity and percentage of annexin V-positive cells in KO-PA were significantly lower than those in WT-PA (Fig. 4c-e). The immunofluorescent staining and intracellular FACS of caspase-3 also revealed the cell death rate was lower in SC- $\beta$ cells with ZnT8 LOF with PAtreatment (Fig. 4, f-h). Then, we explored the effect of lipotoxicity on $\beta$ cell function. PA-treatment significantly suppressed GSIS in WT-PA cells compared to WT-Ct $(p=0.0249)$, but not significantly affected KO-PA cells (Fig. 4i, $p>0.05$ ). These results suggested that $S L C 30 A 8^{-/-} \mathrm{SC}-\beta$ cells are resistant to lipotoxicity induced cell death and GSIS inhibition. 
At the same time, cell death induced by glucotoxicity was also measured by annexin V staining in both WT and SLC30A8-/ SC- $\beta$ cells. $35 \mathrm{mM}$ glucose (Glu) or control solution $(\mathrm{Ct})$ was added to each group (WT-CT, WT-Glu, KO-CT, KO-Glu) for 48h to induce glucotoxicity (Extended Data Fig. 8a). This treatment caused significantly increased percentage of annexin V-positive cells in WT-Glu as compared to KO-Glu (Extended Data Fig. 8b, c), demonstrating that $S L C 30 A 8^{-/}$SC- $\beta$ cells are resistant to glucotoxicity induced cell death as well.

\section{SC- $\beta$ cells with ZnT8 LOF possess significantly improved glycemia restoring capacity in diabetic mice with long-term stability.}

Compared to WT SC- $\beta$ cells, our results revealed that $S L C 30 A 8^{-/-}$SC- $\beta$ cells not only possess improved maturation and function, but also are resistant to diabetic stresses, indicating that $S L C 30 A 8^{-/-} \mathrm{SC}-\beta$ cells could be applied as an advanced cell replacement therapy for diabetes with both improved function and robust viability. To test this hypothesis, insulin dependent diabetes mellitus (IDDM) was induced in SCID-Beige mice by streptozotocin (STZ) administration, then WT or SLC30A8- SC- $\beta$ cell clusters containing about 3 million cells were transplanted to the kidney capsule of the STZdiabetic mice with hyperglycemia (blood glucose level $>400 \mathrm{mg} / \mathrm{dl}$ ) (Fig. 5a). Human insulin level in the transplanted mice serum was measured on day 7 and day 35 after transplantation. On day 7 , no obvious difference of serum human insulin level was observed in each independent group (numbered as 1-7) of mice transplanted with WT or $S L C 30 A 8^{--}$SC- $\beta$ cells. On day 35, except in group 3 and 5, all the other groups showed a significantly increased serum insulin level in the animal transplanted with $S L C 30 A 8^{-/-}$SC- $\beta$ cells as compared to the animal transplanted with WT SC- $\beta$ cells (Fig. 5b). Of significance, the immunostaining of grafts on day 35 showed more insulin positive cells in SLC30A8/ SC- $\beta$ cells transplanted mice (Fig. 5c, d). The body weight gain and blood glucose level were measured every 1 week and 10 days respectively after transplantation. Furthermore, mice transplanted with SLC30A8-/- SC- $\beta$ cells showed significantly increased body weight gain and decreased blood 
glucose level compared to mice transplanted with WT SC- $\beta$ cells, suggesting improved glycemia restoring capacity of the $S L C 30 A 8^{-/}$SC- $\beta$ cells. (Supplementary Fig. 5e, f). After transplantation for 90 days, blood glucose level in three of five mice transplanted SLC $30 A 8^{-/-}$SC- $\beta$ cells were restored to normal (a level below $200 \mathrm{mg} / \mathrm{dl}$ ) whereas only one of five mice transplanted WT SC- $\beta$ cells showed restored normal glucose level (Fig. 5g). For the Intra-peritoneal glucose tolerance test (i.p.GTT), the mice were fasted for $16 \mathrm{~h}$ and consequently challenged with $3 \mathrm{~g} / \mathrm{kg}$ glucose by intraperitoneal injection. The blood glucose change during the 120 min after glucose intraperitoneal injection revealed that the mice carrying $S L C 30 A 8^{-/-} \mathrm{SC}-\beta$ cells responded to the glucose challenge similarly as the nondiabetic untreated mice (Fig. 5h). Moreover, the kidney grafts of $S L C 30 A 8^{-/-} \mathrm{SC}-\beta$ cell were analyzed with immunostaining at 6 months after transplantation, which showed an architecture of intermingled insulin and glucagon positive cells and few somatostatin positive cells (yellow arrows on the image) like human islets (Fig. 5i), demonstrating the long-term stability of the SLC $30 A 8^{-/}$SC- $\beta$ cells in diabetic mice. Altogether, our results provided the first evidence that $S L C 30 A 8^{-/-}$SC- $\beta$ cells could be applied as advanced stem cell-based cell replacement therapy for diabetes due to both improved function and survival.

\section{Discussion}

Recent concerted research advances of generating sustainable SC- $\beta$ cells offer a promising approach of stem cell-based cell replacement therapy for diabetes treatment. Nonetheless, the transplanted $\beta$ cells possess limited functional maturation and still face retained or recurrent metabolic stress in the diabetic patients, thus the remaining challenge is to achieve long-term functionality and survival of these SC- $\beta$ cells. A recent elegant study demonstrated that functional maturation can be achieved by FACS sorting and reaggregating the immature SC- $\beta$ cells ${ }^{10}$. Nevertheless, the relatively complicated procedure still needs to be optimized to makes it practical for large-scale production. 
Given that ZnT8 LOF in pancreatic $\beta$ cells results in increased insulin secretion, it is highly valuable to explore if and how the stem cell-derived islet $\beta$ cells harboring ZnT8 LOF could be of advanced therapeutic importance against diabetes. Although it was recently reported that human induced pluripotent stem cell (iPSC) with ZnT8 haploinsufficiency displayed reduced SLC30A8 expression ${ }^{13}$, further investigation into the therapeutic application of ZnT8 LOF $\beta$ cells derived from hPSCs was still missing, especially possible improved function or viability of these $\beta$ cells harboring ZnT8 LOF. Therefore, our study took this initiative and engineered hESCs harboring SLC30A8 LOF mutation followed by step-wisely differentiation into functional SC- $\beta$ cells. Importantly, we demonstrated $S L C 30 A 8^{-/-}$SC- $\beta$ cells gain accelerated functional maturation and are resistant to diabetes lipotoxicity and glucotoxicity and show significantly improved glycemic control when transplanted to diabetic mice. It is conceivable that, our study provided the first proof of concept to apply SLC $30 A 8^{-/-}$SC- $\beta$ cells generated from pluripotent or other types of stem cells as an advanced cell replacement therapy for insulin-dependent diabetic patients.

Instead of taking too much time and effort to recruit and collect samples from human carriers with SLC30A8 variants, our study applied CRISPR/Cas9 technology and showed the advantage of genome editing on stem cells to interrogate human diabetes associated genes. Especially, the ethical issue limits exploration of ZnT8 LOF's role during $\beta$ cell development in human embryo. By recapitulating human $\beta$ cell development and maturation in a dish, we revealed that ZnT8 LOF accelerates maturation and enhances GSIS in SC- $\beta$ cells and further demonstrated that increased insulin secretion is achieved by releasing the negative feedback of zinc on insulin secretion from insulin secretory granules.

Furthermore, it has been a long-standing discrepancy of the diabetes risk variant ZnT8 Arg325 and Trp325. ZnT8 Arg325 variant was considered to possess reduced zinc transporting capacity compared to the protective Trp325 variant, which contradicted the protective role of ZnT8 LOF ${ }^{1,2,44}$. Instead, we demonstrated that the Arg325 has hyperactive zinc transporting activity concluded from the functional assays on $\beta$ cells derived from hESCs harboring Arg325 versus W325 variants. We therefore 
reconciled the paradoxical diabetes risk of ZnT8 with different mutation variants and showed that ZnT8 mediated granular zinc transportation has a negative impact on $\beta$ cell functional maturation. Taken together, in light of the discovery that inhibition of ZnT8 zinc transportation activity improves insulin release, our study provided a conceptual advance suggesting that ZnT8 is a potential druggable target for treating human diabetes. Further studies will be necessary to perform compound screening to identify ZnT8 inhibitors, which could be utilized as innovative therapeutics for diabetes prevention and treatment.

\section{Methods}

Generation and identification of targeted Mel1 NKX6.1 ${ }^{\text {mCherry } / m \text { Cherry }-I N S}{ }^{\text {GFP/W }}$ hESCs Mel1 hESCs $^{18}$ were provided by Drs. E. Stanley and Dr. A. Elefanty. Briefly, the GFP sequence was targeted into one allele of insulin locus of Mell ESCs using homologous recombination. INS ${ }^{\mathrm{GFP} / \mathrm{w}}$; NKX6.1 $1^{\text {mCherry/mCherry }}$ Mel1 double knock-in cell line was generated by inserting sequences encoding T2A and mCherry to the two alleles of NKX6.1 locus of INS ${ }^{\mathrm{GFP} / \mathrm{w}}$ Mel1 hESCs using CRISPR/CAS9 (Yini-Xiao, Xin Cheng., unpublished). The CRISPR gRNA target sequence for targeting NKX6.1 was 5'-GGCGTTCAGGATGAGCTCTC-3'. Px330 vector ${ }^{48}$ expressing Cas9 and sgRNA was kindly provided by Jingsong Li. A mCherry selection cassette was inserted in it for single cell sorting. The donor vector was generated by inserting homologous left arm-T2A-mCherry-homologous right arm into pMD18-T vector (TaKaRa, \#6011). INS ${ }^{\mathrm{GFP} / \mathrm{W}}$ Mel1 hESCs were transfected with Px330 vector and donor plasmid using Fugene HD (Promega) within $24 \mathrm{~h}$ after passage. Transfected single cells were sorted by mCherry $24 \mathrm{~h}$ after transfection and seeded on MEF-coated dishes. Single cell-derived clones were picked for genotyping 7 9 days later.

\section{Generation and identification of isogeneic mutant human embryonic cell lines.}


SLC30 A8 $\boldsymbol{8}^{-/-}$and $I N S^{-/-}$hES cell lines. Two sgRNAs targeting exon4 of human SLC30A8 gene were designed (http://crispr.mit.edu/) and inserted into a vector (P2U6) carrying a Cas9 gene and a puromycin resistance cassette. The construct $(1 \mu \mathrm{g})$ was electroporated into $0.4 \times 10^{6} \mathrm{hESCs}$ suspended in Human Stem Cell Nucleofector Solution (Lonza) following the manufacturer's instructions. After electroporation, cells were resuspended with hES medium and seeded in a $6 \mathrm{~cm}$ plates. $400 \mathrm{ng} / \mathrm{mL}$ puromycin was added 2 days later for selection. 48-60 h later, puromycin was removed and the medium was changed every day until the colonies were visible. For one colony, a portion of it was lysed and analyzed by sanger sequencing and remaining part was cryopreserved. The sequencing results showed that 46 bp in exon 4 of two alleles of SLC $30 A 8$ were deleted resulting in frameshift of the SLC30A8

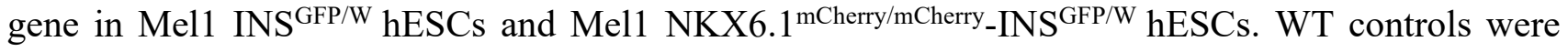
included from the targeting experiment to exclude potential non-specific effects. For $I N S^{-/-}$hES cell lines, A sgRNA targeting exon1 of human INS gene were designed (http://crispr.mit.edu/) and inserted into the vector (P2U6). The methods of transfection in the Mel1 NKX6.1mCherry/mCherryINSGFP/W hESCs as described above.

Insulin B10 and ZnT8 W325 hES cell lines. For insulin B10, Mel1 INS ${ }^{\mathrm{GFP} / \mathrm{W}}$ hESCs were provided by Dr. E. Stanley and Dr. A. Elefanty. A single point mutation (C to G) was induced at position 100 of the coding sequencing of the proinsulin gene resulting in the substitution of aspartic acid for histidine-10 of the $\mathrm{B}$ chain of insulin to break the $\mathrm{Zn}^{2+}$ binding site. The donor vector was generated by inserting homologous left arm-point mutation ( $\mathrm{C}$ to $\mathrm{G}$ ) into the homologous right arm of the pMD18-T vector. Mel1 INS ${ }^{\mathrm{GFP} / \mathrm{W}}$ hESCs were transfected with sgRNA and donor vector as described above. ZnT8 W325 hES cell line was generated based on Mel1 NKX6.1 mCherry/mCherry $-I N S^{\text {GFP/W }}$ hESC. A single point mutation ( $\mathrm{C}$ to $\mathrm{T}$ ) was induced at position 973 of the coding sequencing of SLC30A8 gene resulting in a tryptophan substitution of the arginine at position 325 in ZnT8 protein. The Donor vector was generated by inserting homologous left arm-point mutation ( $\mathrm{C}$ to $\mathrm{T})$ into the homologous right arm of the pMD18-T vector. Mel1 NKX6.1 mCherry/mCherry $-I N S^{\mathrm{GFP} / \mathrm{W}}$ hESCs were transfected 
sgRNA and donor vector as described above. During differentiation process and experiments, all lines were re-sequenced to confirm the correct genotypes.

See the information of isogeneic mutant hESCs in table S1. The sgRNA sequences and PCR primers used to identify successful insertion are in table S2.

\section{Maintenance of hESCs.}

The human embryonic stem cell lines Mel1 INS ${ }^{\mathrm{GFP} / \mathrm{W}}$ and Mel1 NKX6.1 mCherry/mCherry $_{\text {-INS }}{ }^{\mathrm{GFP} / \mathrm{W}}$ were cultured on irradiated mouse embryonic fibroblasts (iMEFs), which were seeded on 1:6 diluted Matrigel (Corning, \#354230) in hESC medium. This medium contains DMEM/F12 (Invitrogen, \#11330-082), 20\% Knockout Serum Replacement (KOSR) (Invitrogen, \#10828028), 1 mM nonessential amino acids (NEAA, Gibco, \#11140-050), 1:100 L-Glutamine (Gibco, \#25-005-CI), 0.05 mM $\beta$-mercaptoethanol (Invitrogen, \#21985023) and supplemented with 10 ng/ml bFGF (R\&D, \#233FB/CF). Cells were maintained at $37{ }^{\circ} \mathrm{C}$ with 5\% CO2 and 5\% O2 and passaged every 3-4 days at 1:61:8 split dilutions using TrypLE (Gibco, \#12604013) to dissociate. The hESC medium need to be changed every 2 days.

\section{In vitro differentiation of pancreatic $\beta$ cells derived from hESCs.}

hESCs were differentiated into pancreatic $\beta$-cells using the protocol adapted from published study ${ }^{9,49}$. In brief, the hESCs were cultured on 1:3 Matrigel in hESCs medium until $90 \%$ confluency to start differentiation. The differentiation process includes planar culture through stages 1 to 4 to generate NKX6. $1^{+}$progenitors at high efficiency and suspension culture from stage 5 to 7 to generate maturing $\beta$-cells (Table S3 and S4).

\section{Quantitative real-time PCR.}


Total RNA was prepared with an RNAprep Pure Kit (For Micro Sample) (Tiangen, \#DP420). RNA (500 ng to $1 \mu \mathrm{g}$ ) was reverse transcribed into cDNA using random hexamers and oligo dTs with the GoScript $^{\mathrm{TM}}$ Reverse Transcriptase Kit (Promega, \#A5001). qPCR was performed on a QuantStudio6 Flex (Life Technologies) using FastStart Universal SYBR Green Master (Rox) (Roche, \#4913914001). A 10-fold dilution series of human genomic DNA standards ranging from $100 \mathrm{ng} / \mu \mathrm{L}$ to $0.1 \mathrm{ng} / \mu \mathrm{L}$ was used to evaluate the efficiency of the PCR and calculate the copy number of each gene relative to the house keeping gene TATA box binding protein $(T B P)^{50}$. The table S5 shows q-PCR primers.

\section{Immunofluorescence staining.}

Adherent cultured or 3D cultured cells (S5-S7) were washed once with precooled PBS and fixed with 4\% paraformaldehyde for $15 \mathrm{~min}$ at RT. After washed with PBS for 3 times ( 5 min each), cells were permeabilized with PBST (PBS with 0.1\% TritonX - 100) for 15 min and then blocked with PBS containing 5\% donkey serum for $2 \mathrm{~h}$ at RT. Some of 3D cultured cells (S5-S7) were embedded in optimum cutting temperature (O.C.T) and stored at $-80{ }^{\circ} \mathrm{C}$ for analysis using cryostat sectioning. For transplanted cell analysis, mouse kidney with grafts were collected and fixed with 4\% paraformaldehyde for $1 \mathrm{~h}$ at $4{ }^{\circ} \mathrm{C}$ and embedded in O.C.T at $-80^{\circ} \mathrm{C}$ after overnight dehydration in the $30 \%$ sucrose solution. Both grafts and kidneys were sliced at $8 \mu \mathrm{m}$ with a cryostat microtome and store at $-20^{\circ} \mathrm{C}$. before incubated with a primary antibody, the slices were PBS containing $5 \%$ donkey serum for $2 \mathrm{~h}$ at RT All the samples were incubated with a primary antibody diluted with blocking solution overnight at $4^{\circ} \mathrm{C}$. After washed with PBS for 3 times, samples were incubated with Alexa Fluro secondary antibodies (diluted with blocking solution for 1:500, Jackson labs) for $1 \mathrm{~h}$ at RT and cell nuclei were stained with DAPI dihydrochloride. The table 6 shows the antibody list used in the immunofluorescence staining.

\section{Intracellular FACS analysis and flow cytometry.}


To analyze INS-GFP or NKX6.1-mCherry, differentiated cells at indicated stages were dissociated with $0.25 \%$ trypsin and resuspended in FACS buffer for live cell flow analysis or sorting directly. For intracellular staining, the cells were fixed with $1.6 \%$ PFA in $37^{\circ} \mathrm{C}$ for 20 min and permeabilized by 1:10 saponin buffer (Biolegend, \#421002) for 5 min. The primary antibodies were diluted in FACS buffer and incubated for $30 \mathrm{~min}$ at RT. After washed with FACS buffer for 2 times, cells were incubated with fluorescence-conjugated secondary antibodies for $30 \mathrm{~min}$ at RT. Then, the cells were washed and resuspended in FACS buffer for flow cytometry analysis by the instrument of BD FACSVerse and Moflo Astrios 4 lasers. Data were analysed using FlowJo v10 software.

\section{Zinquin staining.}

For Zinquin (Sigma-Aldrich, \#Z2251) staining, clusters or adherent cells were washed for once with FACS buffer (PBS plus 0.5\% BSA) and subjected into Zinquin dye (20 nM). The cells were incubated at $37^{\circ} \mathrm{C}$ and $5 \% \mathrm{CO}_{2}$ for $20 \mathrm{~min}$ and observed immediately by Seizz microscope (emission, 482-488 $\mathrm{nm}$; excitation, 361-367 nm).

\section{Annexin $V$ apoptosis analysis.}

SC- $\beta$ cells clusters were washed with cold PBS and subjected to the Annexin V-647 apoptosis detection kit (YEASEN, 40304ES60). The clusters staining with Annexin V were taken Z-stack 3D images by Zeiss microscope. The Annexin V fluorescence intensity were measured by the software image $\mathrm{J}$.

\section{mRNA sequencing by Illumina HiSeq}

Total RNA of each sample was extracted using TRIzol Reagent (Invitrogen)/RNeasy Mini Kit (Qiagen)/other kits. Total RNA of each sample was quantified and qualified by Agilent 2100 Bioanalyzer (Agilent Technologies, Palo Alto, CA, USA), NanoDrop (Thermo Fisher Scientific Inc.) 
and $1 \%$ agrose gel. $1 \mu \mathrm{g}$ total RNA with RIN value above 6.5 was used for following library preparation. Next generation sequencing library preparations were constructed according to the manufacturer's protocol. The poly(A) mRNA isolation was performed using Poly(A) mRNA Magnetic Isolation Module or rRNA removal Kit. The mRNA fragmentation and priming were performed using First Strand Synthesis Reaction Buffer and Random Primers. First strand cDNA was synthesized using ProtoScript II Reverse Transcriptase and the second-strand cDNA was synthesized using Second Strand Synthesis Enzyme Mix. The purified double stranded cDNA by beads was then treated with End Prep Enzyme Mix to repair both ends and add a detailing in one reaction, followed by a T-A ligation to add adaptors to both ends. Size selection of adaptor ligated DNA was then performed using beads, and fragments of $\sim 420 \mathrm{bp}$ (with the approximate insert size of $300 \mathrm{bp}$ ) were recovered. Each sample was then amplified by PCR for 13 cycles using P5 and P7 primers, with both primers carrying sequences which can anneal with flow cell to perform bridge PCR and P7 primer carrying a six-base index allowing for multiplexing. The PCR products were cleaned up using beads, validated using a Qsep100 (Bioptic, Taiwan, China), and quantified by Qubit3.0 Fluorometer (Invitrogen, Carlsbad, CA, USA). Then libraries with different indices were multiplexed and loaded on an Illumina HiSeq instrument according to manufacturer's instructions (Illumina, San Diego, CA, USA). Sequencing was carried out using a 2x150bp paired-end (PE) configuration; image analysis and base calling were conducted by the HiSeq Control Software (HCS) + OLB + GAPipeline-1.6 (Illumina) on the HiSeq instrument. The sequences were processed and analyzed by GENEWIZ.

\section{Insulin secretion assay.}

SC- $\beta$ cell clusters were starved in Krebs-Ringer buffer ${ }^{9}$ supplemented with $2 \mathrm{mM}$ glucose for $2 \mathrm{~h}$ in a $5 \% \mathrm{CO}_{2} / 37^{\circ} \mathrm{C}$ incubator. For GSIS, the cell clusters would be stimulated alternately by Krebs-Ringer buffer with low-glucose or high glucose for 1 or 2 cycles. Supernatants were collected after 30min of each stimulation and the pallet lysed overnight in acidified alcohol $(75 \%$ alcohol, $1.5 \% \mathrm{HCl})$ at $-20{ }^{\circ} \mathrm{C}$ 
for insulin content measure. The same procedure was carried out for treatments with $30 \mathrm{mM} \mathrm{KCl}$ or $200 \mu \mathrm{M}$ tolbutamide. The insulin (secreted or content) was measured by human insulin ELISA kit (ALPCO, \#80-INSHU-E01.1).

\section{Proinsulin to C-peptide content analysis.}

To measure the proinsulin or C-peptide content, the SC- $\beta$ cell clusters were cleared with PBS by brief centrifugation and lysed overnight in acidified alcohol $(75 \%$ alcohol, $1.5 \% \mathrm{HCl})$ at $-20{ }^{\circ} \mathrm{C}$ after $2 \mathrm{~h}$ starving in the low glucose Krebs-Ringer buffer. The proinsulin and C-peptide were measured by human proinsulin ELISA kit (Mercodia, \#1118-1-10) and human ultrasensitive C-peptide ELISA kit (Mercodia, \#0111-1-10).

\section{Dynamic perifusion assay for insulin secretion.}

60-65 healthy S7-cell clusters ( 200 $\mu$ m-diameter) were handpicked, washed with Krebs-Ringer buffer twice and suspended in $2 \mathrm{mM}$ glucose Krebs-Ringer buffer. Then clusters were loaded onto each chamber of an automated Biorep Perifusion System between two layers of Bio-Gel P-4 polyacrylamide beads. Under temperature-controlled conditions, clusters were perfused at a flow rate of $100 \mu 1 / \mathrm{min}$ and samples were collected with 1 min collection points. Prior to sample collection, clusters were equilibrated under basal ( $2 \mathrm{mM}$ glucose) conditions for $60 \mathrm{~min}$. For sample collection, clusters were exposed to low glucose (2 mM) Krebs-Ringer buffer for $15 \mathrm{~min}$, followed by high glucose (20 $\mathrm{mM})$ challenge for $30 \mathrm{~min}$, then were exposed to $10 \mathrm{nM}$ Extendin-4 high glucose condition for $15 \mathrm{~min}$, and were finally exposed to low glucose Krebs-Ringer buffer for an additional $15 \mathrm{~min}$. For the zinc inhibition assay, $250 \mu \mathrm{M} \mathrm{ZnSO}_{4}$ was added during the high glucose challenge for $30 \mathrm{~min}$. Finally, the clusters were perfused by low glucose and $30 \mathrm{mM} \mathrm{KCl}$ for $10 \mathrm{~min}$. Supernatant samples were frozen at $-80{ }^{\circ} \mathrm{C}$ and hormone levels were measured using human C-peptide ultrasensitive ELISA kit 
(Mercodia, \#10-1141-01). For normalization, the DNA content was determined by KAPA extraction and Quant-iT PicoGreen dsDNA Kit (Invitrogen, \#P7589).

\section{Electron microscopy.}

SC- $\beta$ cell clusters were spun down to remove excess medium and washed with PB (PBS without sodium chloride) for 2 times, followed by addition of ice-cold fixative ( $2.5 \%$ glutaraldehyde) over night. The clusters were further processed using electron microscopy sample making protocol by the Electron Microscopy Facility at the School of Life Sciences and Technology, Tongji University. The samples were taken picture (insulin granules) by JEOL JEM-1230 transmission electron microscope.

\section{Single cell RNA sequencing}

Alignment. A 16 bp cell barcode and 9 bp unique molecular identifier (UMI) were contained in read 2 of our paired-end sequencing data, while all genomic information was contained in read 1 . We used the Drop-seq pipeline to perform the alignment (version 1.13). Briefly, we added the barcode and UMI information into tag, trimmed adaptor, 5' primer and 3' polyA from reads. Then the trimmed reads were aligned to the human genome with transcriptome annotation (GRCh38, ensemble 93) using STAR (version 2.6.0a). After that, the tags were merged with the aligned SAM file. The barcode substitution and indel errors were repaired. Finally, a digital gene expression matrix was obtained from barcode-UMI-gene triplets. The remaining cell barcodes were consistent with the ones we used as input.

Scater was used to filter out the low-quality cells. Cells with library sizes greater than 2000 UMI counts, with a number of detected genes greater than 1000 and a percentage of mitochondrial genes less than $25 \%$ were used for subsequent analysis. In total, 1543 cells passed the criteria, while 89 cells failed. Cell clustering. Seurat (version 2.3.4) was used to identify cell clusters. Firstly, First, the UMI counts matrix as input and kept genes expressed in at least 2 cells, leaving 25426 out of 31097 genes for 
downstream analysis. UMI counts were normalized and scaled by the default parameters. Genes with average expression between 0.0125 and 5 and dispersion more than 0.25 were considered variable genes. Then, used scaled data with variable genes were used as input to perform principal component analysis (PCA). Used jackstraw procedure with 1000 replicates to identify significant PCs with a strong enrichment of differences to separate the cells. PCs 1-12 were selected to run t-SNE and perform the clustering through the FindClusters function.

Differential expression analysis and GO enrichment. To identify DEGs between two clusters, we used the Seurat function FindMarkers with the following parameters: logfc.threshold $=0.25$, test.use $=$ "wilcox", min.pct $=0.1$. The cell clusters used for the comparisons were those four clusters corresponding to four given cell types. Genes with adjusted $p$ value no more than 0.05 were selected. Volcano plots and Venn diagrams were plotted using R. Heatmap and violin plots were plotted using Seurat. GO enrichment was performed using ClusterProfiler (version 3.10.0) with the following parameters (ont $=$ "BP", pAdjustMethod $=$ "BH", pvalueCutoff $=0.01$, qvalueCutoff $=0.05$.

\section{Mouse studies.}

SCID-Beige mice were obtained from Charles river and maintained in the animal facility of Tongji University, Shanghai, China. All experiments were performed in accordance with the University of Health Guide for the Care and Use of Laboratory Animals and approved by the Biological Research Ethics Committee of Tongji University. Male mice aged 6-8 weeks were randomly assigned to treatment groups, such that the body weight and blood glucose levels were matched before treatment. For hyperglycemia restoration, the mice of diabetic disease modeling were made by multiple low-dose Streptozocin (STZ) injection $(60 \mathrm{mg} / \mathrm{kg} / \mathrm{d}$, for 5 days) and transplanted with the same amount of WT or $S L C 30 A 8^{-/}$SC- $\beta$ cells under the kidney capsule (3 million cells per animal). Some of nontransplantation diabetic mice were used as control. The body weight gain and random fed blood glucose were measured following transplantation. For SC- $\beta$ cell with ZnT8 LOF function test, same 
amount of WT or SLC30A8-- SC- $\beta$ cells were transplanted into healthy SCID-Beige mice under the kidney capsule ( 2 million cells per animal). Two weeks after transplantation, in vivo GSIS was performed every two weeks by fasting the animals for $16 \mathrm{~h}$ and collecting serum from the eye socket before and $30 \mathrm{~min}$ following intraperitoneal injection of glucose at $3 \mathrm{~g} / \mathrm{kg}$ body weight. The proinsulin and C-peptide were also measured in the serum from the eye socket by using human proinsulin ELISA kit and human ultrasensitive C-peptide ELISA kit. Human ultrasensitive insulin ELISA (ALPCO, \#80INSHUU-E01.1) was used to measure the human insulin content in the mouse serum.

\section{Statistical analysis.}

Data are derived from at least three independent biological replicates, unless otherwise specifically indicated. Mean \pm s.e.m. was used to present quantification data. $p$-values were calculated by twotailed unpaired student's $t$-test if not otherwise specifically indicated. For multiple comparisons, $p$ values were calculated by One-way repeated measures ANOVA or two-way repeated measures ANOVA. ${ }^{*} p<0.05, * * p<0.01, * * * p<0.001$, n.s. not significant.

\section{References and Notes}

1 Flannick, J. et al. Loss-of-function mutations in SLC30A8 protect against type 2 diabetes. Nature genetics 46, 357-363, doi:10.1038/ng.2915 (2014).

2 Pearson, E. Zinc transport and diabetes risk. Nature genetics 46, 323-324, doi:10.1038/ng.2934 (2014).

3 Zhu, Z. et al. Genome Editing of Lineage Determinants in Human Pluripotent Stem Cells Reveals Mechanisms of Pancreatic Development and Diabetes. Cell Stem Cel/ 18, 755-768, doi:10.1016/j.stem.2016.03.015 (2016).

4 Shi, Z. D. et al. Genome Editing in hPSCs Reveals GATA6 Haploinsufficiency and a Genetic Interaction with GATA4 in Human Pancreatic Development. Cel/ stem ce//20, 675-688 e676, doi:10.1016/j.stem.2017.01.001 (2017).

5 Zeng, $\mathrm{H}$. et al. An Isogenic Human ESC Platform for Functional Evaluation of Genome-wide-AssociationStudy-Identified Diabetes Genes and Drug Discovery. Ce/l stem ce// 19, 326-340, doi:10.1016/j.stem.2016.07.002 (2016).

6 Desai, T. \& Shea, L. D. Advances in islet encapsulation technologies. Nature reviews. Drug discovery 16, 338-350, doi:10.1038/nrd.2016.232 (2017).

$7 \quad$ Gerber, P. A. et al. Hypoxia lowers SLC30A8/ZnT8 expression and free cytosolic Zn2+ in pancreatic beta cells. Diabetologia 57, 1635-1644, doi:10.1007/s00125-014-3266-0 (2014).

8 Pagliuca, F. W. et al. Generation of functional human pancreatic beta cells in vitro. Ce// 159, 428-439, doi:10.1016/j.cell.2014.09.040 (2014). 

pluripotent stem cells. Nature biotechnology 32, 1121-1133, doi:10.1038/nbt.3033 (2014). Nair, G. G. et al. Recapitulating endocrine cell clustering in culture promotes maturation of human stemcell-derived beta cells. Nature cell biology 21, 263-274, doi:10.1038/s41556-018-0271-4 (2019). Dooley, J. et al. Genetic predisposition for beta cell fragility underlies type 1 and type 2 diabetes. Nature genetics 48, 519-527, doi:10.1038/ng.3531 (2016). Liston, A., Todd, J. A. \& Lagou, V. Beta-Cell Fragility As a Common Underlying Risk Factor in Type 1 and Type 2 Diabetes. Trends Mol Med 23, 181-194, doi:10.1016/j.molmed.2016.12.005 (2017).

Dwivedi, O. P. et al. Loss of ZnT8 function protects against diabetes by enhanced insulin secretion. Nature genetics 51, 1596-1606, doi:10.1038/s41588-019-0513-9 (2019). Nurit Kaiser, G. L. a. R. N. Glucotoxicity and B-Cell Failure in Type 2 Diabetes Mellitus. Pediatric Endocrinology \& Metabolism, doi:10.1515/jpem.2003.16.1.5 (2003).

Scha. Lipotoxicity: when tissues overeat. Current Opinion in Lipidology, 281-287, doi:10.1097/00041433200306000-00008 (2003).

Engin, A. B. Obesity and Lipotoxicity. (2017).

Ran, F. A. et al. Genome engineering using the CRISPR-Cas9 system. Nature protocols 8, 2281-2308, doi:10.1038/nprot.2013.143 (2013).

Micallef, S. J. et al. INS(GFP/w) human embryonic stem cells facilitate isolation of in vitro derived insulinproducing cells. Diabetologia 55, 694-706, doi:10.1007/s00125-011-2379-y (2012). Veres, A. et al. Charting cellular identity during human in vitro beta-cell differentiation. Nature 569, 368373, doi:10.1038/s41586-019-1168-5 (2019).

Blum, B. et al. Functional beta-cell maturation is marked by an increased glucose threshold and by expression of urocortin 3. Nat Biotechno/30, 261-264, doi:10.1038/nbt.2141 (2012).

Smeekens, S. P. et al. Proinsulin processing by the subtilisin-related proprotein convertases furin, PC2, and PC3. Proc Natl Acad Sci U S A 89, 8822-8826, doi:10.1073/pnas.89.18.8822 (1992).

Zhu, X. et al. Severe block in processing of proinsulin to insulin accompanied by elevation of des-64,65 proinsulin intermediates in islets of mice lacking prohormone convertase 1/3. Proc Natl Acad Sci U S A 99, 10299-10304, doi:10.1073/pnas.162352799 (2002).

Ramos-Molina, B., Martin, M. G. \& Lindberg, I. PCSK1 Variants and Human Obesity. Prog Mol Biol Trans/ Sci 140, 47-74, doi:10.1016/bs.pmbts.2015.12.001 (2016).

Zalewski, P. D. et al. Video image analysis of labile zinc in viable pancreatic islet cells using a specific fluorescent probe for zinc. J Histochem Cytochem 42, 877-884, doi:10.1177/42.7.8014471 (1994).

Pound, L. D. et al. Deletion of the mouse Slc30a8 gene encoding zinc transporter-8 results in impaired insulin secretion. The Biochemical journa/ 421, 371-376, doi:10.1042/BJ20090530 (2009).

Wijesekara, N. et al. Beta cell-specific Znt8 deletion in mice causes marked defects in insulin processing, crystallisation and secretion. Diabetologia 53, 1656-1668, doi:10.1007/s00125-010-1733-9 (2010).

Nicolson, T. J. et al. Insulin storage and glucose homeostasis in mice null for the granule zinc transporter ZnT8 and studies of the type 2 diabetes-associated variants. Diabetes 58, 2070-2083, doi:10.2337/db090551 (2009).

Lemaire, K. et al. Insulin crystallization depends on zinc transporter ZnT8 expression, but is not required for normal glucose homeostasis in mice. Proceedings of the National Academy of Sciences of the United States of America 106, 14872-14877, doi:10.1073/pnas.0906587106 (2009).

Tamaki, M. et al. The diabetes-susceptible gene SLC30A8/ZnT8 regulates hepatic insulin clearance. J Clin Invest 123, 4513-4524, doi:10.1172/JCI68807 (2013).

Cai, Y., Kirschke, C. P. \& Huang, L. SLC30A family expression in the pancreatic islets of humans and mice: cellular localization in the beta-cells. J Mol Histo/49, 133-145, doi:10.1007/s10735-017-9753-0 (2018). Greider, M. H., Howell, S. L. \& Lacy, P. E. Isolation and properties of secretory granules from rat islets of Langerhans. II. Ultrastructure of the beta granule. J Cel/ Bio/41, 162-166, doi:10.1083/jcb.41.1.162 (1969). Lange, R. H. Crystalline islet B-granules in the grass snake (Natrix natrix (L.)): tilting experiments in the electron microscope. J Ultrastruct Res 46, 301-307, doi:10.1016/s0022-5320(74)80064-x (1974). 
Dunn, M. F. Zinc-ligand interactions modulate assembly and stability of the insulin hexamer -- a review. Biometals : an international journal on the role of metal ions in biology, biochemistry, and medicine 18, 295-303, doi:10.1007/s10534-005-3685-y (2005).

34 Brange, J., Owens, D. R., Kang, S. \& Volund, A. Monomeric insulins and their experimental and clinical implications. Diabetes Care 13, 923-954, doi:10.2337/diacare.13.9.923 (1990).

35 Shoelson, S. E., Lu, Z. X., Parlautan, L., Lynch, C. S. \& Weiss, M. A. Mutations at the dimer, hexamer, and receptor-binding surfaces of insulin independently affect insulin-insulin and insulin-receptor interactions. Biochemistry 31, 1757-1767, doi:10.1021/bi00121a025 (1992).

Bakaysa, D. L. et al. Physicochemical basis for the rapid time-action of LysB28ProB29-insulin: dissociation of a protein-ligand complex. Protein Sci 5, 2521-2531, doi:10.1002/pro.5560051215 (1996). Groskreutz, D. J., Sliwkowski, M. X. \& Gorman, C. M. Genetically engineered proinsulin constitutively processed and secreted as mature, active insulin. J Biol Chem 269, 6241-6245 (1994).

Gaither, L. A. \& Eide, D. J. Eukaryotic zinc transporters and their regulation. Biometals 14, 251-270 (2001). Jeong, J. \& Eide, D. J. The SLC39 family of zinc transporters. Mol Aspects Med 34, 612-619, doi:10.1016/j.mam.2012.05.011 (2013).

Lawson, R., Maret, W. \& Hogstrand, C. Expression of the ZIP/SLC39A transporters in beta-cells: a systematic review and integration of multiple datasets. BMC Genomics 18, 719, doi:10.1186/s12864-0174119-2 (2017).

Ghafghazi, T., McDaniel, M. L. \& Lacy, P. E. Zinc-induced inhibition of insulin secretion from isolated rat islets of Langerhans. Diabetes 30, 341-345, doi:10.2337/diab.30.4.341 (1981).

Cunha, G. R. \& Donjacour, A. A. Mesenchymal-epithelial interactions in the growth and development of the prostate. Cancer Treat Res 46, 159-175 (1989).

Ferrer, R., Soria, B., Dawson, C. M., Atwater, I. \& Rojas, E. Effects of Zn2+ on glucose-induced electrical activity and insulin release from mouse pancreatic islets. Am J Physio/246, C520-527, doi:10.1152/ajpcell.1984.246.5.C520 (1984).

Sladek, R. et al. A genome-wide association study identifies novel risk loci for type 2 diabetes. Nature 445, 881-885, doi:10.1038/nature05616 (2007). Kirchhoff, K. et al. Polymorphisms in the TCF7L2, CDKAL1 and SLC30A8 genes are associated with impaired proinsulin conversion. Diabetologia 51, 597-601, doi:10.1007/s00125-008-0926-y (2008). $\mathrm{Kim}$, I. et al. A low-risk ZnT-8 allele (W325) for post-transplantation diabetes mellitus is protective against cyclosporin A-induced impairment of insulin secretion. Pharmacogenomics J11, 191-198, doi:10.1038/tpj.2010.22 (2011).

Merriman, C., Huang, Q., Rutter, G. A. \& Fu, D. Lipid-tuned Zinc Transport Activity of Human ZnT8 Protein Correlates with Risk for Type-2 Diabetes. J Biol Chem 291, 26950-26957, doi:10.1074/jbc.M116.764605 (2016). Cong, L. et al. Multiplex genome engineering using CRISPR/Cas systems. Science 339, 819-823, doi:10.1126/science.1231143 (2013).

Nostro, M. C. et al. Efficient generation of NKX6-1+ pancreatic progenitors from multiple human pluripotent stem cell lines. Stem cell reports 4, 591-604, doi:10.1016/j.stemcr.2015.02.017 (2015).

Nostro, M. C., Cheng, X., Keller, G. M. \& Gadue, P. Wnt, activin, and BMP signaling regulate distinct stages in the developmental pathway from embryonic stem cells to blood. Cel/ stem ce//2, 60-71, doi:10.1016/j.stem.2007.10.011 (2008).

\section{Acknowledgments}

This work was supported by the National Key Research and Development Program of China [2016YFA0102200, 2017YFA0106500, 2018YFA0107102]; Q.M., Y.X., X.C., and W.L conceived 
and designed the experiments. Q.M., Y.X., S.L., R.H., T.X., Q.S., F.Y. and Z. Z. performed the genome editing, differentiations, immunofluorescence, ELISA and flow cytometry experiments. T.Z., and W.S., performed single cell RNA-seq library construction. M.W. and Q.D. performed single cell RNAseq profiling analyses. J.Z and Z.C helped to perform perifusion assays. Q.M., Y.X., F.Y., Q.D., X.C., and W.L. wrote the manuscript. The authors would like to thank Mushan Li and Dr. Zhen Shao for advice on single cell RNA-seq analyses and thank Gang Liu for the assistance of transplantation. 


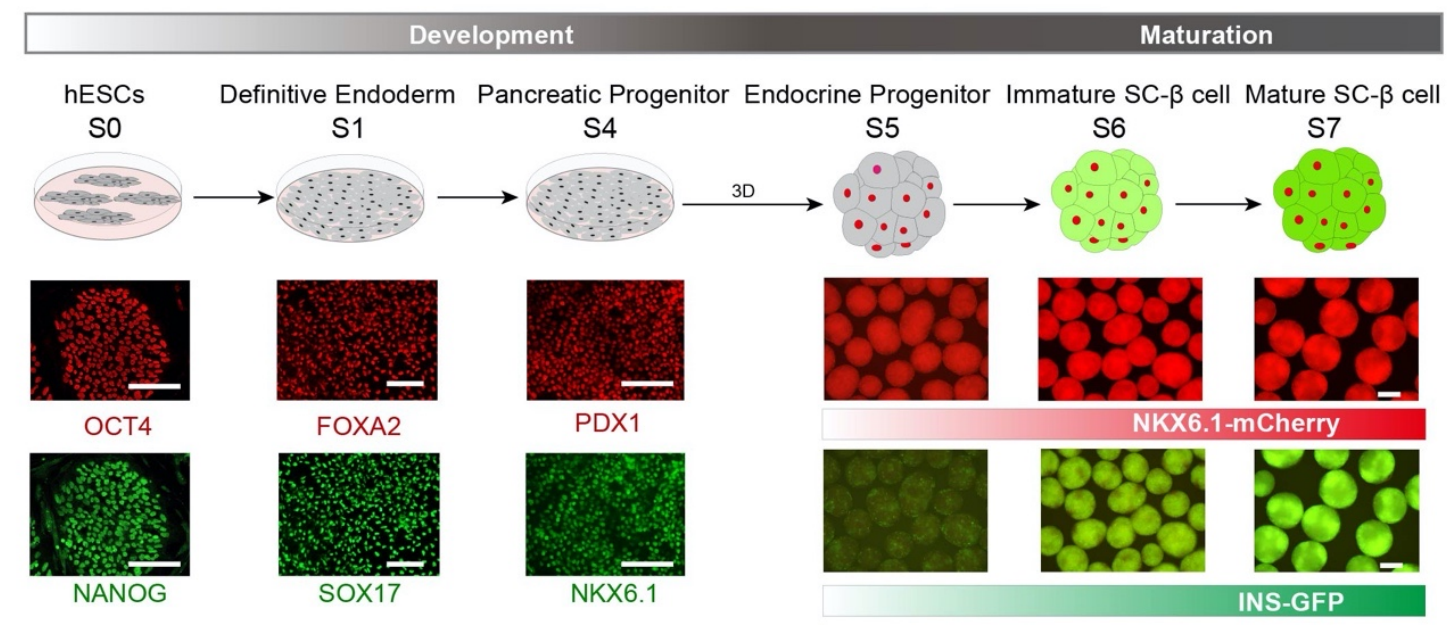

b

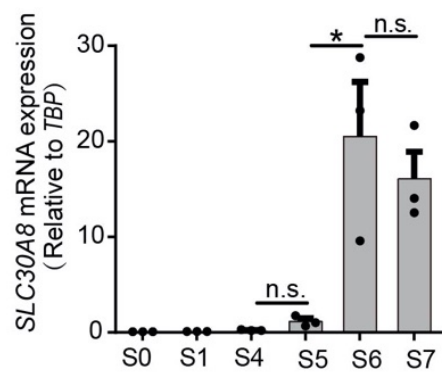

d
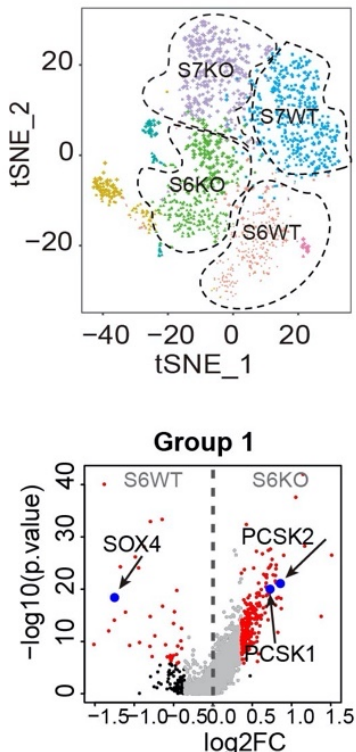

f

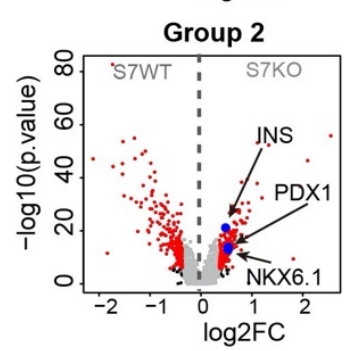

g
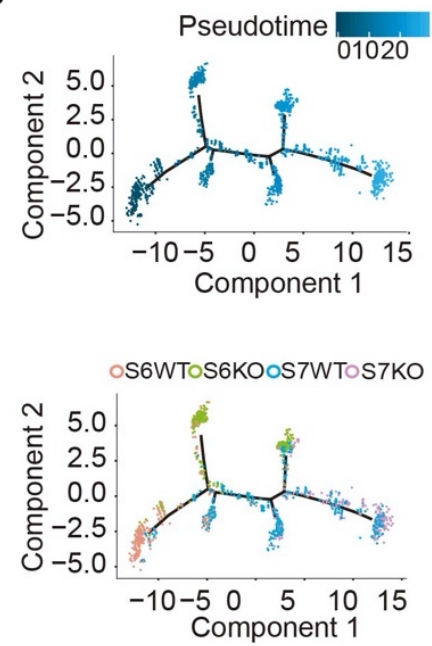

h

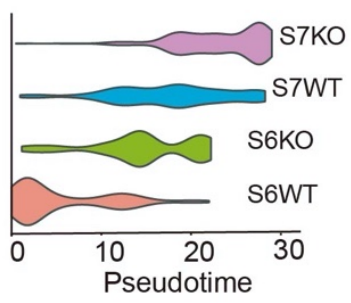

i

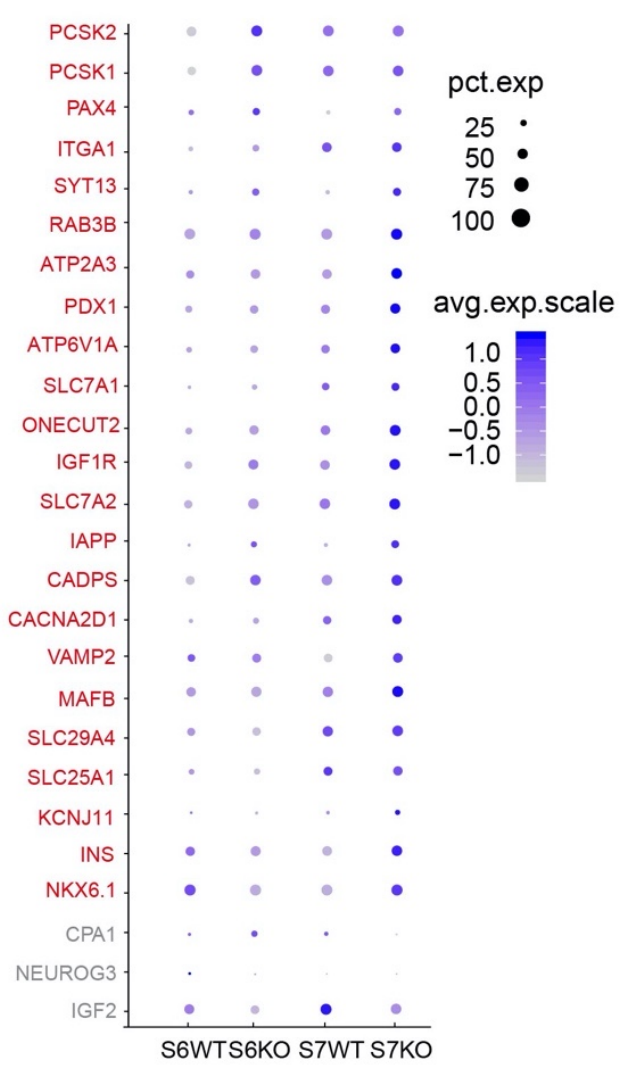




\section{Fig. 1 | ZnT8 LOF accelerates SC- $\beta$ cell maturation by upregulating maturity-related markers.}

a, A schematic of differentiation of Mel1 NKX6.1 ${ }^{\text {mCherry/mCherry }}$ INSSFP/W $\mathrm{hESCs}$ into $\beta$ cell from S0 to S7 (S, stage; major stages are shown). During this process, the cells of S0-S4 are adherent culture, and the cells at the end of S4 are digested and aggregated into mini clusters and then cultured in 3D environment by using low-attachment plate. The differentiation process recapitulates two status: S0S5 represent the development process and S6-S7 represent the maturation process of SC- $\beta$ cell. This schematic includes representative immunofluorescence images which represent typical markers of major stages $\left(\mathrm{S} 0, \mathrm{OCT}_{4}^{+} / \mathrm{NANOG}^{+} ; \mathrm{S} 1, \quad \mathrm{FOXA}^{+} / \mathrm{SOX} 17^{+} ; \mathrm{S} 4, \quad \mathrm{PDX} 1^{+} / \mathrm{NKX} 6.1^{+} ; \quad \mathrm{S} 5-\mathrm{S} 7\right.$, NKX6. $1^{+} / \mathrm{INS}^{+}$). Scale bars, $100 \mu \mathrm{m}(\mathrm{S} 0-\mathrm{S} 5) ; 200 \mu \mathrm{m}$ (S6-S7). The red bar and green bar represent temporal expression of $N K X 6.1$ and INS respectively. b, qRT-PCR analysis of SLCOA8 mRNA expression level during the SC- $\beta$ cell differentiation process. $n=3$ independent samples for each stage. Data are presented as mean \pm s.e.m. $p$-values are calculated by one-way ANOVA with Bonferroni test for multiple comparisons. ${ }^{*} p<0.05$; ns, not significant. c, A schematic representation of single-cell analysis process: hESCs (WT and $S L C 30 A 8^{-/}$) differentiation into the immature (S6) and mature (S7) SC- $\beta$ cells; cell isolation by FACS (INS-GFP ${ }^{+} / \mathrm{NKX} 6.1-\mathrm{mCherry}^{+}$); single-cell sequencing. d, $t-S N E$ projection of S6WT (pink), S6KO (green), S7WT (blue) and S7KO (purple) cells colored by Seurat identified clusters. e and f, Volcano plots of the upregulated and downregulated differentially expressed genes (DEGs) according to the comparisons (Group 1, S6WT vs. S6KO; Group 2, S7WT vs. S7KO). Genes with absolute fold change not more than 1.28 are in grey, genes with absolute fold change larger than 1.28 and adjusted $p$ value not more than 0.05 are in red, and others are in black. $\mathbf{g}$, In silico pseudotime ordering of S6WT, S6KO, S7 WT and S7KO, colored by pseudotime value and clusters. h, The distribution of pseudotime in S6WT, S6KO, S7WT and S7KO. i, Dot plot showing gene signature shifts among different cell lines and stages (S6 WT, S6KO, S7 WT and S7KO); Red, the genes upregulated in the S7KO relative to S7WT; Grey, downregulated genes in S7KO relative to S7WT. 
a

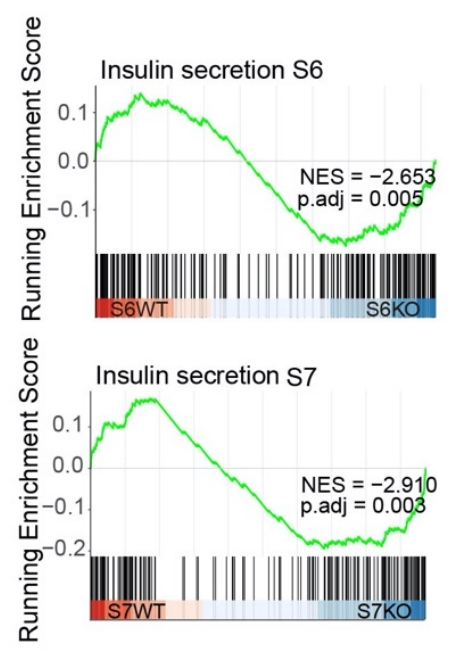

b

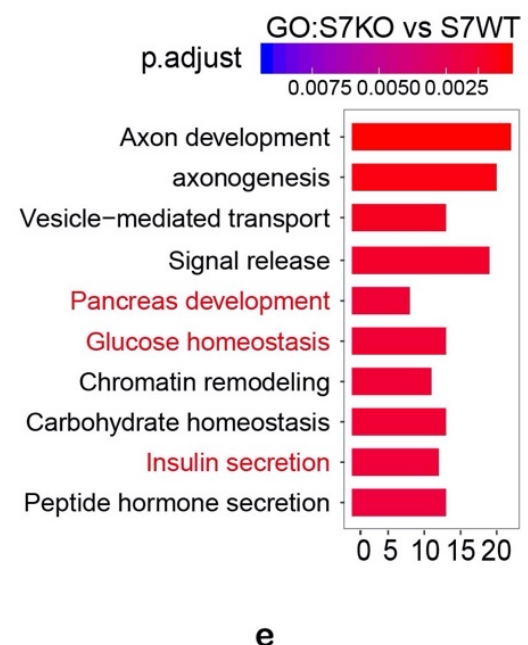

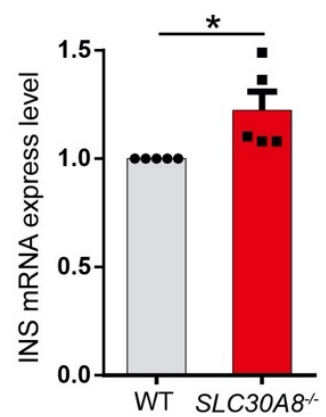

d

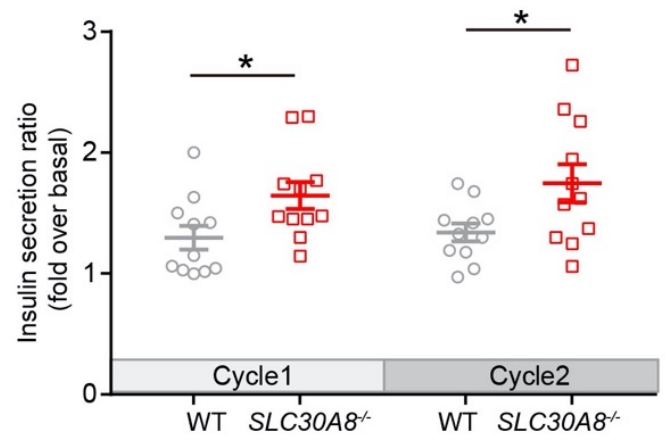

g

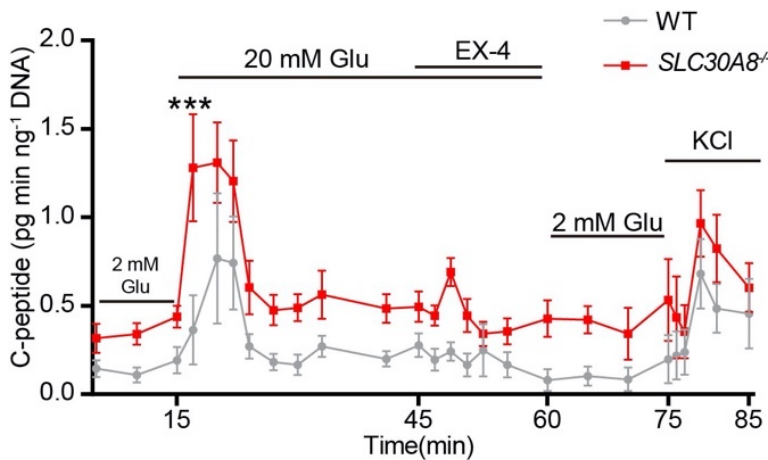

i

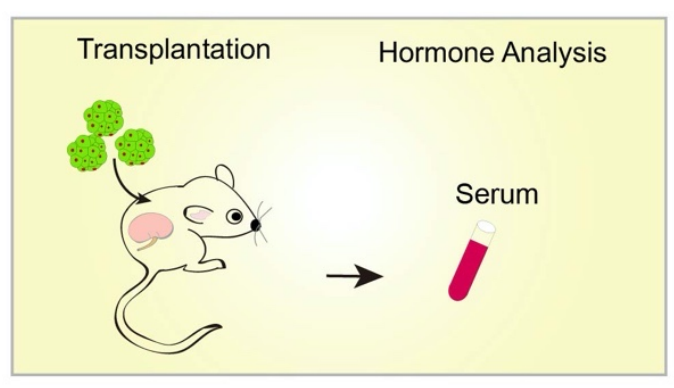

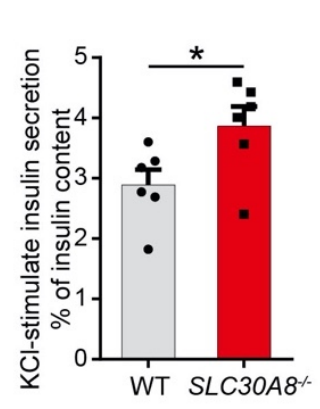

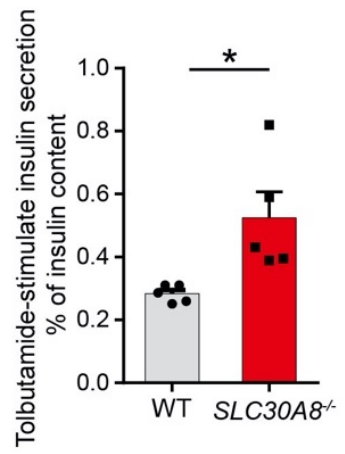

h
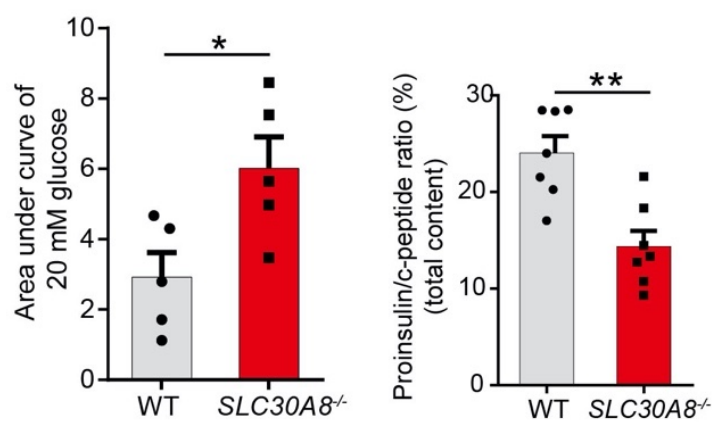

j
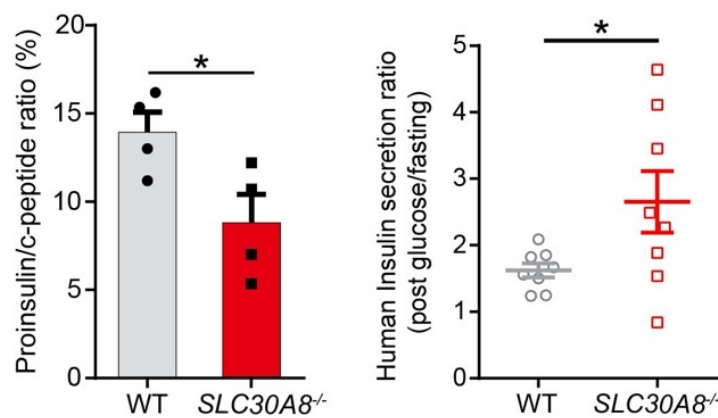
Fig. 2 | SC- $\beta$ cells with ZnT8 LOF gain improved sensitivity to glucose stimulation and proinsulin conversion both in vivo and in vitro. a, Top 10 gene ontology (GO) terms were significantly upregulated in S7KO compared to S7 WT. The terms colored red highlight the biological processes related to SC- $\beta$ cell function. b, GSEA traces demonstrating enrichment of the insulin secretion genes in the cells of S6WT compared to those in S6KO and in the cells of S7WT compared

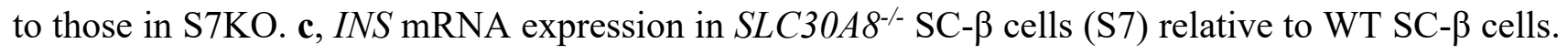
$n=5$. $\mathbf{d}$, Glucose stimulate insulin secretion of WT and SLC $30 A 8^{-/-}$mature SC- $\beta$ cells. The amount of secreted insulin stimulated with $20 \mathrm{mM}$ glucose was normalized to that in the basal glucose condition of $2 \mathrm{mM}$ concentration. $n=11$. e and $\mathbf{f}$, Effect of ZnT8 LOF on insulin secretion (as a percentage of total insulin content) in response to $\mathrm{KCl}(30 \mathrm{mM}, \mathrm{n}=6)(\mathbf{e})$ and tolbutamide $(200 \mu \mathrm{M}, n=5)(\mathbf{f})$ in mature SC- $\beta$ cells. g, Left panel, dynamic perifusion assay of C-peptide secretion from WT and $S L C 30 A 8^{-/}$mature SC- $\beta$ cells, in response to $2 \mathrm{mM}$ glucose, $20 \mathrm{mM}$ glucose, $10 \mathrm{nM}$ exendin-4 (Ex-4, added $20 \mathrm{mM}$ glucose) and $30 \mathrm{mM} \mathrm{KCl}$, stimulation respectively. $n=5$ independent samples. Grey line, WT SC- $\beta$ cells; red line, SLC $30 A 8^{-/-}$mature SC- $\beta$ cells; Right panel, AUC of C-peptide dynamic secretion in response to $20 \mathrm{mM}$ glucose stimulation in WT and $S L C 30 A 8^{-/-}$mature SC- $\beta$ cells. h, Total proinsulin/C-peptide ratio in mature SC- $\beta$ cells. $n=7$. i, A schematic of WT and SLC $30 A 8^{-/-}$mature SC- $\beta$ cells function test in vivo. The same number ( 2 million) of WT and SLC $30 A 8^{-/-}$mature SC- $\beta$ cells were transplanted into the kidney capsule of SCID-Beige mice respectively. The insulin or C-peptide or proinsulin in the serum were tested by ELISA during 2-10 weeks after transplantation. $\mathbf{j}$, Human proinsulin/C-peptide ratio in mouse serum with transplanted mature SC- $\beta$ cells (WT, $n=4 ; S L C 30 A 8^{-}$ $\left.{ }^{/}, n=4\right)$. $\mathbf{k}$, Mice transplanted with WT or SLC $30 A 8^{-/-}$mature SC- $\beta$ cells were measured as the ratio of human insulin secretion in the serum upon intraperitoneal glucose challenge to that after $16 \mathrm{~h}$ fasting (WT, $n=8 ; S L C 30 A 8^{-/-}, n=8$ ). Data are presented as mean \pm s.e.m. ${ }^{*} p<0.05 ;{ }^{*} p<0.01 ; * * * p<0.001$. In perifusion assay, $p$-values are calculated by two-way repeated measures ANOVA with Bonferroni 
test for multiple comparisons between WT and $S L C 30 A 8^{-/-}$SC- $\beta$ cells. In other assays of this figure, $p$-values are determined by two-tailed unpaired student's $t$-test. 


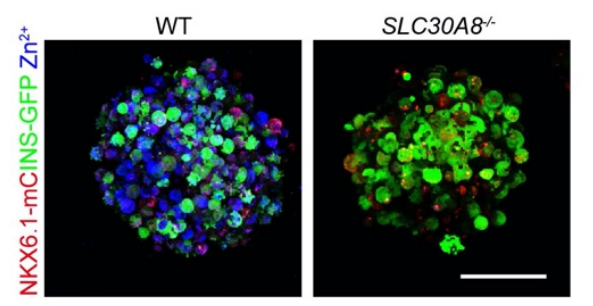

d

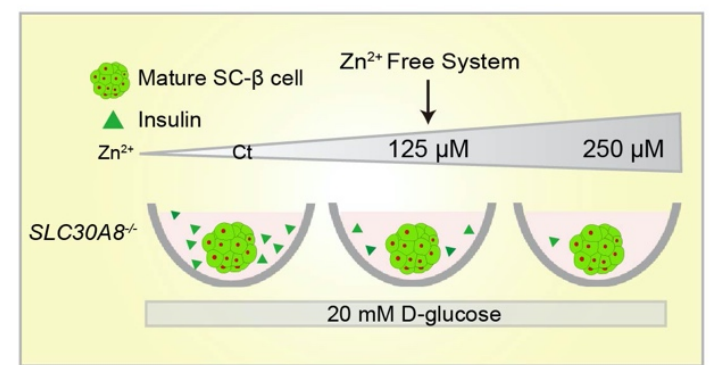

g

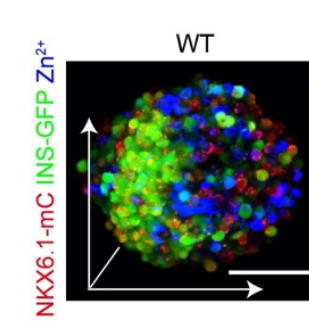

b

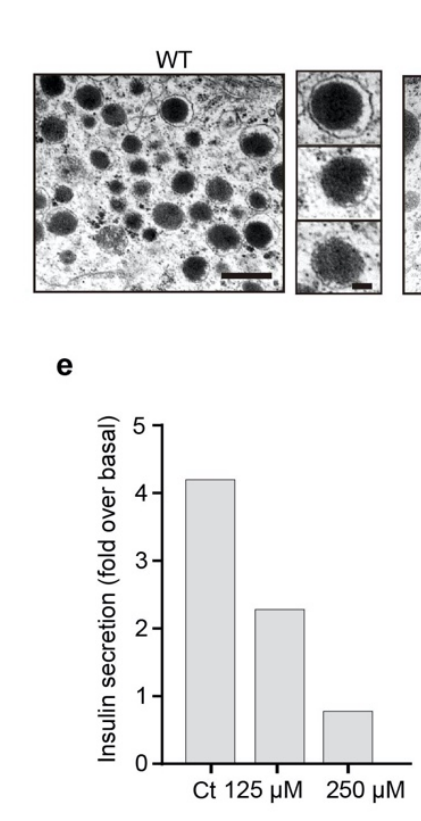

h

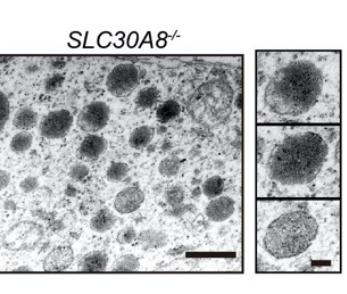

f c

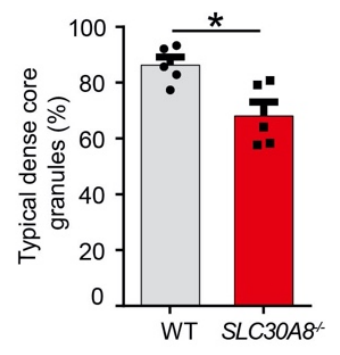

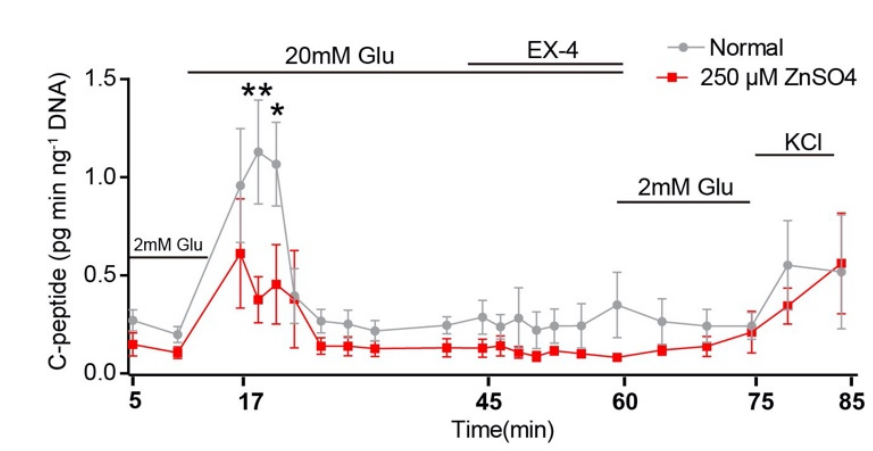
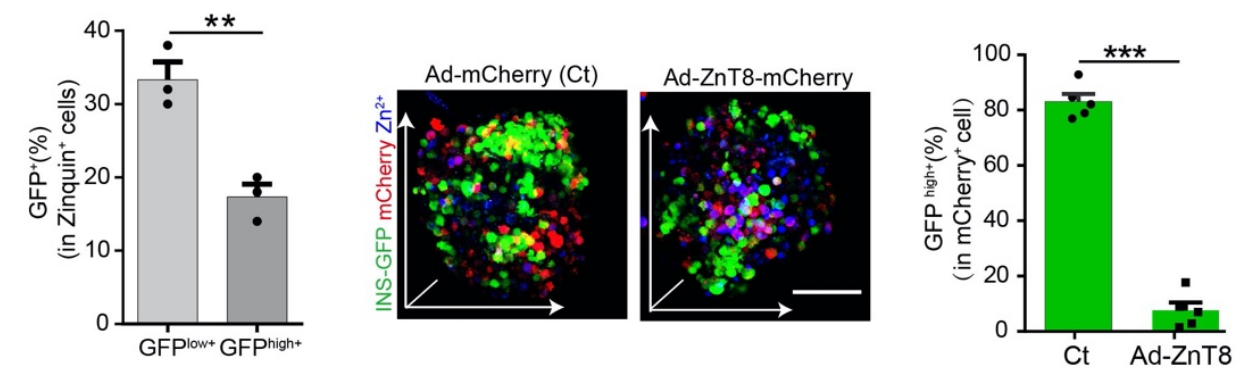
Fig. 3 | Granular zinc content influences insulin expression and secretion. a, 3D confocal reconstruction images of Zinquin staining to track zinc (blue) inside insulin granules of WT and SLC $30 A 8^{-/-}$mature SC- $\beta$ cells (green, INS-GFP; red, mCherry); scale bar, $50 \mu \mathrm{m}$. b, Transmission electron microscopy images of insulin granules in WT and SLC $30 A 8^{-/-}$mature SC- $\beta$ cells. Scale bars in low magnification images, $0.5 \mu \mathrm{m}$; Scale bars in high magnification images, $0.1 \mu \mathrm{m}$. c, Typical insulin dense core granules as a percentage of total granules in WT and SLC $30 \mathrm{~A} 8^{-/-}$mature SC- $\beta$ cells. $n=5$. d, A schematic of dosage-dependent zinc inhibition of insulin secretion. SLC $30 A 8^{-/-}$mature SC$\beta$ cell clusters were stimulated with $20 \mathrm{mM}$ glucose and elevated dosages of zinc $(\mathrm{Ct}, 125 \mu \mathrm{M}, 250$ $\mu \mathrm{M})$ respectively for $30 \mathrm{~min}$. e, Insulin secretion upon glucose challenge with a dosage-dependent zinc inhibition manner. $n=60$ mature SC- $\beta$ cell clusters in each condition. $\mathbf{f}$, Dynamic perifusion assay of zinc-dependent inhibition of C-peptide secretion from $S L C 30 A 8^{-/-}$mature SC- $\beta$ cell clusters, in response to $2 \mathrm{mM}$ glucose, $20 \mathrm{mM}$ glucose (added with 0 or $250 \mu \mathrm{M} \mathrm{ZnSO}$ ), $10 \mathrm{nM}$ exendin-4 (Ex4, added $20 \mathrm{mM}$ glucose) and $30 \mathrm{mM} \mathrm{KCl}$ stimulation. Grey line, normal condition; red line, treated with $250 \mu \mathrm{M} \mathrm{ZnSO}_{4} . n=3$ independent samples. g, Fluorescence images of NKX6.1-mCherry, INSGFP and Zinquin $\left(\mathrm{Zn}^{2+}\right)$ in WT and $S L C 30 A 8^{-/-}$mature SC- $\beta$ cells. Left panel: 3D confocal reconstruction image; scale bar, $100 \mu \mathrm{m}$. Right panel: images of adherent single cells digested from SC$\beta$ cell clusters; scale bar in low magnification images, $20 \mu \mathrm{m}$; scale bar in high magnification images, $10 \mu \mathrm{m} . \mathbf{h}, \mathrm{INS}_{-\mathrm{GFP}^{+}}$cells as a percentage of Zinquin ${ }^{+}$cells $\left(\mathrm{GFP}^{\text {high }}{ }^{+}\right.$, mature SC- $\beta$ cell with strong GFP intensity; GFP ${ }^{\text {low }}$, mature SC- $\beta$ cell with weak GFP intensity; the GFP signal intensity was measured by the software image J). $n=3$. i, Zinquin staining (blue) in $S L C 30 A 8^{-/-}$mature SC- $\beta$ cells (derived from Mel1 ${ }^{G F P / W} \mathrm{hES}$ cell lines) infected with ZnT8-mCherry or mCherry via adenovirus (AdZnT8-mCherry, Ad-ZnT8; Ad-mCherry, Ct). Images shown are 3D confocal re-construction with maximum intensity projections. Scale bar,100 $\mu \mathrm{m}$. j, Proportion of the SC- $\beta$ cells with strong GFP signal $\left(\mathrm{GFP}^{\text {high }}{ }^{+}\right)$in $\mathrm{mCherry}^{+}$(successfully infected with adenovirus) cells. $n=5$. Data in this figure are presented as mean \pm s.e.m. ${ }^{*} p<0.05 ; * * p<0.01 ; * * *<0.001$. In perifusion assay, $p$-values are 
determined by two-way repeated measures ANOVA with Bonferroni test for multiple comparisons between $S L C 30 A 8^{-/-}$SC- $\beta$ cells added with $\mathrm{ZnSO} 4$ or vehicle. In other assays of this figure, two-tailed unpaired student's $t$-test was used to calculate $p$-values. 


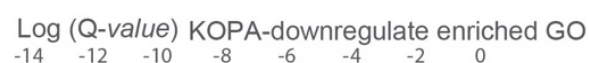

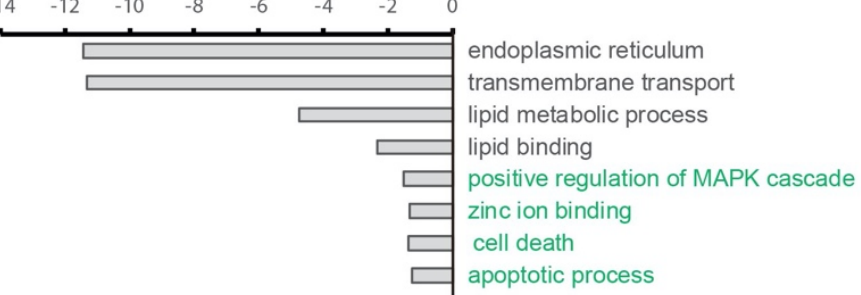

c

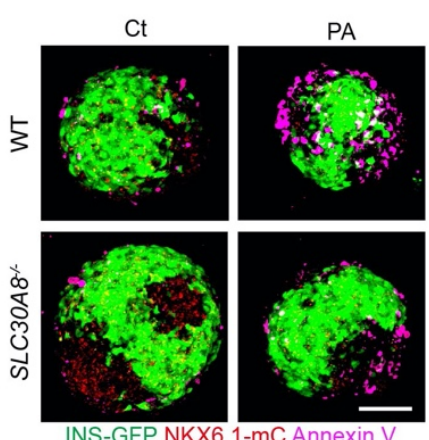

g

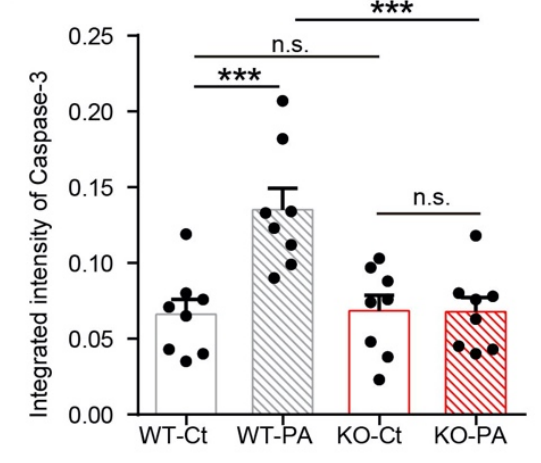

d

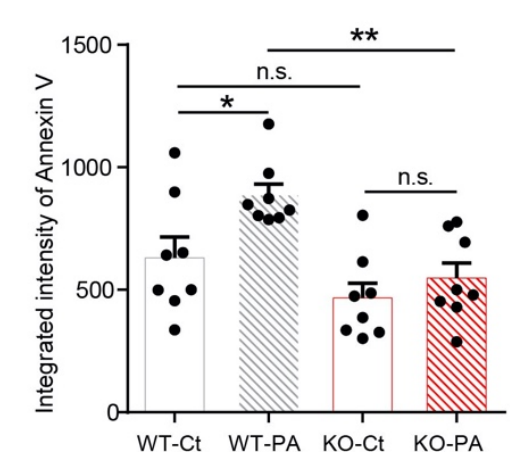

h
Log (Q-value) KOPA-upregulate enriched GO

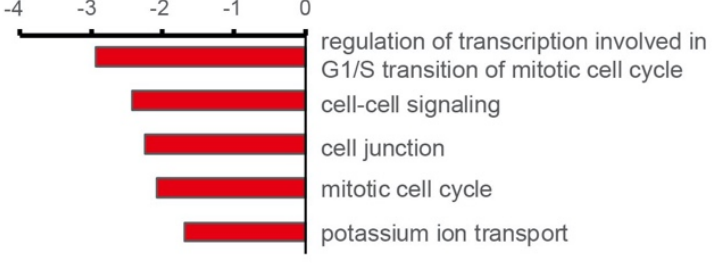

e
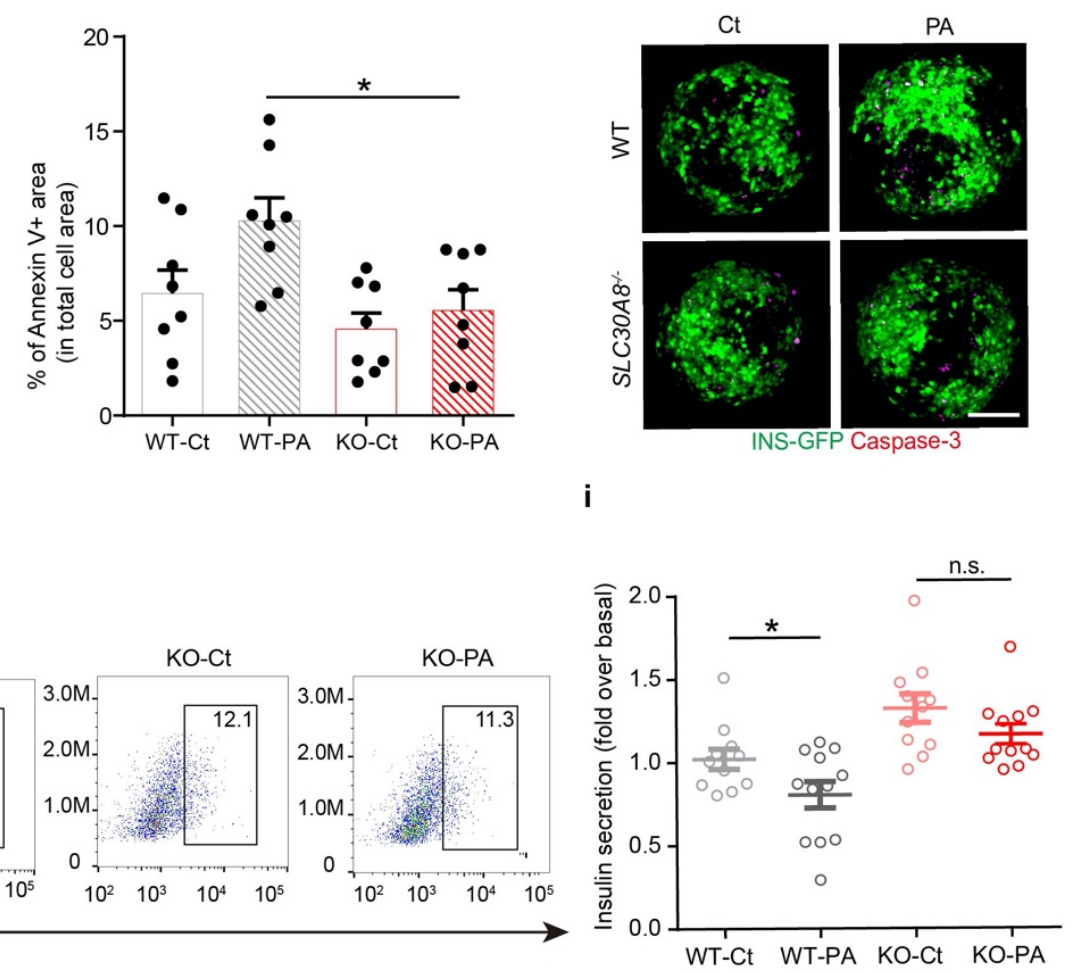
Fig. 4 | ZnT8 LOF enhances SC- $\beta$ cell survival under the pressure of lipotoxicity. a and b, Gene ontology (GO) analysis of genes significantly downregulated (a) and upregulated (b) (Q-value < 0.05) in KO-PA cells (relative to WT-PA cells). c, Annexin V (magenta) staining analysis of WT and SLC $30 A 8^{-/-}(\mathrm{KO})$ mature SC- $\beta$ cell clusters (green, INS-GFP; red, mCherry) treated with $1 \mathrm{mM}$ palmitate (PA) or vehicles (Control, Ct) for $48 \mathrm{~h}$. Scale bar, $100 \mu \mathrm{m}$. d and e, Integrated intensity (d) and area percentage (e) of annexin V in the cells of WT-Ct, WT-PA, KO-Ct, KO-PA $(n=8$ of each group). f and $\mathbf{g}$, Immunostaining analysis (f) and the mean intensity (g) of Caspase-3 (magenta) in WT and $\mathrm{S} L C 30 A 8^{-/}(\mathrm{KO})$ mature SC- $\beta$ cell clusters treated with $1 \mathrm{mM}$ palmitate $(\mathrm{PA})$ or vehicles (Control, Ct) for 48 h. h, Intracellular FACS of Caspase-3 in the cells of WT-Ct, WT-PA, KO-Ct, KO-PA. i, the ratio of GSIS of WT and $S L C 30 A 8^{-/-}(\mathrm{KO})$ mature SC- $\beta$ cell clusters treated with $1 \mathrm{mM}$ palmitate (PA) or vehicles (Control, $\mathrm{Ct}$ ) for $48 \mathrm{~h}$. $p$-values are calculated by two-tailed student's $t$-test. Data in this figure are presented as mean \pm s.e.m. ${ }^{*} p<0.05 ; * * p<0.01 ; * * *<0.001$; ns, not significant. $p$-values are calculated by one-way ANOVA with Bonferroni test for multiple comparisons between selected groups. 


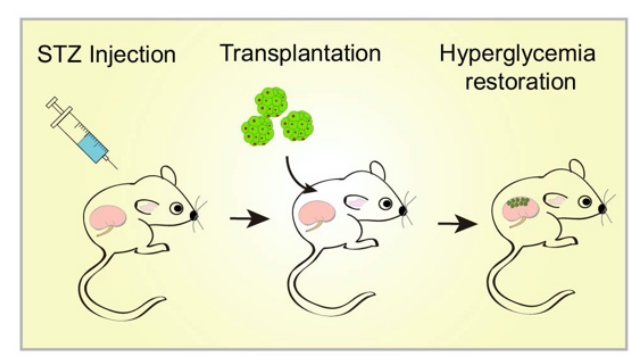

d
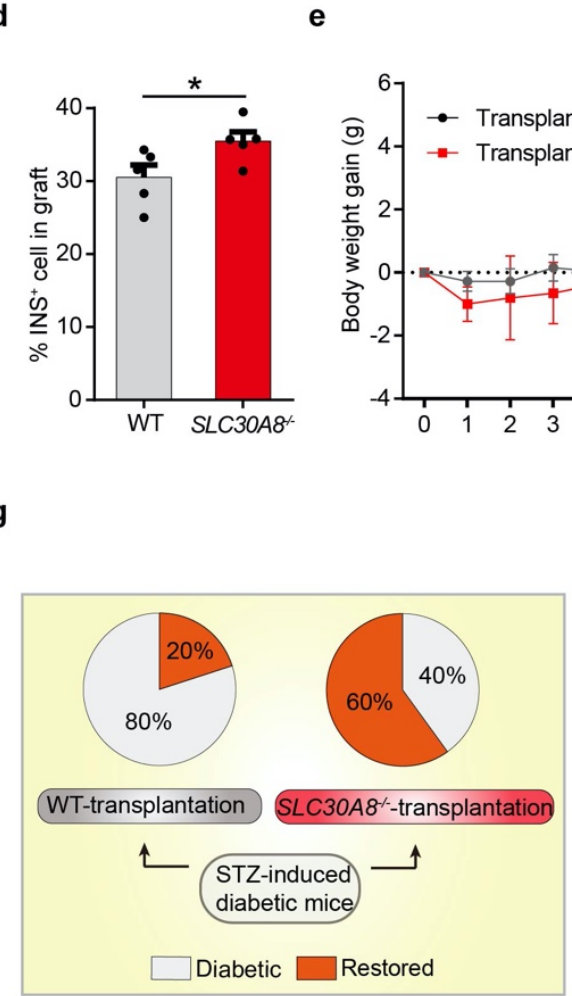

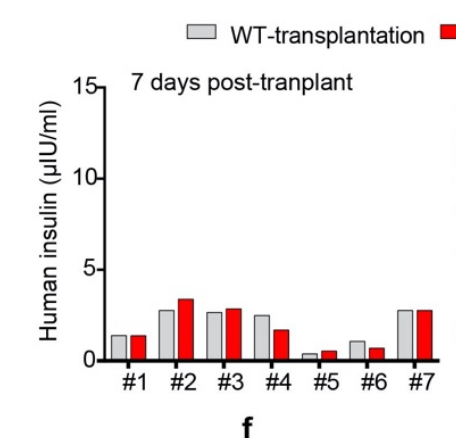

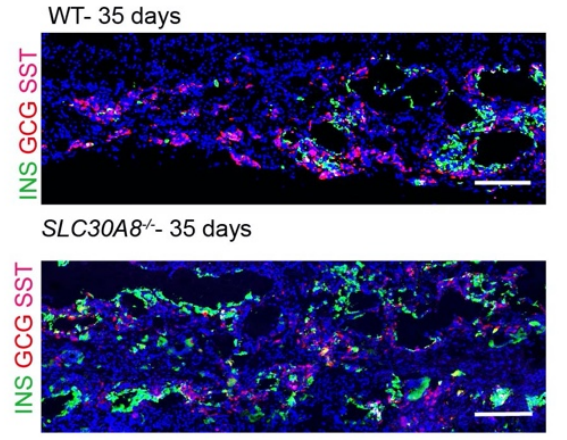

Transplantation

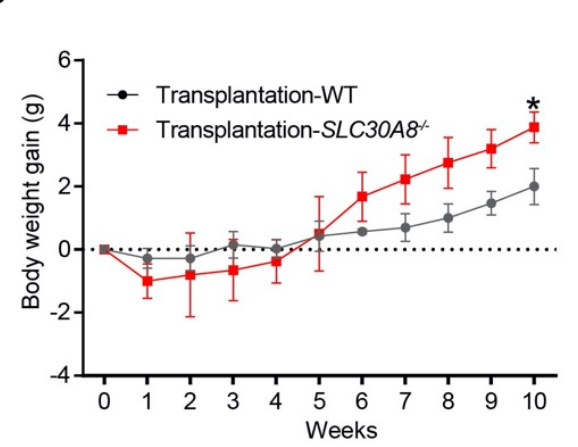

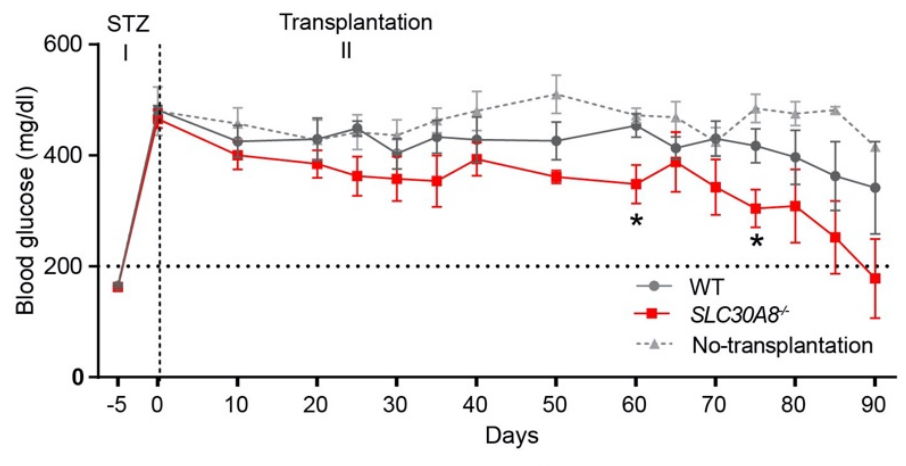

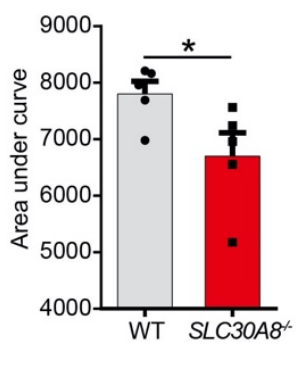

- 2. STZ-treated
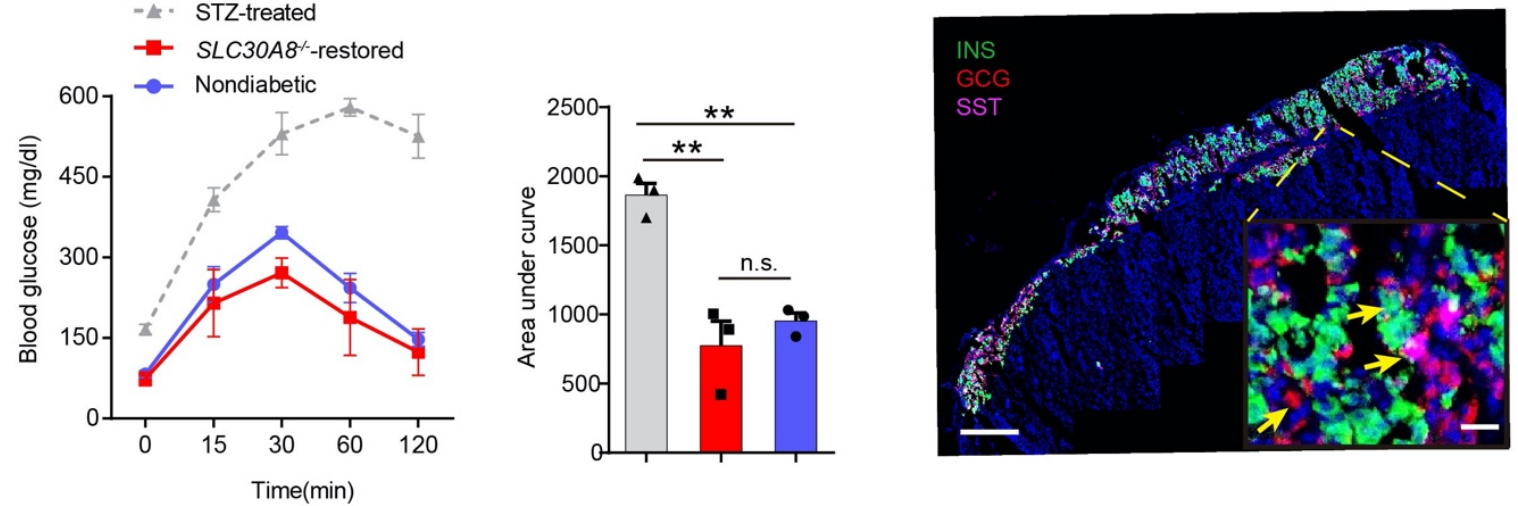
Fig. 5 | SC- $\beta$ cells with ZnT8 LOF significantly improve the ability of glycemic restoration. a, A schematic of experiment processes in vivo. b, The serum human insulin is measured at day 7and day 35 after the mice transplanted with WT and $S L C 30 A 8^{-/}$SC- $\beta$ cells (all mice were divided into 7 groups, each group consisting of one mouse transplanted with WT cells and one mouse transplanted with SLC $30 \mathrm{~A}^{-/}$cells). c and d, Representative immunofluorescent staining images (c) and $\mathrm{INS}^{+}$cell quantification (d) of WT and $S L C 30 A 8^{-/-}$mature SC- $\beta$ cells engrafted under the kidney capsule and harvested at 35 days post-transplant. Scale bar, $250 \mu \mathrm{m}$. e, Body weight gain measurements in the 10 weeks after the mice transplanted with WT (dark gray, $n=4)$ or $S L C 30 A 8^{-/}$(red, $\left.n=4\right)$ mature SC- $\beta$ cells for. See Supplementary Table 3 for source data. f, Random fed blood glucose measurements taken from the mice without any transplantation (light gray, $n=4$ ) or transplanted with WT (dark gray, $n=$ 5) or $S L C 30 A 8^{-/}$(red, $\left.n=5\right)$ mature SC- $\beta$ cells. Some of diabetic mice died before 90 days. See Supplementary Table 4 for source data. $\mathbf{g}$, A schematic of hyperglycemia restoration percentage of STZ-induced diabetic mice transplanted with WT and $S L C 30 A 8^{-/-}$mature SC- $\beta$ cells. Grey panel, the mice in diabetic status after transplantation for 90 days; Orange panel, hyperglycemia restored after transplantation for 90 days. h, Blood glucose were measured during an intraperitoneal injection glucose tolerance test on 90 days after transplantation. Gray line, STZ-induced diabetic mice without transplantation $(n=3)$; blue line, healthy mice $(n=3)$; red line, STZ-induced diabetic mice with SLC $30 A 8^{-/-}$SC $-\beta$ cell transplantation $(\mathrm{n}=3)$. i, Representative immunofluorescent staining of SLC $30 A 8^{-/-}$mature SC- $\beta$ cells engrafted under the kidney capsule and harvested at 6 months posttransplant; insulin (INS, green), glucagon (GCG, red) and somatostatin (SST, magenta). Scale bars in low magnification images, $500 \mu \mathrm{m}$; high magnification images, $20 \mu \mathrm{m}$. Data are presented as mean \pm s.e.m. ${ }^{*} p<0.05 ; * * p<0.01 ; * * p<0.001$; ns, not significant. In i.p.GTT assay, p-values are calculated 
by two-way repeated measures ANOVA with Bonferroni test for multiple comparisons between the mice transplanted with WT and SLC $30 A 8^{-/-}$SC- $\beta$ cells at each time; $p$-values of AUC are calculated by on-way ANOVA with Tukey test for multiple comparisons. In other assays of this figure, p-values are determined by two-tailed unpaired student's t-test. 
a

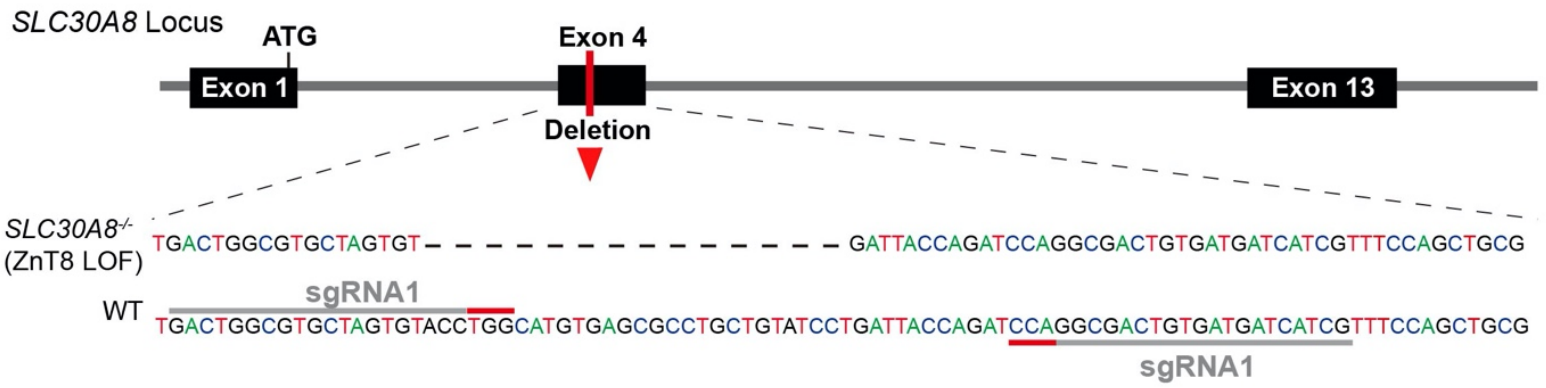

b

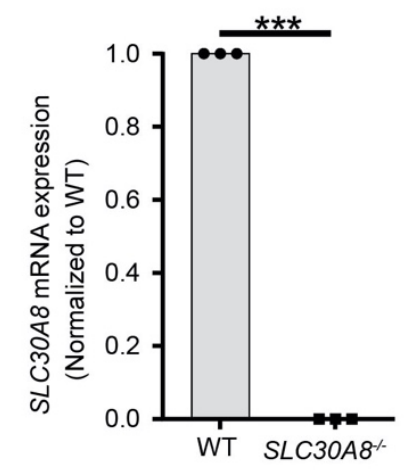

d
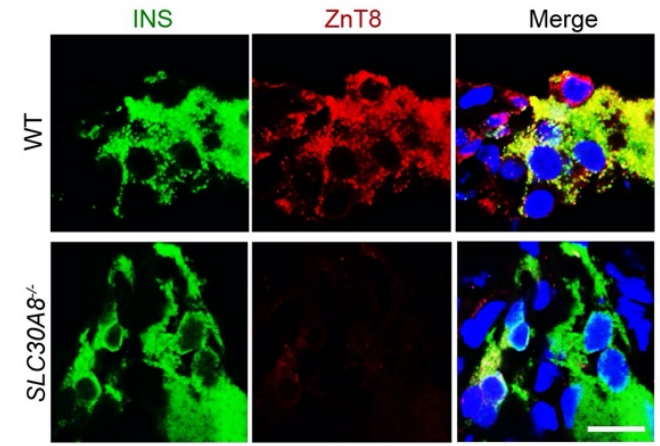

f
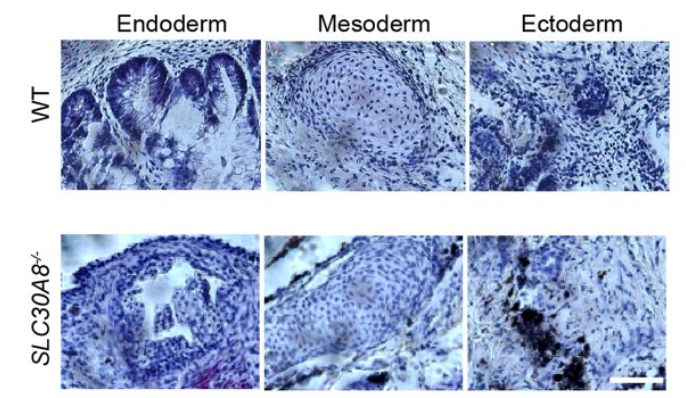

C

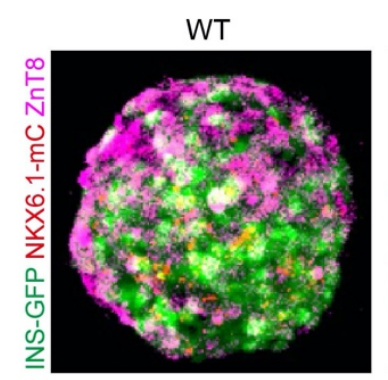

SLC30A8

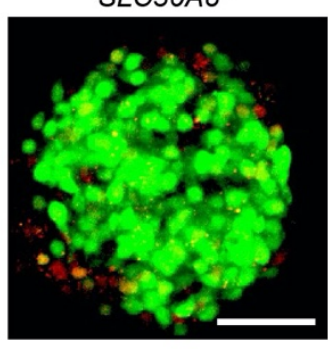

e

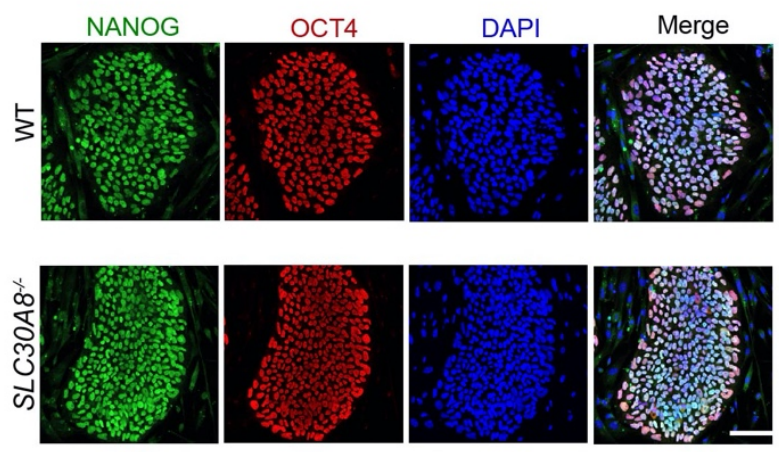


Extended Data Fig. 1 | Generation of $S L C 30 A 8$ knockout hESC line. a, A schematic of CRISPR/Cas9 targeting for generating $S L C 30 A 8^{-/}$hESC lines. b, qRT-PCR analysis of $S L C 30 A 8$ mRNA expression level in WT and $S L C 30 A 8^{-/-}$mature SC- $\beta$ cells (SLC30A8 mRNA expression level in knockout cell line was normalized to WT cell line). $n=3$. c, Representative immunofluorescence

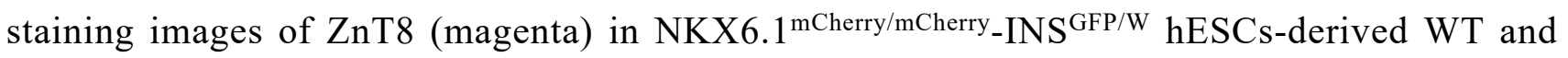
SLC $30 A 8^{-/-}$mature SC- $\beta$ cells. Scale bar, $100 \mu \mathrm{m}$. d, Representative immunofluorescent staining of insulin (green), and ZnT8 (red) in WT and $S L C 30 A 8^{-/-}$mature SC- $\beta$ cells engrafted under the kidney capsule and harvested at 90 days post-transplant. Scale bar, $10 \mu \mathrm{m}$. e, Representative immunostaining of WT and $S L C 30 A 8^{-/-}$hESCs for NANOG (green), OCT4 (red) and DAPI (blue). Scale bar, $100 \mu \mathrm{m}$. f, Hematoxylin and eosin staining showing teratoma formation after WT and $S L C 30 A 8^{-/} \mathrm{hESCs}$ were transplanted subcutaneously in SCID-Beige mice for 6 weeks. The images show typical teratomas containing ectoderm, mesoderm and endoderm derived tissues. Scale bar,100 $\mu \mathrm{m}$. Data in this figure presented as mean \pm s.e.m. ${ }^{* * *} p<0.001 . p$-values determined by two-tailed unpaired student's $t$-test. 
a
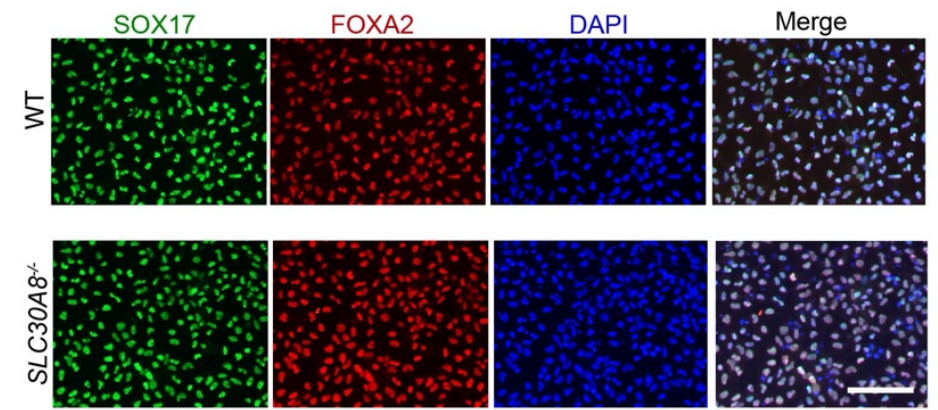

C
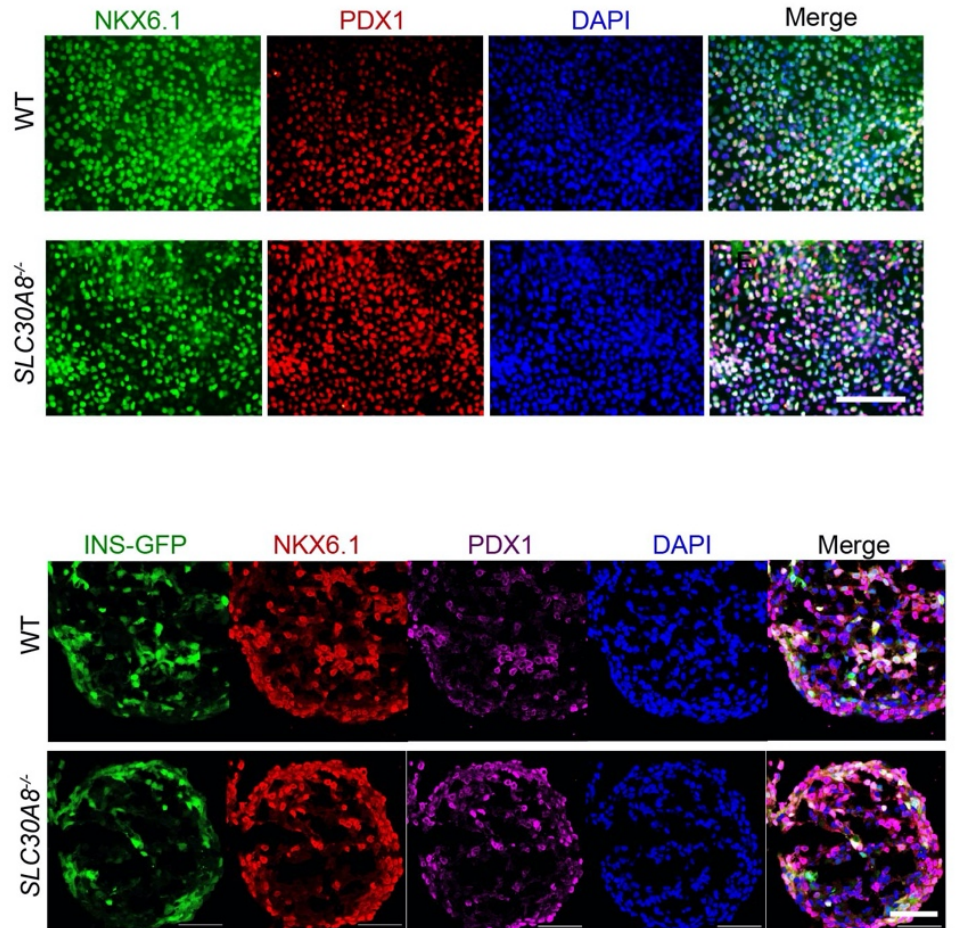

b

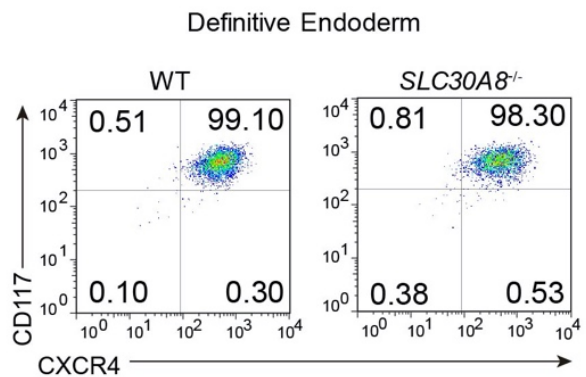

d

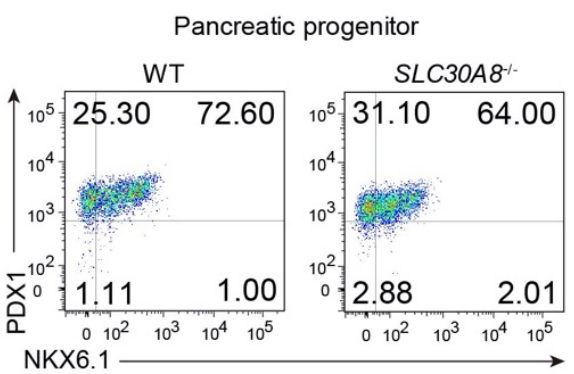

f

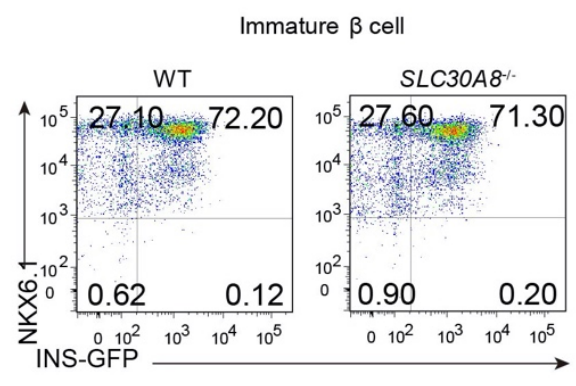

Extended Data Fig. 2 | The differentiation efficiency is not affected by ZnT8 LOF. a, Representative immunostaining of WT and $S L C 30 A 8^{-/-}$hESCs-derived definitive endoderm cells (SOX17, green; FOXA2, red; DAPI, blue). Scale bar, $100 \mu \mathrm{m}$. b, Representative flow cytometry dot plots showing the double-positive cell percentage of CXCR4 versus CD117 at definitive endoderm stage. c, Representative immunostaining of WT and $S L C 30 A 8^{-/-} \mathrm{hESC}$-derived pancreatic progenitor cells (NKX6.1, green; PDX1, red; DAPI, blue). Scale bar, $100 \mu \mathrm{m}$. d, Representative flow cytometry dot plots showing the double-positive cell percentage of PDX1 versus NKX6.1 at pancreatic progenitor 
stage. e, Representative immunostaining of WT and SLC $30 A 8^{-/-}$hESCs-derived immature SC- $\beta$ cells (INS-GFP; NKX6.1, red; PDX1, magenta; and DAPI, blue). Scale bar, $100 \mu \mathrm{m}$. f, Representative flow cytometry dot plots showing the double-positive cell percentage of NKX6.1 versus INS-GFP at immature SC- $\beta$ cell stage. 


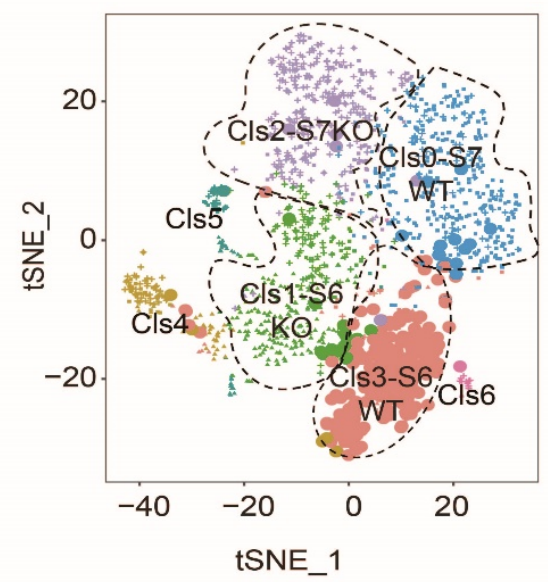

B

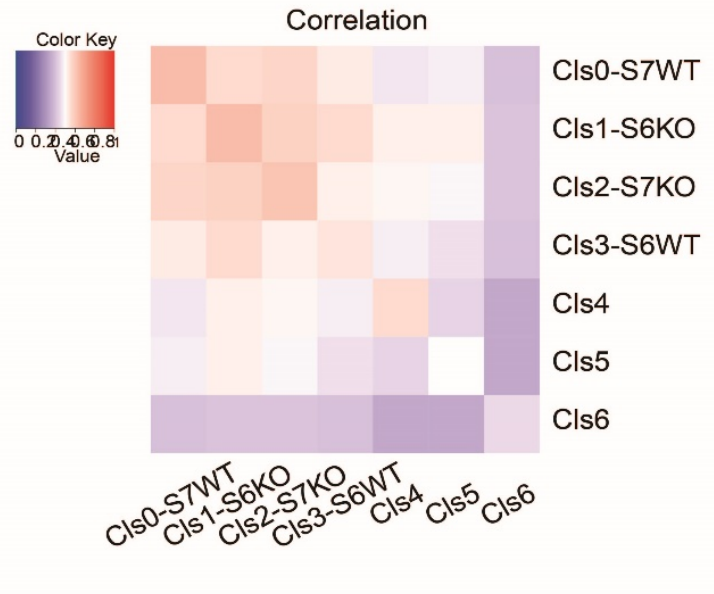

Extended Data Fig. 3 | $t$-SNE projection of the all clusters analyzed by single cell RNA-seq. a, $t$ SNE projection of Cls0-S7 WT, Cls1-S6KO, Cls2-S7KO, Cla3-S6WT, and Cls4-6 cells colored by Seurat identified clusters (cls, cluster). (B) The heatmap of mean Spearman correlation coefficient between clusters. 
Group 1: top DEGs of S6WT vs S6KO

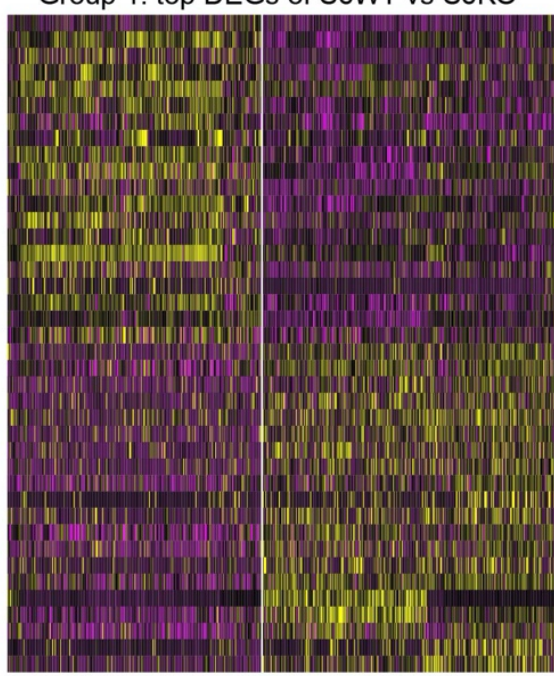

C

Group 3: top DEGs of S6WT vs S7WT
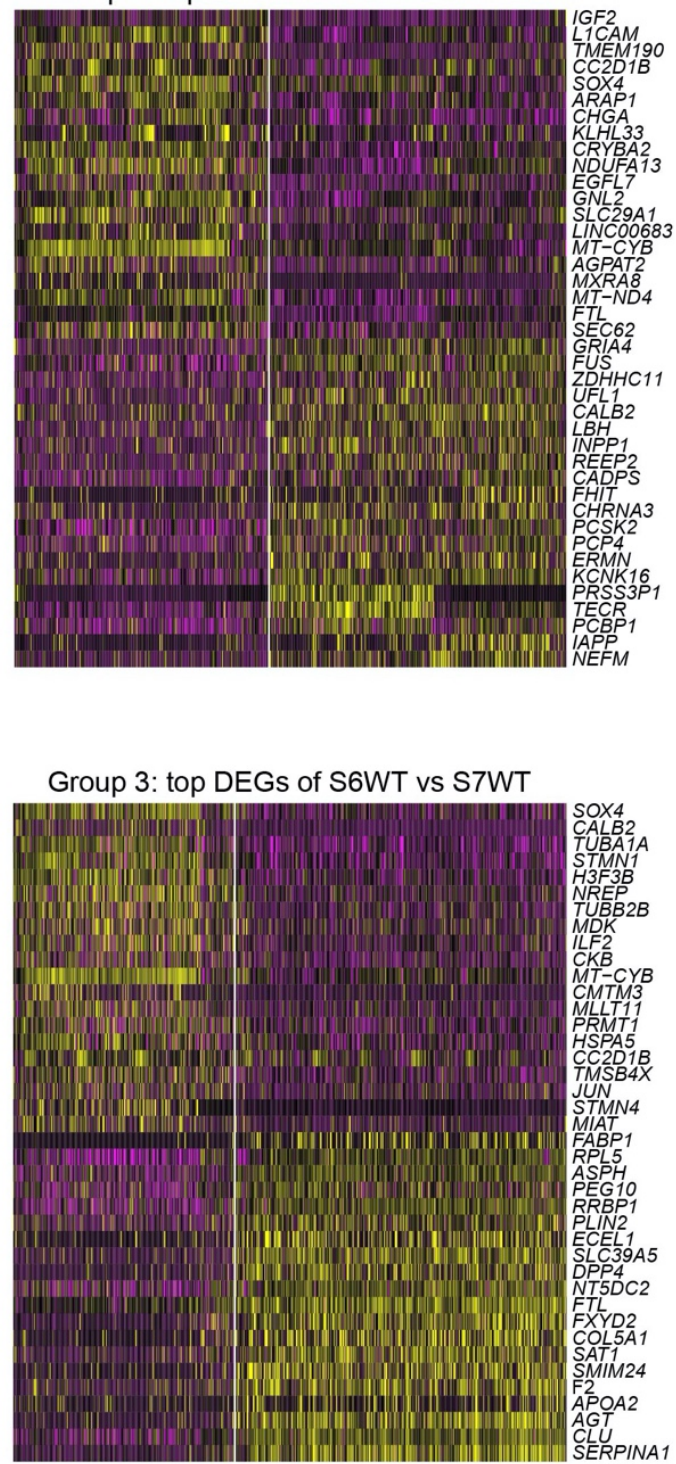

b

Group 2: top DEGs of S7WT vs S7KO

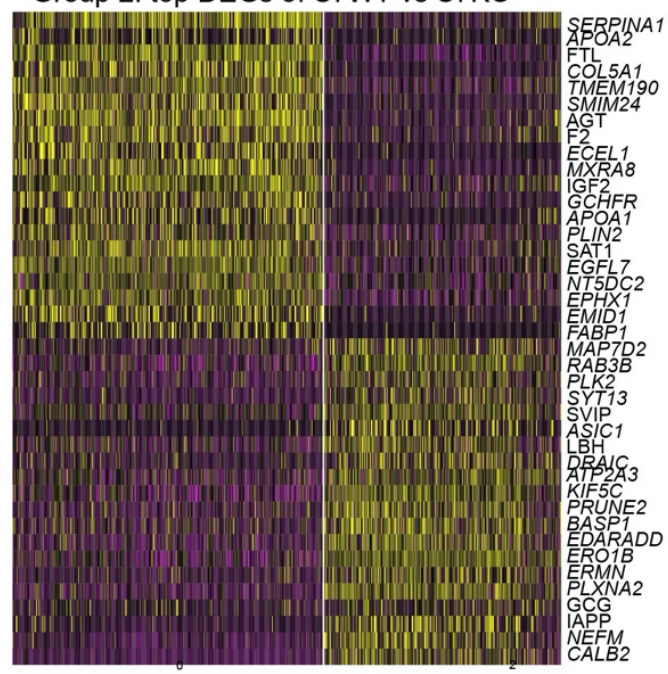

d

Group 4: top DEGs of S6KO vs S7KO

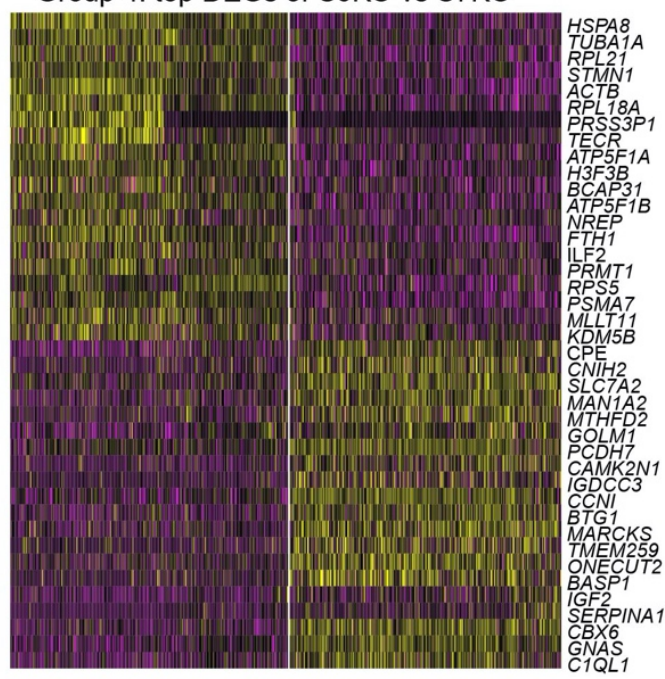

e
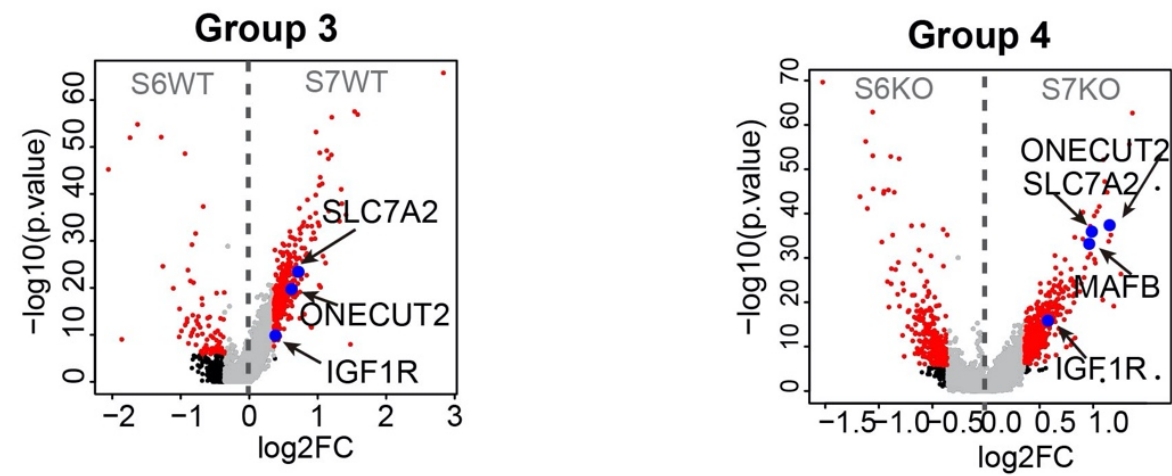
Extended Data Fig. 4 | Top differentially expressed genes in S6WT, S6KO, S7WT and S7KO. a-

d, The heatmap of top 20 differentially expressed genes between S6WT and S6KO (a), S7WT and S7KO (b), S6WT and S7WT (c), S6KO and S7KO (d). e, Volcano plots of the upregulated and downregulated differentially expressed genes (DEGs) according to the comparison (S6WT vs. S7WT; S6KO vs. S7KO). Genes with absolute fold change not more than 1.28 are in grey, genes with absolute fold change larger than 1.28 and adjusted p value not more than 0.05 are in red, and others are in black. 

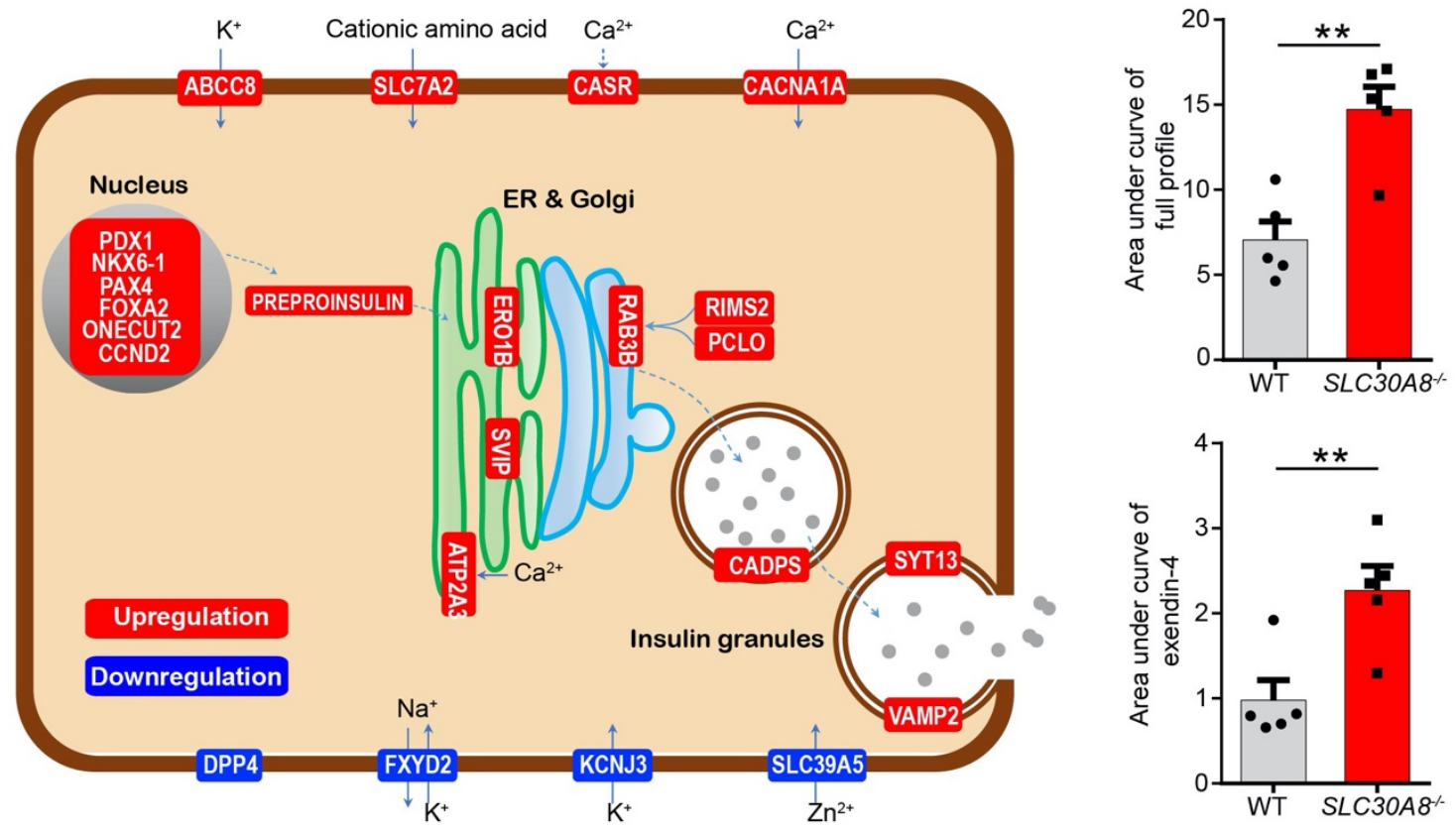

C

d
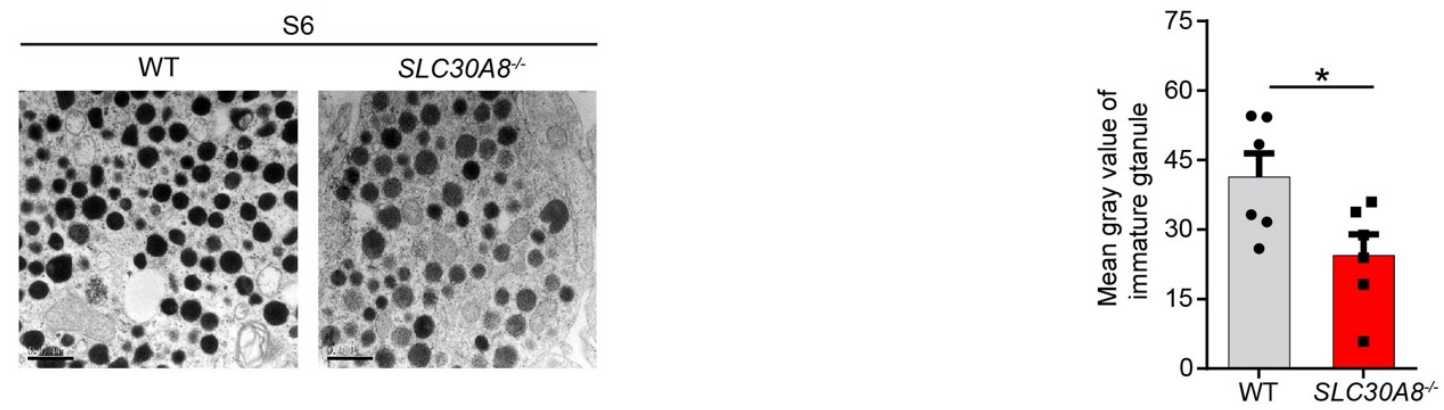

Extended Data Fig. 5 | The genes related to insulin secretion pathway are upregulated in SC- $\beta$

cells with ZnT8 LOF. a, The genes related to insulin secretion pathway that are upregulated and down regulated in S7KO relative to S7WT (fold change $>1.28$ and $\mathrm{p}<0.05$ ). $\mathbf{b}$, AUC of experiment in the Fig. 2G: the AUC of c-peptide secretion in full profile and in response to exendin-4 (Ex-4, added 20 $\mathrm{mM}$ glucose) stimulation. c, Transmission electron micrograph of insulin granules in immature WT and SLC30A8 ${ }^{-/}$SC- $\beta$ cells (S6). Scale bar, $0.5 \mu \mathrm{m}$. d, Mean gray value of immature insulin granules in transmission electron micrograph for WT and $S L C 30 A 8^{-/-}$immature SC- $\beta$ cells $(n=6)$. Data in this 
figure presented as mean \pm s.e.m. ${ }^{* *} p<0.01 . p$-values determined by two-tailed unpaired student's $t$ test. 
a

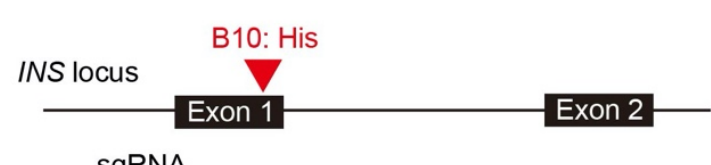

b
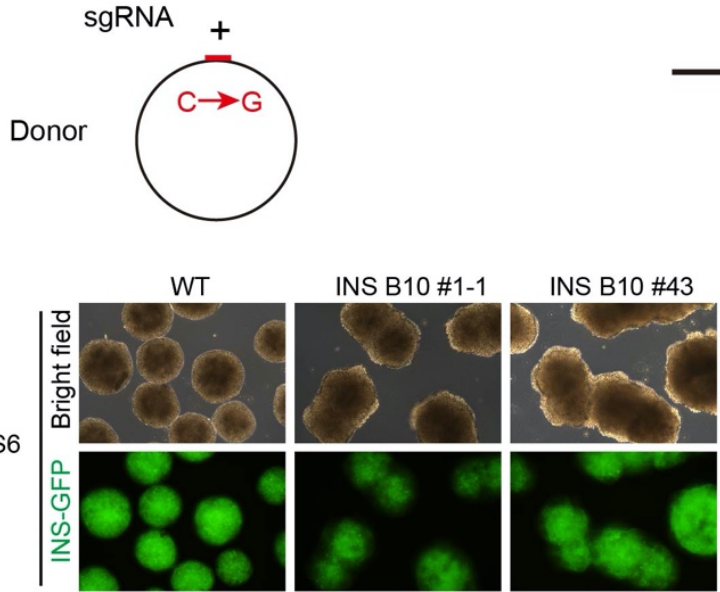

s7
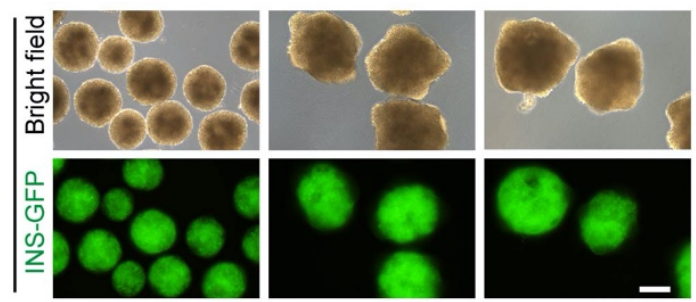

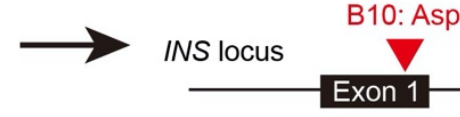

C

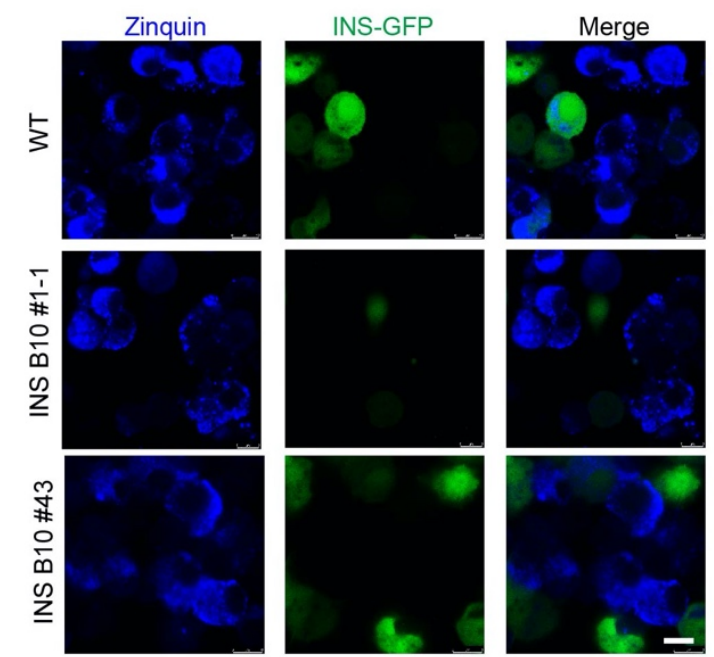

d
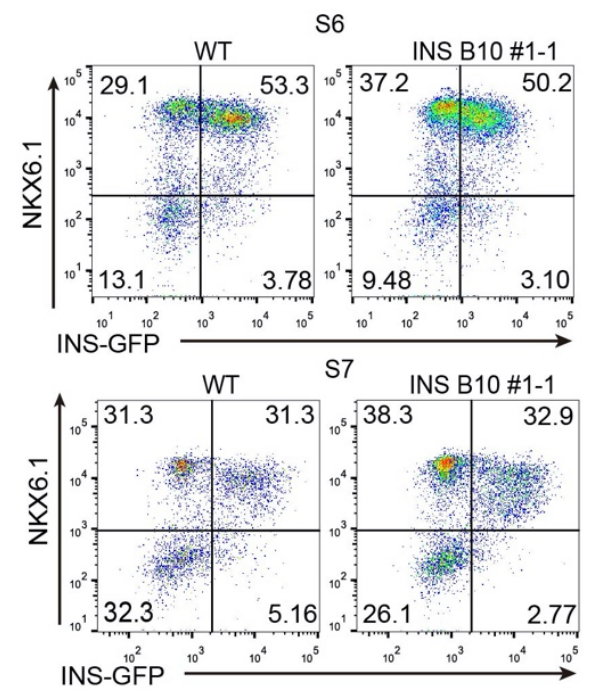

f

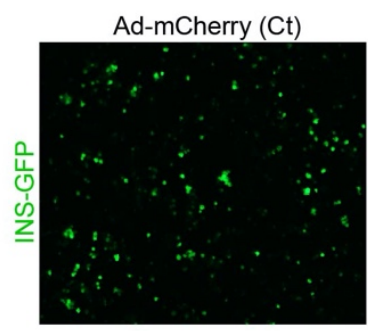

Ad-ZnT8-mCherry

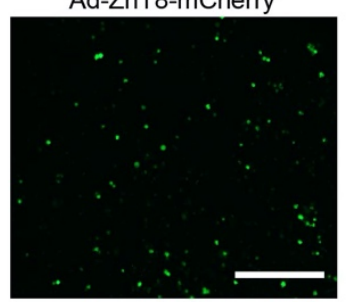

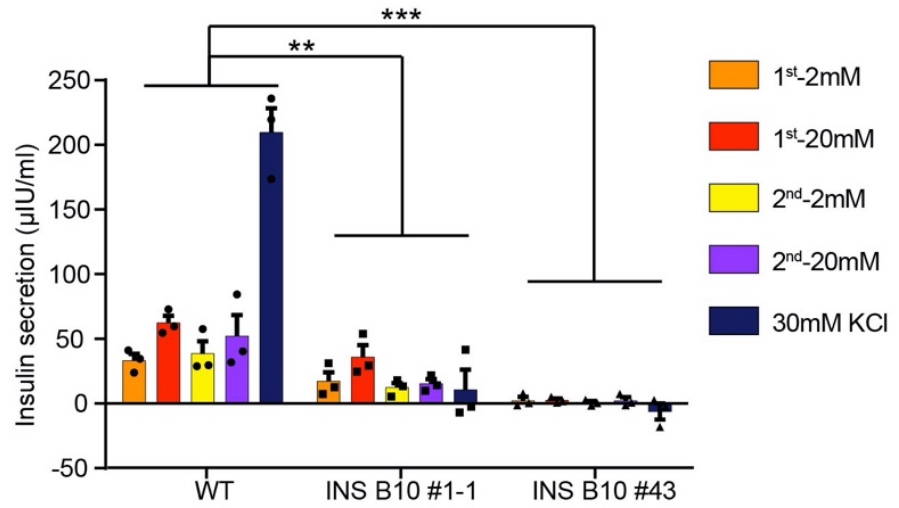

g

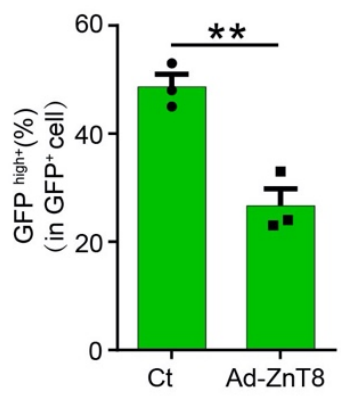


Extended Data Fig. 6 | The relationship between zinc content and insulin level in the SC- $\beta$ cells.

a, A schematic of the generation of insulin HisB10Asp (INS B10) by CRISPR/Cas9 in Mel1 INS GFP/W hES cell line. b, Representative images showing the bright field and the expression of INS-GFP a during S6 and S7 in WT and INS B10 \#1-1, INS B10 \#43 cells. Scale bar: $200 \mu \mathrm{m}$. c, Representative images showing the expression of INS-GFP and Zinquin at S7 in WT and INS B10 \#1-1, \#43 cells. Scale bar: $10 \mu \mathrm{m}$ d, Representative flow cytometry dot plots showing NKX6.1-mCherry and INS-GFP expression level during S6 to S7 of WT and INS B10 \#1-1 SC- $\beta$ cells. e, Glucose/KCl-stimulated insulin secretion of WT, INS B10 \#1-1 and INS B10 \#43 mature SC- $\beta$ cells. Low-glucose, 2 mM; high-glucose, $20 \mathrm{mM}$; KCl, $30 \mathrm{mM}$. f, Images of INS-GFP expression in the $S L C 30 A 8^{-/}$single $\beta$ cells, which were digested from $\beta$ cell clusters after Ad-ZnT8-mCherry or Ad-mCherry $(\mathrm{Ct})$ infection. Scale bar, $200 \mu \mathrm{m}$. g, GFPhigh+ cells as a percentage of total $\mathrm{mCherry}^{+}$cells in $S L C 30 A 8^{-/-}$mature SC- $\beta$ cells after Ad-ZnT8-mCherry or Ad-mCherry $(\mathrm{Ct})$ infection. $n=3$. Data in this figure presented as mean \pm s.e.m. ${ }^{*} p<0.05, * * p<0.01 ; * * * p<0.001$. $p$-values determined by two-tailed unpaired student's $t$-test (g) and two-way repeated measures ANOVA with Tukey test for multiple comparisons (e). 


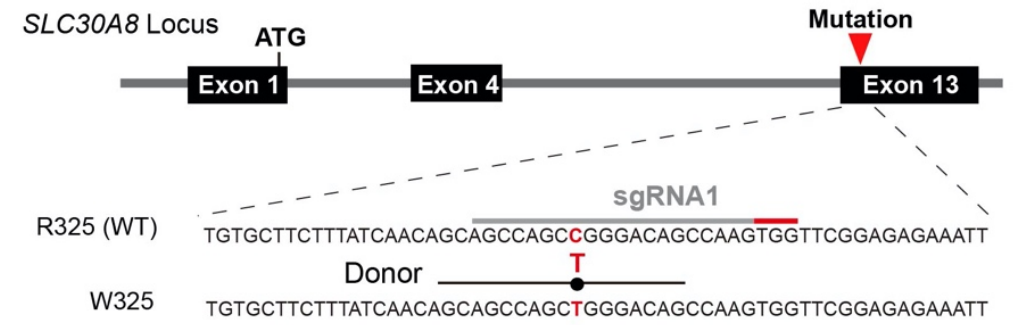

c

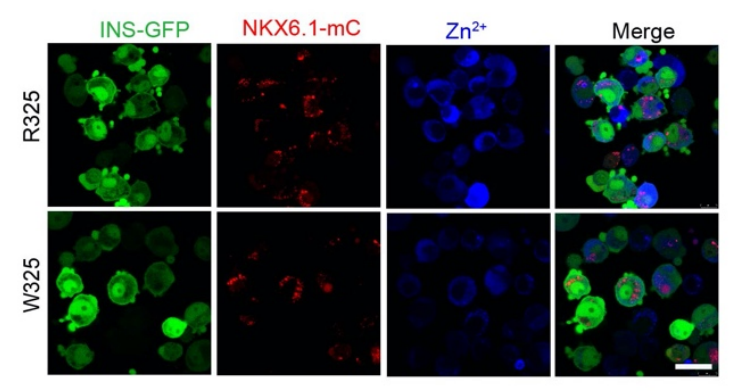

f

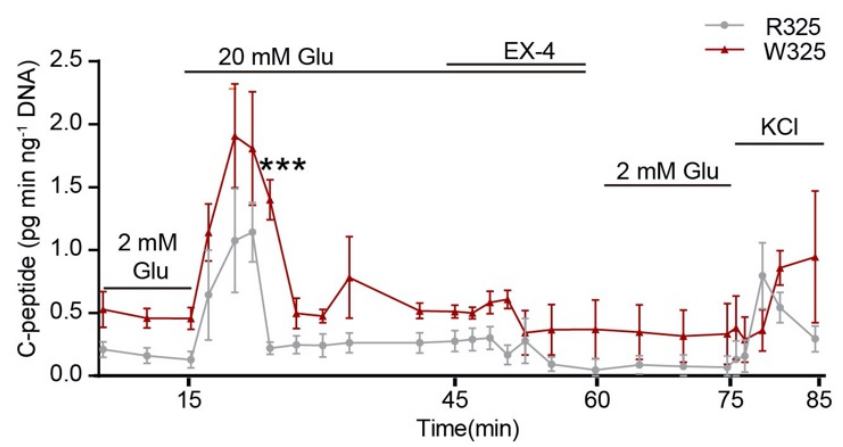

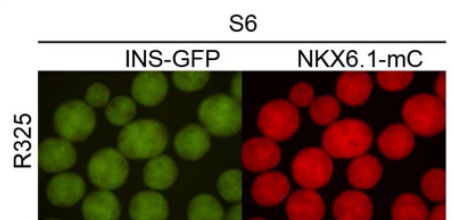

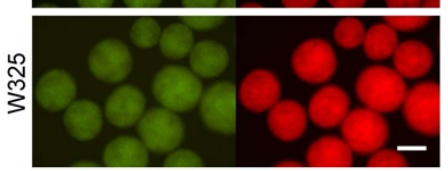

e

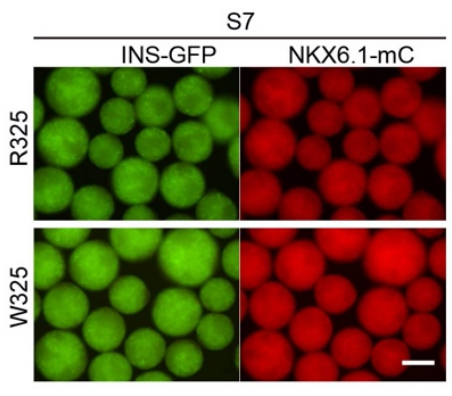

d
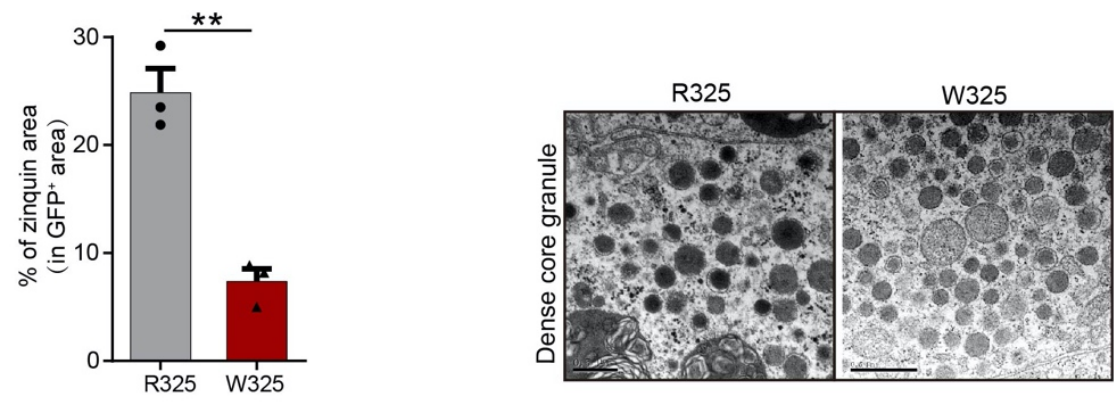
Extended Data Fig. 7 | ZnT8 R325 possesses superior zinc transportation activity to W325. a,

Schematic of the generation of ZnT8 W325 by CRISPR/Cas9 in Mel1 NKX6.1 mCherry/mCherry $_{-I N S}^{\text {GFP/W }}$ hESCs. b, Representative images showing the expression of INS-GFP and NKX6.1-mCherry during S6 and S7 in R325 and W325 cells. Scale bar: $200 \mu \mathrm{m}$. c, Representative Zinquin staining (blue) in mature SC- $\beta$ cells (S7) of R325 and W325 adherent single $\beta$ cells, which were digested from SC- $\beta$ cells clusters. scale bar, $20 \mu \mathrm{m}$. d, Quantification of Zinquin intensity in INS-GFP ${ }^{+}$cells in R325 and W325 mature $\beta$ cells, as measured by ratio of Zinquin $^{+}$area to $\mathrm{GFP}^{+}$area. $n=3$. e, Transmission electron micrograph of insulin granules in mature SC- $\beta$ cell derived from R325 and W325 hESCs. Images are representative of 5 independent experiments. f, Dynamic perifusion assay of C-peptide secretion stimulated with $2 \mathrm{mM}$ glucose, $20 \mathrm{mM}$ glucose, $10 \mathrm{nM}$ exendin-4 (added $20 \mathrm{mM}$ glucose) and $30 \mathrm{mM} \mathrm{KCl}$ in both $\mathrm{R} 325$ and W325 SC- $\beta$ cells. $n=3$ independent experiments. Area under the curve was determined for each cell lines. Data in this figure presented as mean \pm s.e.m. ${ }^{*} p<0.05,{ }^{*} p$ $<0.01$. In perifusion assay, $p$-values are determined by two-way repeated measures ANOVA with Bonferroni test for multiple comparisons between R325 and W325 SC- $\beta$ cells. In other assays of this figure, two-tailed unpaired student's $t$-test was used to calculate $p$-values. 
a

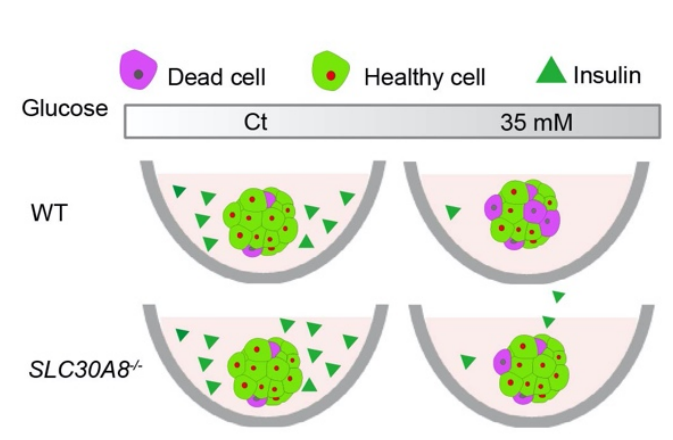

b

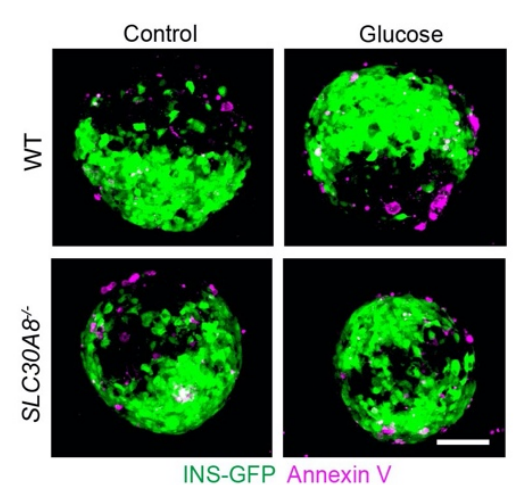

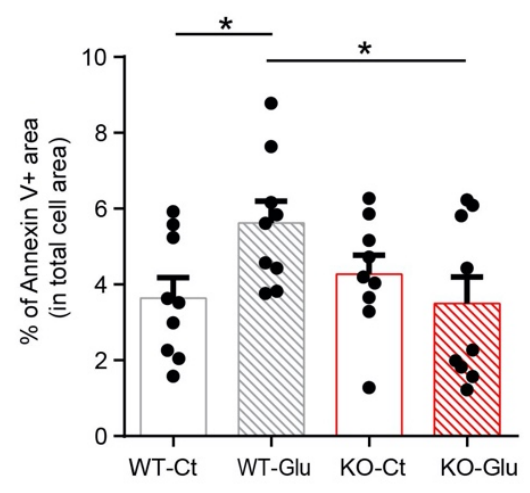

Extended Data Fig. 8 | SC- $\beta$ cells with ZnT8 LOF are resistant to glucotoxicity. a, A schematic of glucose-induced mature SC- $\beta$ cell apoptosis. The WT and SLC $30 A 8^{-/-}$mature SC- $\beta$ cell clusters were treated with glucose $(35 \mathrm{mM})$ or vehicles (control) for $48 \mathrm{~h}$. b and c, Annexin V (magenta) staining analysis (b) and quantification (c) of WT and SLC30A8-/- mature SC- $\beta$ cell clusters treated with $35 \mathrm{mM}$ glucose or vehicles (control) for $48 \mathrm{~h}$. Scale bar, $100 \mu \mathrm{m} . n=9$ of each group. Data are presented as mean \pm s.e.m. ${ }^{*} p<0.05$. $p$-values calculated by one-way ANOVA with Bonferroni test for multiple comparisons between selected groups. 
Supplementary Table 1. Additional cell lines information.

\begin{tabular}{|c|c|c|c|}
\hline \multicolumn{4}{|c|}{ Mel 1 INS ${ }^{G F P / W}$} \\
\hline $\begin{array}{c}\text { Mel } 1 \\
\text { NKX6. } 1^{\text {mCherry/mCherry }} \\
\text { INS }\end{array}$ & MRP & - & NKX6.1::mCherry \\
\hline \multicolumn{4}{|c|}{ Mel 1 NKX6.1 ${ }^{\text {mCherry/mCherry-INS }}{ }^{\text {GFP/W }}$} \\
\hline \multirow{4}{*}{ SLC30A8 $8^{-/-}$} & MRP-2 & $-/-$ & Y169fs/Y169fs \\
\hline & MRP-5 & $-/-$ & Y169fs/Y169fs \\
\hline & MRP-11 & $-1-$ & Y169fs/Y169fs \\
\hline & MRP-C11 & $-/-$ & T176RfsX \\
\hline \multicolumn{4}{|c|}{ Mel 1 INS ${ }^{\text {GFP/W }}$} \\
\hline \multirow{3}{*}{$S L C 30 A 8^{-1-}$} & $\begin{array}{c}\text { Mel1-G-4- } \\
1 \\
\end{array}$ & $-/-$ & Y169fs/Y169fs \\
\hline & $\begin{array}{c}\text { Mel1-G-4- } \\
4\end{array}$ & $-/-$ & Y169fs/Y169fs \\
\hline & $\begin{array}{c}\text { Mel1-G-4- } \\
5 \\
\end{array}$ & $-/-$ & Y169fs/Y169fs \\
\hline \multicolumn{4}{|c|}{ Mel 1 NKX6.1 ${ }^{\text {mCherry/mCherry-INS }}{ }^{\text {GFP/W }}$} \\
\hline \multirow{2}{*}{ ZnT8 W325 } & MRP-36-1 & $973 \mathrm{~A}>\mathrm{T}$ & Arg325Trp \\
\hline & MRP-36-3 & $973 A>T$ & Arg325Trp \\
\hline \multicolumn{4}{|c|}{ Mel 1 INS } \\
\hline \multirow{2}{*}{ Insulin HisB10Asp } & MRP-1-1 & $100 \mathrm{C}>\mathrm{G}$ & B10Asp \\
\hline & MRP-43 & $100 C>G$ & B10Asp \\
\hline
\end{tabular}


Supplementary Table 2. The sgRNA and sequencing primers of mutant cell lines

\begin{tabular}{|c|c|c|c|}
\hline & sgRNA (5'-3') & primer-forward & primer-reverse \\
\hline \multirow[t]{2}{*}{ SLC30A8 ${ }^{-/-}$} & GACTGGCGTGCTAGTGTACC & \multirow[t]{2}{*}{ CCTTTTTGGGGGAAGTGGCAAAGT } & \multirow[t]{2}{*}{ CTAACCCTGCCTCTAGCACACCAGA } \\
\hline & CGATGATCATCACAGTCGCC & & \\
\hline $\begin{array}{l}\text { Insulin } \\
\text { HisB10Asp }\end{array}$ & GGTGTGAGCCGCACAGGTGT & TGCGCCTCCTGCCCCTGCT & CCCAGCATGGGCAGAAGGGGGC \\
\hline ZnT8 W325 & AGCCAGCCGGGACAGCCAAG & CCTGCCTTGTCTGTGTGAATGTAGC & TGTGCATTGCACCATGACATGAAT \\
\hline
\end{tabular}


Supplementary Table 3. Differentiation protocol

\begin{tabular}{|c|c|c|c|c|}
\hline Day & Stage & basal medium & Factor & Final Concentration \\
\hline \multirow{3}{*}{ Day 0} & \multirow{10}{*}{$\begin{array}{l}\text { Stage } 1 \text { (Definitive } \\
\text { Endoderm) }\end{array}$} & \multirow{10}{*}{ RPMI1640 } & Activin A & $50 \mathrm{ng} / \mathrm{ml}$ \\
\hline & & & Chir99021 & $2 \mu \mathrm{M}$ \\
\hline & & & MTG & $4.5 \times 10^{-4} \mathrm{M}$ \\
\hline \multirow{7}{*}{ Day 1-2 } & & & BMP4 & $0.25 \mathrm{ng} / \mathrm{ml}$ \\
\hline & & & bFGF & $5 \mathrm{ng} / \mathrm{ml}$ \\
\hline & & & Activin A & $100 \mathrm{ng} / \mathrm{ml}$ \\
\hline & & & VEGF & $10 \mathrm{ng} / \mathrm{ml}$ \\
\hline & & & MTG & $4.5 \times 10^{-4} \mathrm{M}$ \\
\hline & & & SAA & $50 \mu \mathrm{g} / \mathrm{ml}$ \\
\hline & & & L-glutamine & $1 X$ \\
\hline \multirow{4}{*}{ Day 3-5 } & \multirow{4}{*}{$\begin{array}{l}\text { Stage } 2 \text { (Primitive } \\
\text { Gut Tube) }\end{array}$} & \multirow{4}{*}{ RPMI1640 } & FGF10 & $50 \mathrm{ng} / \mathrm{ml}$ \\
\hline & & & Wnt3a & $3 \mathrm{ng} / \mathrm{ml}$ \\
\hline & & & MTG & $4.5 \times 10^{-4} \mathrm{M}$ \\
\hline & & & SAA & $50 \mu \mathrm{g} / \mathrm{ml}$ \\
\hline \multirow{6}{*}{ Day 6-7 } & \multirow{6}{*}{$\begin{array}{c}\text { Stage } 3 \text { (Posterior } \\
\text { Foregut) }\end{array}$} & \multirow{6}{*}{ DMEM } & $\mathrm{B} 27$ & $1 \mathrm{X}$ \\
\hline & & & SAA & $50 \mu \mathrm{g} / \mathrm{ml}$ \\
\hline & & & KAAD-cyclopamine & $0.25 \mu \mathrm{M}$ \\
\hline & & & RA & $2 \mu \mathrm{M}$ \\
\hline & & & NOGGIN & $50 \mathrm{ng} / \mathrm{ml}$ \\
\hline & & & FGF10 & $50 \mathrm{ng} / \mathrm{ml}$ \\
\hline \multirow{5}{*}{ Day 8-10 } & \multirow{5}{*}{$\begin{array}{c}\text { Stage } 4 \text { (Pancreatic } \\
\text { Progenitors) }\end{array}$} & \multirow{5}{*}{ DMEM } & B27 & $1 X$ \\
\hline & & & SAA & $50 \mu \mathrm{g} / \mathrm{ml}$ \\
\hline & & & NOGGIN & $50 \mathrm{ng} / \mathrm{ml}$ \\
\hline & & & hEGF & $50 \mathrm{ng} / \mathrm{ml}$ \\
\hline & & & Nicotinamide & $10 \mathrm{mM}$ \\
\hline \multirow{6}{*}{ Day $11-13$} & \multirow{6}{*}{$\begin{array}{l}\text { Stage } 5 \text { (Endocrine } \\
\text { Progenitors) }\end{array}$} & \multirow{6}{*}{ MCDB131 } & SANT1 & $0.25 \mu \mathrm{M}$ \\
\hline & & & Alk5i-II & $10 \mu \mathrm{M}$ \\
\hline & & & LDN193189 & $100 \mathrm{nM}$ \\
\hline & & & $\mathrm{RA}$ & $0.05 \mu \mathrm{M}$ \\
\hline & & & hEGF & $50 \mathrm{ng} / \mathrm{ml}$ \\
\hline & & & T3 & $1 \mu \mathrm{M}$ \\
\hline \multirow{5}{*}{ Day $14-19$} & \multirow{5}{*}{$\begin{array}{c}\text { stage } 6 \text { (Immature } \beta \\
\text { Cell) }\end{array}$} & \multirow{5}{*}{ MCDB131 } & Alk5i-II & $10 \mu \mathrm{M}$ \\
\hline & & & LDN193189 & $100 \mathrm{nM}$ \\
\hline & & & DBZ(GSI-XX) & $100 \mathrm{nM}$ \\
\hline & & & hEGF & $50 \mathrm{ng} / \mathrm{ml}$ \\
\hline & & & T3 & $1 \mu \mathrm{M}$ \\
\hline \multirow{5}{*}{ Day 20-33 } & \multirow{5}{*}{$\begin{array}{c}\text { Stage } 7 \text { (Mature } \beta \\
\text { Cell) }\end{array}$} & \multirow{5}{*}{ MCDB131 } & T3 & $1 \mu \mathrm{M}$ \\
\hline & & & Alk5i-II & $10 \mu \mathrm{M}$ \\
\hline & & & Trolox & $10 \mu \mathrm{M}$ \\
\hline & & & R428 & $2 \mu \mathrm{M}$ \\
\hline & & & N-Cys & $1 \mathrm{mM}$ \\
\hline
\end{tabular}


Supplementary Table 4. Differentiation factors.

\begin{tabular}{l|l}
\hline Compound & Company \\
\hline Activin A & R\&D \\
\hline BMP4 & R\&D \\
\hline bFGF & R\&D \\
\hline VEGF & R\&D \\
\hline FGF10 & R\&D \\
\hline Wnt3a & R\&D \\
\hline NOGGIN & R\&D \\
\hline hEGF & R\&D \\
\hline Chir99021 & Selleck \\
\hline Retinoic acid & sigma \\
\hline Nicotinamide & sigma \\
\hline D-glucose & sigma \\
\hline Heparine & sigma \\
\hline ZnSO4 & sigma \\
\hline SANT1 & sigma \\
\hline Alk5i-II & ENZO \\
\hline LDN193189 & sigma \\
\hline T3 & sigma \\
\hline GSI-XX & Merck MP \\
\hline Trolox & millipore \\
\hline R428 & Selleck \\
\hline N-Cys & sigma \\
\hline
\end{tabular}


Supplementary Table 5. Primers used for real-time PCR

\begin{tabular}{l|l|l}
\hline Gene Name & Forward Primer Sequence & Reverse Primer Sequence \\
\hline SLC30A8 & TTGCACCAGAGATGCCTTG & TCCAAGGGCATGCACAAA \\
\hline INS & CAATGCCACGCTTCTGC & TTCTACACACCCAAGACCCG \\
\hline
\end{tabular}


Supplementary Table 6. Antibody list.

\begin{tabular}{c|c}
\hline $\begin{array}{c}\text { Antibody } \\
\text { Target }\end{array}$ & Company \\
\hline OCT4 & Abcam \\
\hline NANOG & Cell Signaling Technology \\
\hline SOX17 & R\&D \\
\hline FOXA2 & Abcam \\
\hline PDX1 & R\&D Systems \\
\hline NKX6.1 & Developmental Studies Hybridoma Bank \\
\hline Insulin & DAKO \\
\hline ZnT8 & MyBioSource \\
\hline Caspase-3 & Cell Signaling Technology
\end{tabular}


a

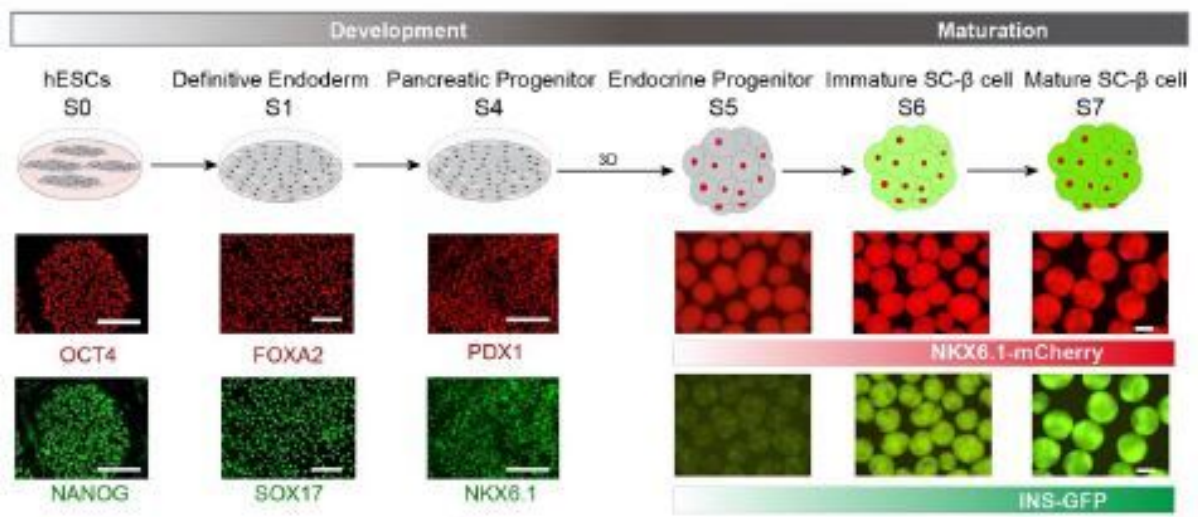

b

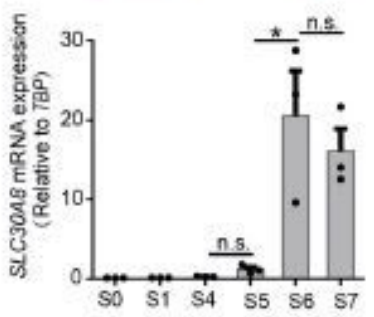

c
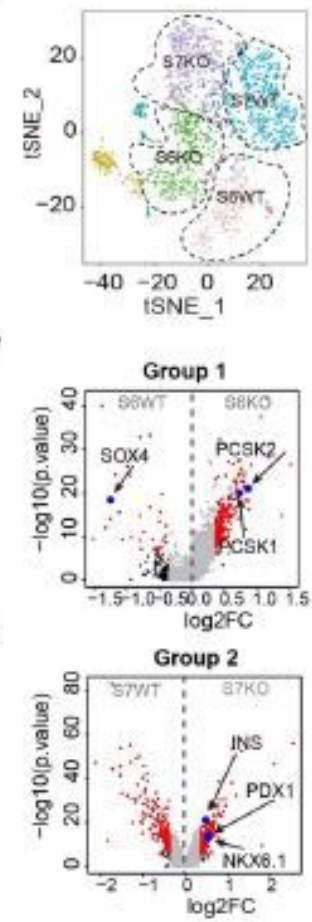

g

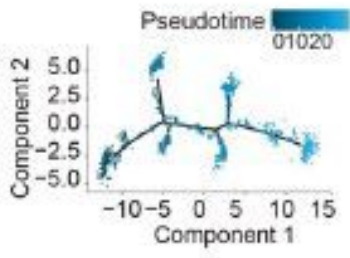

CSสWTOS6KOoSTWTOS7KO

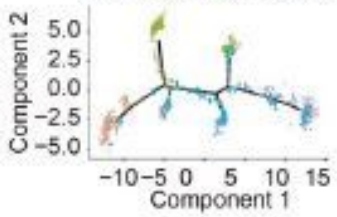

h

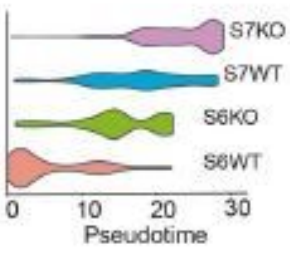

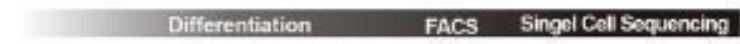

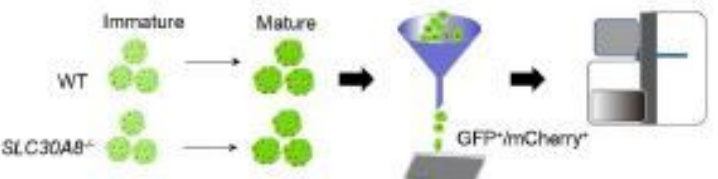

i

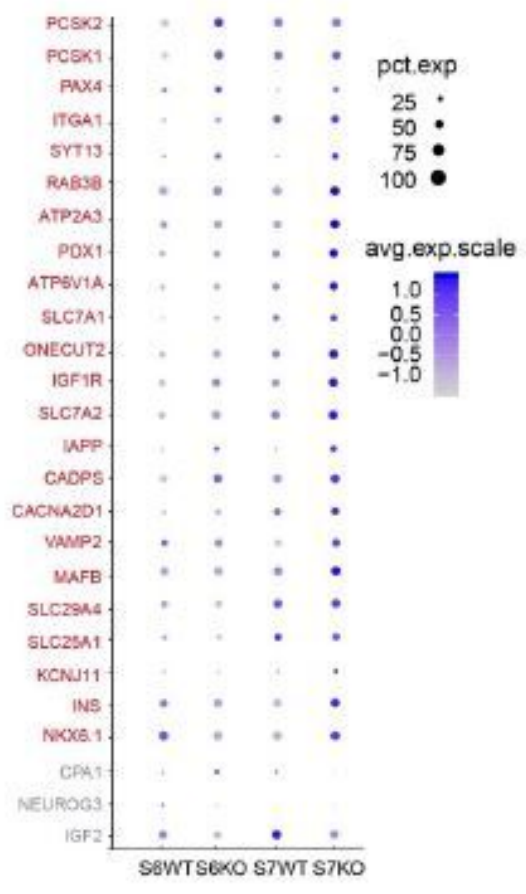

Figure 1

ZnT8 LOF accelerates SC- $\beta$ cell maturation by upregulating maturity-related markers. a, A schematic of differentiation of Mel1 NKX6.1mCherry/mCherry-INSGFP/W hESCs into $\beta$ cell from S0 to S7 (S, stage; major stages are shown). During this process, the cells of SO-S4 are adherent culture, and the cells at the 
end of $\mathrm{S} 4$ are digested and aggregated into mini clusters and then cultured in 3D environment by using low-attachment plate. The differentiation process recapitulates two status: S0- S5 represent the development process and S6-S7 represent the maturation process of SC- $\beta$ cell. This schematic includes representative immunofluorescence images which represent typical markers of major stages (S0, OCT4+/NANOG+; S1, FOXA2+/SOX17+; S4, PDX1+/NKX6.1+; S5-S7, NKX6.1+/INS+). Scale bars, $100 \mu \mathrm{m}$ (S0-S5); 200 $\mu \mathrm{m}$ (S6-S7). The red bar and green bar represent temporal expression of NKX6.1 and INS respectively. b, qRT-PCR analysis of SLCOA8 mRNA expression level during the SC- $\beta$ cell differentiation process. $\mathrm{n}=3$ independent samples for each stage. Data are presented as mean \pm s.e.m. $\mathrm{p}$-values are calculated by one-way ANOVA with Bonferroni test for multiple comparisons. ${ }^{*} \mathrm{p}<0.05$; ns, not significant. c, A schematic representation of single-cell analysis process: hESCs (WT and SLC30A8-/-) differentiation into the immature (S6) and mature (S7) SC- $\beta$ cells; cell isolation by FACS (INS-GFP+/NKX6.1-mCherry+); single-cell sequencing. d, t-SNE projection of S6WT (pink), S6KO (green), S7WT (blue) and S7KO (purple) cells colored by Seurat identified clusters. e and $\mathrm{f}$, Volcano plots of the upregulated and downregulated differentially expressed genes (DEGs) according to the comparisons (Group 1, S6WT vs. S6KO; Group 2, S7WT vs. S7KO). Genes with absolute fold change not more than 1.28 are in grey, genes with absolute fold change larger than 1.28 and adjusted $p$ value not more than 0.05 are in red, and others are in black. $\mathrm{g}$, In silico pseudotime ordering of S6WT, S6KO, S7 WT and S7KO, colored by pseudotime value and clusters. h, The distribution of pseudotime in S6WT, S6KO, S7WT and S7KO. i, Dot plot showing gene signature shifts among different cell lines and stages (S6 WT, S6KO, S7 WT and S7KO); Red, the genes upregulated in the S7KO relative to S7WT; Grey, downregulated genes in S7KO relative to S7WT. 
a

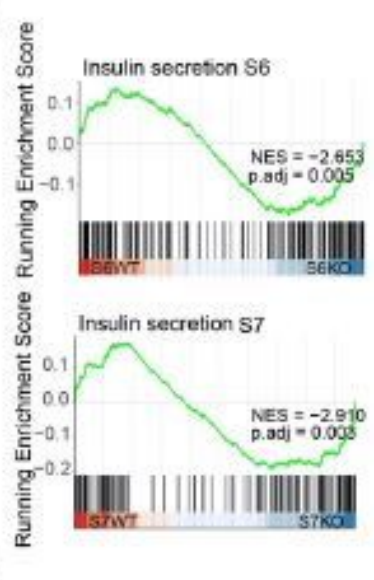

d

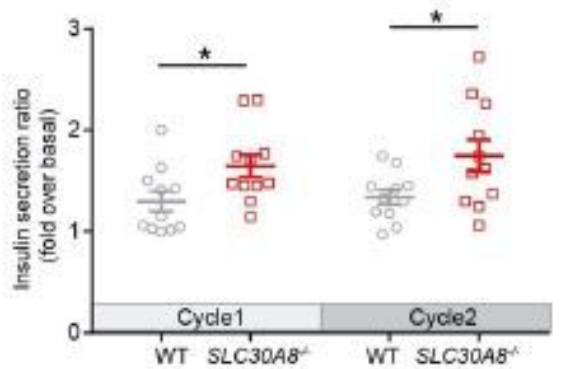

g

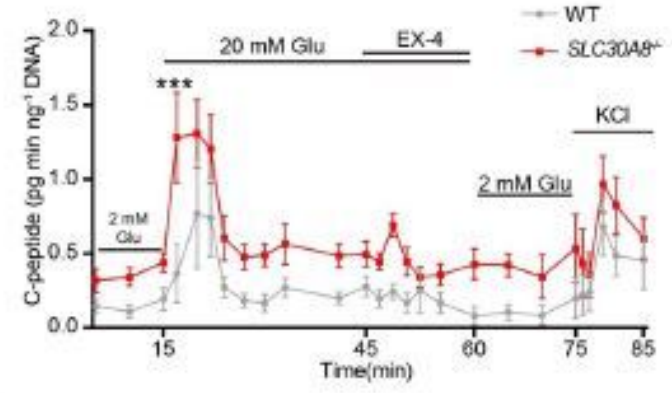

i

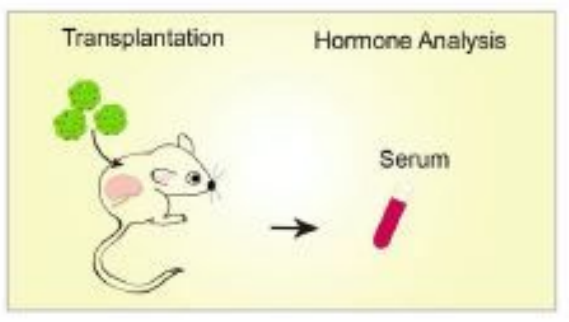

b

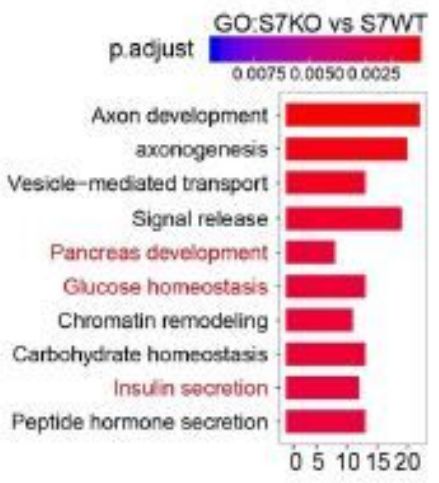

c

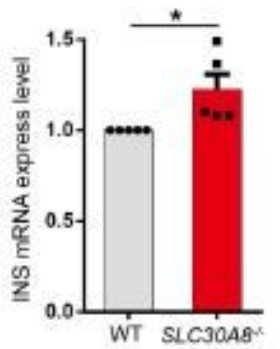

f

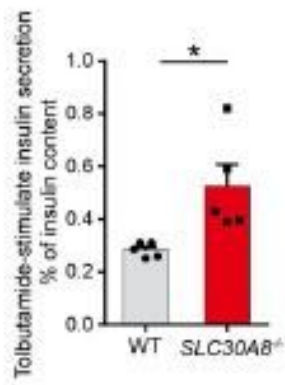

h
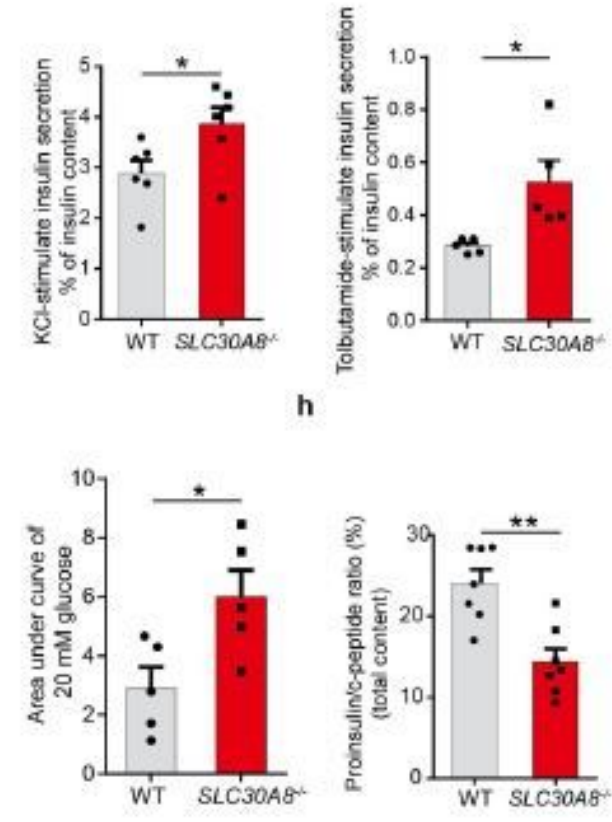

j

k
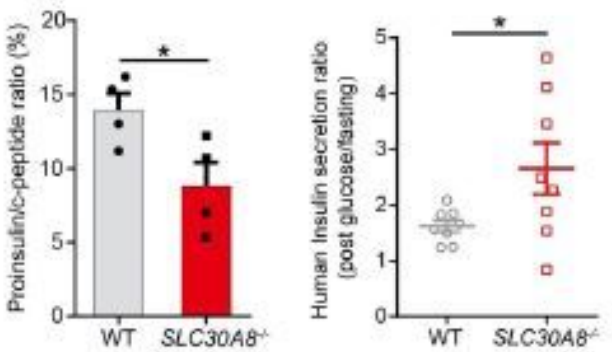

\section{Figure 2}

SC- $\beta$ cells with ZnT8 LOF gain improved sensitivity to glucose stimulation and proinsulin conversion both in vivo and in vitro. a, Top 10 gene ontology (GO) terms were significantly upregulated in S7KO compared to S7 WT. The terms colored red highlight the biological processes related to SC- $\beta$ cell function. b, GSEA traces demonstrating enrichment of the insulin secretion genes in the cells of S6WT compared to those in S6KO and in the cells of S7WT compared to those in S7KO. c, INS mRNA expression in SLC30A8-/- SC- $\beta$ 
cells (S7) relative to WT SC- $\beta$ cells. $n=5$. d, Glucose stimulate insulin secretion of WT and SLC30A8-/mature SC- $\beta$ cells. The amount of secreted insulin stimulated with $20 \mathrm{mM}$ glucose was normalized to that in the basal glucose condition of $2 \mathrm{mM}$ concentration. $n=11$. e and $f$, Effect of ZnT8 LOF on insulin secretion (as a percentage of total insulin content) in response to $\mathrm{KCl}(30 \mathrm{mM}, \mathrm{n}=6)$ (e) and tolbutamide $(200 \mu \mathrm{M}, \mathrm{n}=5)$ (f) in mature SC- $\beta$ cells. g, Left panel, dynamic perifusion assay of C-peptide secretion from WT and SLC30A8-/- mature SC- $\beta$ cells, in response to $2 \mathrm{mM}$ glucose, $20 \mathrm{mM}$ glucose, $10 \mathrm{nM}$ exendin-4 (Ex-4, added $20 \mathrm{mM}$ glucose) and $30 \mathrm{mM} \mathrm{KCl}$, stimulation respectively. $\mathrm{n}=5$ independent samples. Grey line, WT SC- $\beta$ cells; red line, SLC30A8-/- mature SC- $\beta$ cells; Right panel, AUC of C-peptide dynamic secretion in response to $20 \mathrm{mM}$ glucose stimulation in WT and SLC30A8-/- mature SC- $\beta$ cells. $h$, Total proinsulin/C-peptide ratio in mature SC- $\beta$ cells. $n=7$. i, A schematic of WT and SLC30A8-/- mature SC $-\beta$ cells function test in vivo. The same number (2 million) of WT and SLC30A8-/- mature SC- $\beta$ cells were transplanted into the kidney capsule of SCID-Beige mice respectively. The insulin or C-peptide or proinsulin in the serum were tested by ELISA during 2-10 weeks after transplantation. j, Human proinsulin/C-peptide ratio in mouse serum with transplanted mature SC- $\beta$ cells (WT, $n=4$; SLC30A8- /-, $n$ = 4). $\mathrm{k}$, Mice transplanted with WT or SLC30A8-/- mature SC- $\beta$ cells were measured as the ratio of human insulin secretion in the serum upon intraperitoneal glucose challenge to that after $16 \mathrm{~h}$ fasting $(W T, n=8$; SLC30A8-/-, $n=8)$. Data are presented as mean \pm s.e.m. ${ }^{\star} p<0.05 ; * x p<0.01 ; * \star * p<0.001$. In perifusion assay, $\mathrm{p}$-values are calculated by two-way repeated measures ANOVA with Bonferroni test for multiple comparisons between WT and SLC30A8-/- SC- $\beta$ cells. In other assays of this figure, $p$-values are determined by two-tailed unpaired student's t-test. 


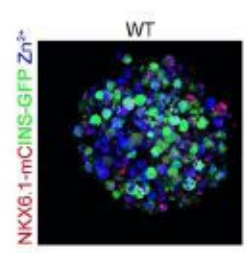

d

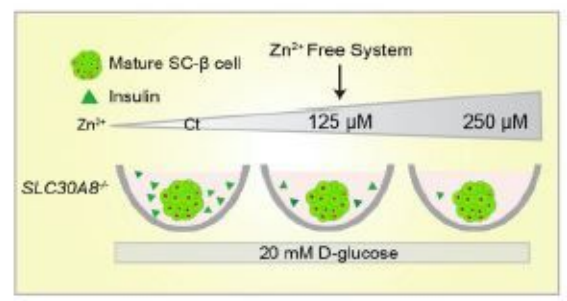

g

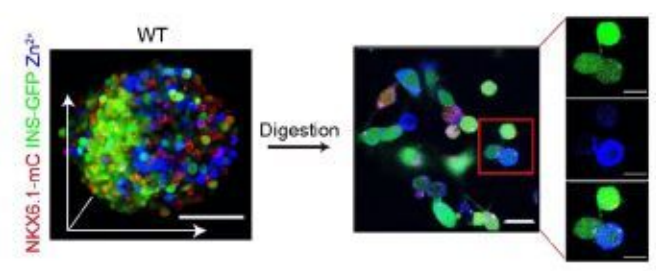

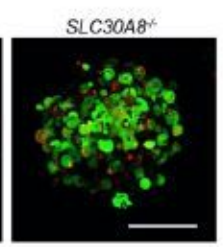
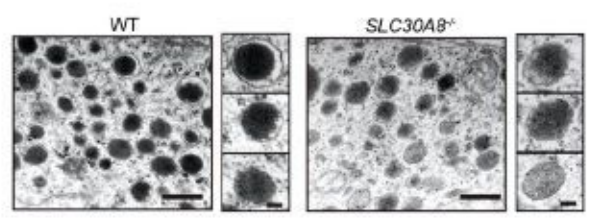

e

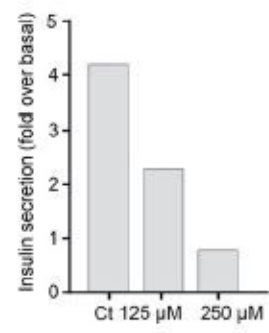

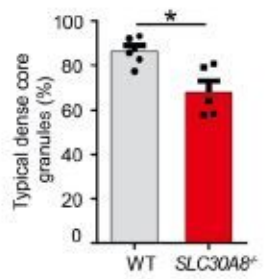

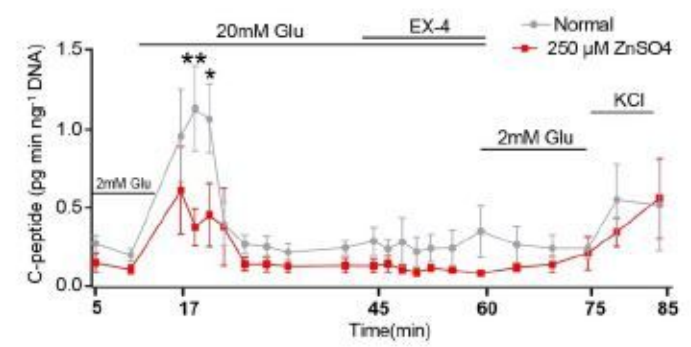

j
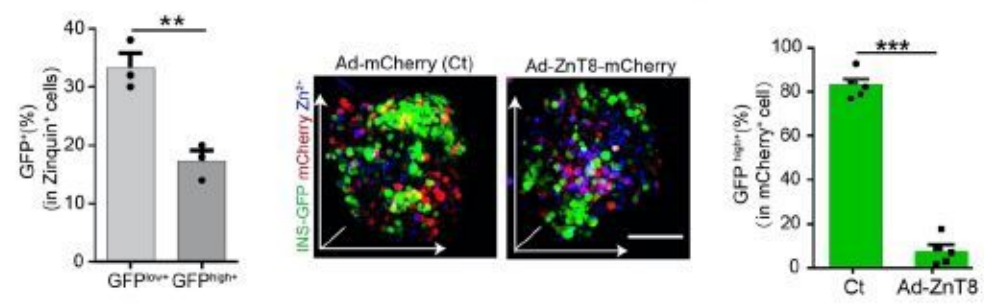

\section{Figure 3}

Granular zinc content influences insulin expression and secretion. a, 3D confocal reconstruction images of Zinquin staining to track zinc (blue) inside insulin granules of WT and SLC30A8-/- mature SC- $\beta$ cells (green, INS-GFP; red, mCherry); scale bar, $50 \mu \mathrm{m}$. b, Transmission electron microscopy images of insulin granules in WT and SLC30A8-/- mature SC- $\beta$ cells. Scale bars in low magnification images, $0.5 \mu \mathrm{m}$; Scale bars in high magnification images, $0.1 \mu \mathrm{m}$. c, Typical insulin dense core granules as a percentage of total granules in WT and SLC30A8-/- mature SC- $\beta$ cells. $n=5$. $d$, A schematic of dosage-dependent zinc inhibition of insulin secretion. SLC30A8-/- mature SC- $\beta$ cell clusters were stimulated with $20 \mathrm{mM}$ glucose and elevated dosages of zinc $(\mathrm{Ct}, 125 \mu \mathrm{M}, 250 \mu \mathrm{M})$ respectively for 30 min. e, Insulin secretion upon glucose challenge with a dosage-dependent zinc inhibition manner. $n=60$ mature SC- $\beta$ cell clusters in each condition. $\mathrm{f}$, Dynamic perifusion assay of zinc-dependent inhibition of C-peptide secretion from SLC30A8-/- mature SC- $\beta$ cell clusters, in response to $2 \mathrm{mM}$ glucose, $20 \mathrm{mM}$ glucose (added with 0 or 250 $\mu \mathrm{M}$ ZnSO4), $10 \mathrm{nM}$ exendin-4 (Ex-4, added $20 \mathrm{mM}$ glucose) and $30 \mathrm{mM} \mathrm{KCl}$ stimulation. Grey line, normal condition; red line, treated with $250 \mu \mathrm{M} Z \mathrm{ZnSO} 4 . \mathrm{n}=3$ independent samples. g, Fluorescence images of NKX6.1-mCherry, INSGFP and Zinquin (Zn2+) in WT and SLC30A8-/- mature SC- $\beta$ cells. Left panel: 3D confocal reconstruction image; scale bar, $100 \mu \mathrm{m}$. Right panel: images of adherent single cells digested from SC- $\beta$ cell clusters; scale bar in low magnification images, $20 \mu \mathrm{m}$; scale bar in high magnification images, $10 \mu \mathrm{m}$. h, INS-GFP+ cells as a percentage of Zinquin+ cells (GFPhigh+, mature SC- $\beta$ cell with 
strong GFP intensity; GFPlow+, mature SC- $\beta$ cell with weak GFP intensity; the GFP signal intensity was measured by the software image J). $n=3$. i, Zinquin staining (blue) in SLC30A8-/- mature SC- $\beta$ cells (derived from Mel1GFP/W hES cell lines) infected with ZnT8-mCherry or mCherry via adenovirus (AdZnT8-mCherry, Ad-ZnT8; Ad-mCherry, Ct). Images shown are 3D confocal re-construction with maximum intensity projections. Scale bar,100 $\mu \mathrm{m}$. j, Proportion of the SC- $\beta$ cells with strong GFP signal (GFPhigh+) in mCherry+ (successfully infected with adenovirus) cells. $n=5$. Data in this figure are presented as mean \pm s.e.m. ${ }^{*} p<0.05 ;{ }^{* *} p<0.01 ;{ }^{* * *} p<0.001$. In perifusion assay, $p$-values are determined by two-way repeated measures ANOVA with Bonferroni test for multiple comparisons between SLC30A8-/- SC- $\beta$ cells added with ZnSO4 or vehicle. In other assays of this figure, two-tailed unpaired student's t-test was used to calculate p-values.

a

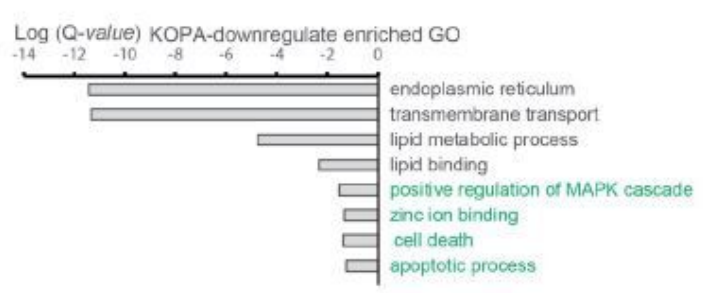

c

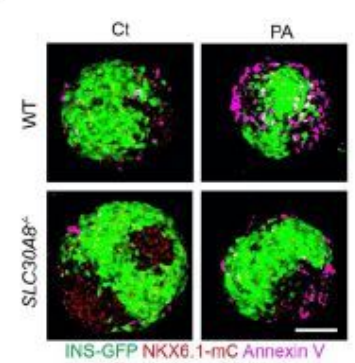

g

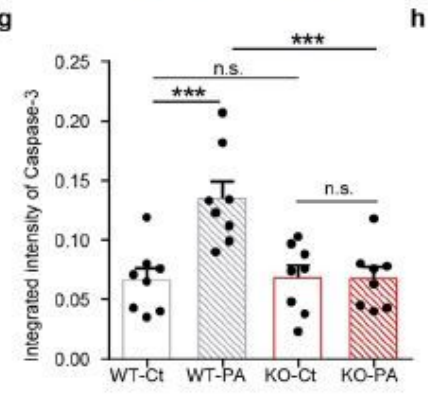

d

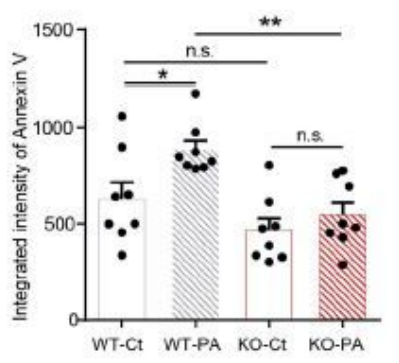

h b

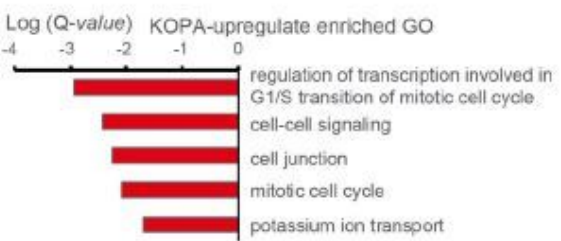

e

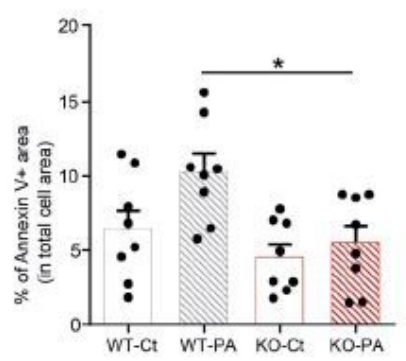

f

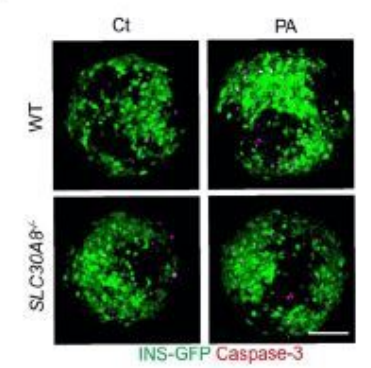

i

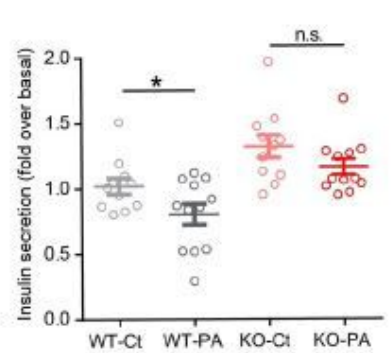

\section{Figure 4}

ZnT8 LOF enhances SC- $\beta$ cell survival under the pressure of lipotoxicity. a and b, Gene ontology (GO) analysis of genes significantly downregulated (a) and upregulated (b) (Q-value < 0.05) in KO-PA cells (relative to WT-PA cells). c, Annexin V (magenta) staining analysis of WT and SLC30A8-/- (KO) mature SC$\beta$ cell clusters (green, INS-GFP; red, mCherry) treated with $1 \mathrm{mM}$ palmitate (PA) or vehicles (Control, Ct) for $48 \mathrm{~h}$. Scale bar, $100 \mu \mathrm{m}$. $\mathrm{d}$ and e, Integrated intensity (d) and area percentage (e) of annexin $\mathrm{V}$ in the cells of WT-Ct, WT-PA, KO-Ct, KO-PA ( $n=8$ of each group). $f$ and $g$, Immunostaining analysis $(f)$ and the mean 
intensity (g) of Caspase-3 (magenta) in WT and SLC30A8-/- (KO) mature SC- $\beta$ cell clusters treated with 1 $\mathrm{mM}$ palmitate (PA) or vehicles (Control, Ct) for $48 \mathrm{~h}$. h, Intracellular FACS of Caspase-3 in the cells of WTCt, WT-PA, KO-Ct, KO-PA. i, the ratio of GSIS of WT and SLC30A8-/- (KO) mature SC- $\beta$ cell clusters treated with $1 \mathrm{mM}$ palmitate (PA) or vehicles (Control, $\mathrm{Ct}$ ) for $48 \mathrm{~h}$. $\mathrm{p}$-values are calculated by two-tailed student's t-test. Data in this figure are presented as mean \pm s.e.m. ${ }^{*} p<0.05$; ${ }^{* \star} p<0.01 ;{ }^{* \star} p<0.001$; ns, not significant. $p$-values are calculated by one-way ANOVA with Bonferroni test for multiple comparisons between selected groups.

a

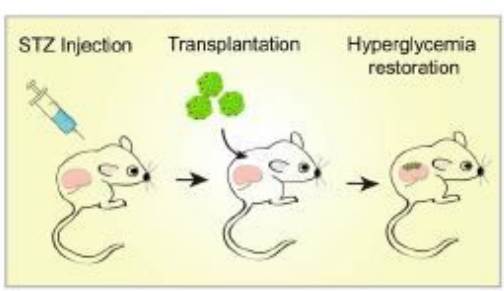

d

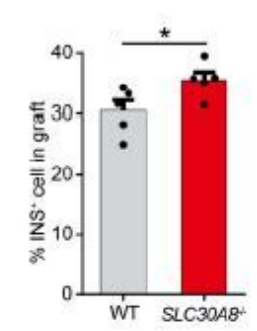

g

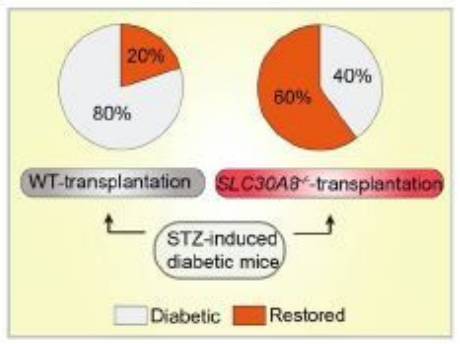

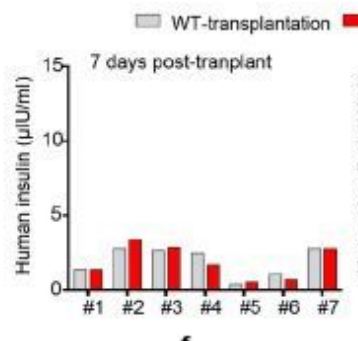

f
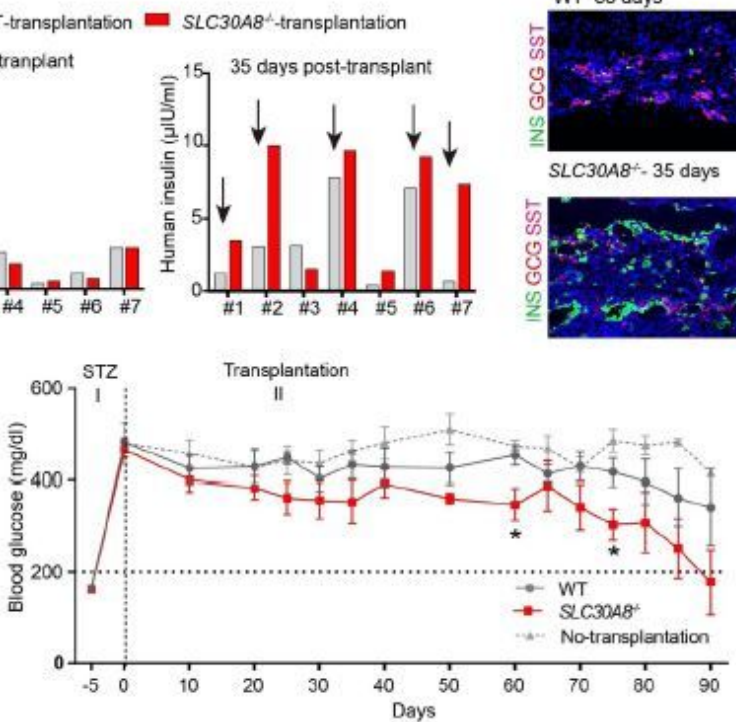
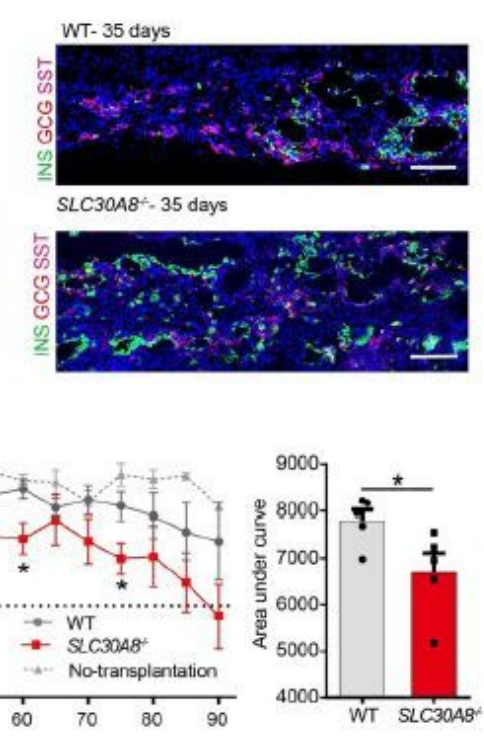

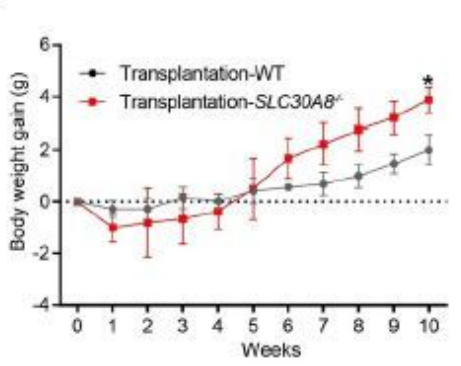

h
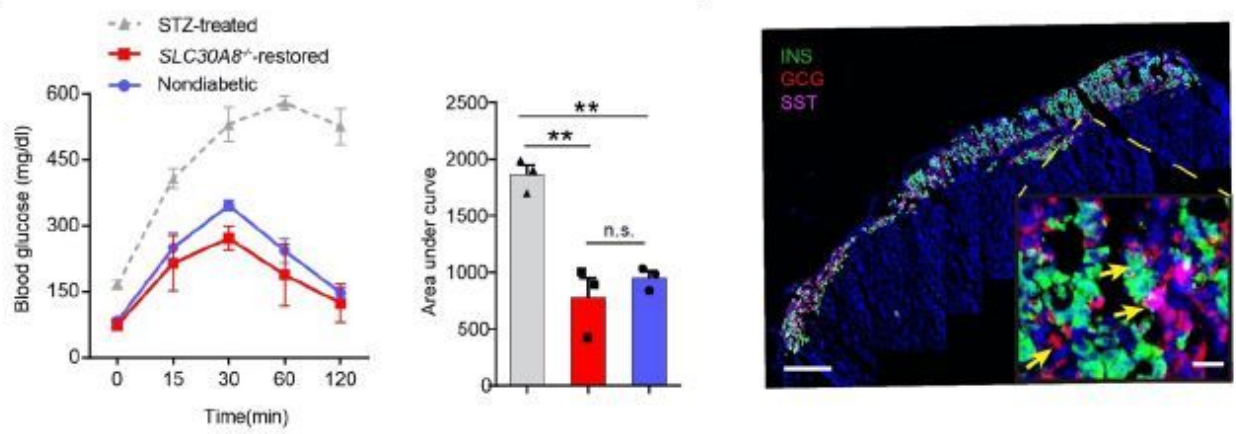

\section{Figure 5}

SC- $\beta$ cells with ZnT8 LOF significantly improve the ability of glycemic restoration. a, A schematic of experiment processes in vivo. $b$, The serum human insulin is measured at day 7and day 35 after the mice transplanted with WT and SLC30A8-/-SC- $\beta$ cells (all mice were divided into 7 groups, each group consisting of one mouse transplanted with WT cells and one mouse transplanted with SLC30A8-/- cells). c and d, Representative immunofluorescent staining images (c) and INS+ cell quantification (d) of WT and SLC30A8-/- mature SC- $\beta$ cells engrafted under the kidney capsule and harvested at 35 days posttransplant. Scale bar, $250 \mu \mathrm{m}$. e, Body weight gain measurements in the 10 weeks after the mice transplanted with WT (dark gray, $n=4)$ or SLC30A8-/- (red, $n=4)$ mature SC- $\beta$ cells for. See 
Supplementary Table 3 for source data. f, Random fed blood glucose measurements taken from the mice without any transplantation (light gray, $n=4$ ) or transplanted with WT (dark gray, $n=5$ ) or SLC30A8-/(red, $n=5$ ) mature SC- $\beta$ cells. Some of diabetic mice died before 90 days. See Supplementary Table 4 for source data. $g$, A schematic of hyperglycemia restoration percentage of STZ-induced diabetic mice transplanted with WT and SLC30A8-/- mature SC- $\beta$ cells. Grey panel, the mice in diabetic status after transplantation for 90 days; Orange panel, hyperglycemia restored after transplantation for 90 days. h, Blood glucose were measured during an intraperitoneal injection glucose tolerance test on 90 days after transplantation. Gray line, STZ-induced diabetic mice without transplantation $(n=3)$; blue line, healthy mice $(n=3)$; red line, STZ-induced diabetic mice with SLC30A8-/-SC- $\beta$ cell transplantation $(n=3)$. i, Representative immunofluorescent staining of SLC30A8-/- mature SC- $\beta$ cells engrafted under the kidney capsule and harvested at 6 months posttransplant; insulin (INS, green), glucagon (GCG, red) and somatostatin (SST, magenta). Scale bars in low magnification images, $500 \mu \mathrm{m}$; high magnification images, $20 \mu \mathrm{m}$. Data are presented as mean \pm s.e.m. ${ }^{*} p<0.05$; ${ }^{\star \star} p<0.01$; ${ }^{\star \star *} p<0.001$; ns, not significant. In i.p.GTT assay, p-values are calculated by two-way repeated measures ANOVA with Bonferroni test for multiple comparisons between the mice transplanted with WT and SLC30A8-/- SC- $\beta$ cells at each time; $p$ values of AUC are calculated by on-way ANOVA with Tukey test for multiple comparisons. In other assays of this figure, $p$-values are determined by two-tailed unpaired student's t-test.

\section{Supplementary Files}

This is a list of supplementary files associated with this preprint. Click to download.

- ExtendedDataFig1.JPG

- ExtendedDataFig2.JPG

- ExtendedDataFig3.JPG

- ExtendedDataFig4.JPG

- ExtendedDataFig5.JPG

- ExtendedDataFig6.JPG

- ExtendedDataFig7.JPG

- ExtendedDataFig8.JPG

- SupplementalTables.pdf 